\title{
The effect of grade retention on secondary school dropout: Evidence from a natural experiment
}

Citation for published version (APA):

Ferreira Sequeda, M. (2020). The effect of grade retention on secondary school dropout: Evidence from a natural experiment. ROA. ROA Research Memoranda No. 014 https://doi.org/10.26481/umaror.2020014

Document status and date:

Published: $31 / 12 / 2020$

DOI:

10.26481/umaror.2020014

Document Version:

Publisher's PDF, also known as Version of record

\section{Please check the document version of this publication:}

- A submitted manuscript is the version of the article upon submission and before peer-review. There can be important differences between the submitted version and the official published version of record.

People interested in the research are advised to contact the author for the final version of the publication, or visit the DOI to the publisher's website.

- The final author version and the galley proof are versions of the publication after peer review.

- The final published version features the final layout of the paper including the volume, issue and page numbers.

Link to publication

\footnotetext{
General rights rights.

- You may freely distribute the URL identifying the publication in the public portal. please follow below link for the End User Agreement:

www.umlib.nl/taverne-license

Take down policy

If you believe that this document breaches copyright please contact us at:

repository@maastrichtuniversity.nl

providing details and we will investigate your claim.
}

Copyright and moral rights for the publications made accessible in the public portal are retained by the authors and/or other copyright owners and it is a condition of accessing publications that users recognise and abide by the legal requirements associated with these

- Users may download and print one copy of any publication from the public portal for the purpose of private study or research.

- You may not further distribute the material or use it for any profit-making activity or commercial gain

If the publication is distributed under the terms of Article $25 \mathrm{fa}$ of the Dutch Copyright Act, indicated by the "Taverne" license above, 


\section{Maastricht University ROA}

The effect of grade retention on secondary school dropout: Evidence from a natural experiment

Maria Ferreira Sequeda

\section{ROA Research Memorandum}

ROA-RM-2020/14

Researchcentrum voor Onderwijs en Arbeidsmarkt | ROA Research Centre for Education and the Labour Market / ROA 


\title{
The effect of grade retention on secondary school dropout: Evidence from a natural experiment
}

\author{
Maria Ferreira Sequeda
}

ROA-RM-2020/14

December 2020

Research Centre for Education and the Labour Market Maastricht University P.O. Box 616, 6200 MD Maastricht, The Netherlands

$\mathrm{T}+31433883647 \mathrm{~F}+31433884914$

secretary-roa-sbe@maastrichtuniversity.nl www.roa.nl 


\section{Abstract \\ The effect of grade retention on secondary school dropout: Evidence from a natural experiment*}

This paper analyses the effects of grade retention on secondary school dropout by evaluating a retention policy reform introduced in 2010 in Colombia. The reform ended the restriction that the annual number of retained students at a school could not exceed 5 percent of the total school population. Using administrative data at the school level, we estimate a difference-in-differences model that exploits variation in schools' retention rates before and after the reform. We distinguish dropout rates by grade (grade 6 to 11). Moreover, we distinguish between retained students who dropped out of school by the end of the year of their retention and the dropout effect on all students enrolled in school the year after retention. Our robust estimates reveal that higher retention increases the rate of students dropping out of school the same year of their retention, that means not enrolling to repeat the failed grade. However, there is little, if any, causal effect of grade retention on the dropout rates of all other students enrolled in the school one year after retention. We find that the latter effect is stronger when retention takes place at the earlier grades whereas the effect for retained students is strongest when retention occurs at grade 9 and grade 11, when students would be entitled to receive the lower secondary school certicate and the high-school diploma respectively.

JEL classification: 120, 121, J24

Keywords: retention, school dropout, difference-in-differences

Maria Ferreira Sequeda

Maastricht University

ROA

P.O. Box 616

NL-6200 MD Maastricht

The Netherlands

m.ferreirasequeda@maastrichtuniversity.nl

* I am grateful to Barbara Belfi, Lex Borghans, Bart Golsteyn, Andries de Grip, Annemarie Künn-Nelen, Cécile Magnée, Olivier Marie, and Sergio Parra-Cely for their insightful comments and suggestions. I also thank the Colombian Bureau of Statistics (DANE) for making available their longitudinal datasets on the C-600 schools' national census. 


\section{Introduction}

Despite increasing attention by policy makers, school dropout is still a serious issue of particular importance in developing countries, where universalisation of education continues to be a challenge. ${ }^{1}$ Although graduation from secondary school is considered the minimum level of educational attainment needed for successful participation in further education and the labour market, the numbers of young children leaving school without completing a secondary qualification are quite large in some countries (Lamb and Markussen, 2011; OECD, 2012). ${ }^{2}$

Both in public policy and in the academic literature, grade repetition is often associated to low enrolment, low graduation rates and high dropout rates (e.g. Bowers, Sprott, and Taff, 2012; Busso, Bassi, and Muñoz, 2013; Ikeda and García, 2014; Jimerson, Anderson, and Whipple, 2002; OECD, 2016; Roderick, 1994; Stearns, Moller, Blau, and Potochnick, 2007). In the literature, it is commonly conjectured that being retained may influence factors associated with dropping out of school such as low self-esteem, socio-emotional adjustment, peer relations, and school engagement.

An important caveat in the literature on retention and dropout is that the largest part of the evidence remains strictly correlational. Although correlations are informative, if students are selected into retention on the basis of unobservable factors, important confounders may lead to biased conclusions regarding the actual effects of retention on school dropout. In addition, the possibility that the strength of the association between retention and dropout may differ depending on the timing of retention during the secondary school cycle has been largely overlooked. These existing research gaps are most notable in the context of developing countries, where most of the studies are restricted to trend analyses (e.g. Busso et al., 2013; Di Gropello, 2006).

In this study, we contribute to filling these gaps in three ways. First, we propose a difference-in-differences framework to find the causal effect of retention on secondary school dropout rates, distinguishing between (1) retained students who drop out of school by the end of the year of their retention and (2) the dropout effect on all students enrolled in school the year after retention. Second, we analyse the heterogeneity of these effects at different moments of the education cycle by estimating the impact of retention on dropouts at each grade of secondary school from grade 6 to 11 . Last, we are able to examine the heterogeneity and (non)linearity of the main effects with regard to treatment intensity by distinguishing between students in schools that reacted differently to the policy reform from which we obtain the plausibly exogenous variation in school retention rates.

To overcome the endogeneity problem, we exploit a policy change with respect to retention in Colombia. Until 2009, schools were restricted by national regulation to retain up to a maximum of 5 percent of their students. This retention restriction was ended by the Ministry of Education through a new regulation mandate, allowing schools from 2010 onwards to retain as many students as they considered necessary, and thereby giving them

\footnotetext{
1 School dropout is also a central theme in the policy agendas of developed countries. For instance, the European Horizon 2020 Strategy and the US No Child Left Behind Act include policy targets to reduce early school-leaving.

2 Nearly 40 percent of adolescents (between 15 and 19 years old) in Latin America drop out of school before completing the secondary school cycle. The greatest dropout rates occur at upper secondary education. Most students leave school during the first year of secondary education, one of the critical points for dropping out. Approximately 45 percent of those that enter secondary education do not graduate. Upper secondary school completion rates in Latin America are well below the average for OECD countries, of around 85 percent (Kattan and Székely, 2015; OECD, 2011).
} 
more discretion in their promotion approaches. We use the term Free Retention Policy (FRP) reform to refer to this policy change.

To estimate the effects of grade retention on school dropout rates, we use administrative school-grade records across nine school years and exploit variation in retention rates at the school level, as induced by the FRP reform in Colombia. This reform increased retention rates dramatically in some schools, while in others it had no effect.

Since similar schools reacted differently to the policy change, our approach compares the grade dropout rates in secondary school before and after the reform, between schools where retention rates increased substantially and schools where retention rates remained relatively constant across both periods. Treatment and control groups are defined by the above-median historical increase in retention attributed to the law change, analogue to the method used in recent papers in a different context than ours (Bauernschuster, Hener, and Rainer, 2016; Havnes and Mogstad, 2011). Schools in which retention rates increased more than the median change are defined as the treatment group and those schools that responded less than the median, the control group. Several placebo and falsification tests show that pre-treatment trends in dropout rates were similar in treatment and control schools, indicating that the key identifying assumption of our difference-in-differences model holds and, therefore, we can confirm that the estimated effects on dropout rates can be attributed to the FRP reform only.

In this paper, we distinguish between two outcomes as the effects of the reform. ${ }^{3}$ First, we consider end-of-year dropout rates, referring to the proportion of pupils from a cohort enrolled in a given grade, who concluded the school year but were retained, and did not register in the educational system to repeat the failed grade. Since this is the rate of retained students who stop their school education in the same year of retention, we measure end-of-year dropout rates in year $t$ as the outcome of retention rates during the same year t. Second, we consider early dropout rates that refer to the proportion of all students enrolled in each grade who abandoned the educational system without concluding the school year. This is the dropout rate among all students enrolled in year $t+1$, which also gives insights into the spill-over effects of retention on non-retained students. Therefore, early dropout rates in year $t$ are measured as the outcome of retention rates in year $t-1$.

We highlight two major findings. First, a remarkably large positive effect of grade retention on end-of-year dropout rates among retained students and a positive but relatively small effect of grade failure on consecutive early dropout rates among all students enrolled in education. Second, we show significant heterogeneity in both effects depending on the timing of retention along the secondary education cycle: the effects of grade failure on early dropout rates are stronger when retention takes place at the earlier grades whereas the effect on retained students is strongest if retention occurs at grade 9 and grade 11 . These are precisely the grades for which successful completion entitles the students to receive the lower secondary school certificate and the high-school diploma, respectively. In line with the human capital literature, this finding suggests a high cost of retention at these grades due to the forgone opportunity for students to finalise either one of the two cycles of secondary education as well as the subsequent long-term forgone labour market

\footnotetext{
${ }^{3}$ In Ferreira, Golsteyn, and Parra-Cely (2018), we study the effects of this retention reform on another relevant outcome, i.e. school achievement and performance. Taken together, these two studies emphasise the importance of developing a more holistic approach to assess the effects of retention while considering both the potential negative and positive effects, and to understand whether these effects outbalance each other or not.
} 
gains such as earnings.

We first provide evidence of a significant positive effect of increased retention - as induced by the FRP reform - on the average dropout rate of secondary school students. The effect of increased retention on early dropout seems to be rather small: on average, a 10 percentage points rise in retention rates increases early dropout rates by 0.8 of a percentage point in the year following retention. However, the same increase in retention of 10 percentage points is shown to cause an increase of 4.2 percentage points in end-ofyear dropout rates for retained students, which means that approximately 40 percent of retained students after the reform did not continue with their secondary education, after learning they needed to repeat the grade. We also show that both our main effects seem to be linearly proportional to the extent of retention growth, that is, the strongest effect on dropout rates was experienced by students enrolled in schools where retention rates increased the most.

Second, we show that the overall positive effect of retention on early dropout rates is stronger in the earlier grades of secondary school and that there is not any significant effect during the last two years of high school, i.e. grades 10 and 11 . This means that the strongest effect we observe occurs at grade 6 , the year of transition from primary to secondary education. Conversely, the retention effect on the dropout rates of retained students is not only significant across all six grades but strongest if students are retained at the end of grade 9 and grade 11, suggesting there is a high cost of retention at these grades due to the forgone opportunity for students to finalise either one of the two cycles of secondary education as well as the subsequent long-term forgone labour market gains such as earnings.

Finally, we show further heterogeneity in the effect of retention across the six grades of secondary education if we distinguish between schools treated with different intensity. Although we find most of our main effects to be linear to schools' retention growth, we observe that retained students from grade 9 to grade 11 in mid-treated schools show higher dropout rates than similar students in high-treated schools where retention rates were even higher. This last finding suggests that students retained at later stages of secondary education in a school environment where retention is not common can cause more harm to the future perspectives of those students than if they would have been in schools where retention is more pronounced or a more likely to occur at the end of the school year.

The remainder of the paper is organised as follows. Section 2 discusses the literature related to our research question. Section 3 summarises the Colombian educational system and the FRP reform we exploit. Section 4 presents our model and empirical strategy. Section 5 describes our data and descriptive statistics. In Section 6, we discuss the plausibility of the identifying assumptions and present our empirical results and robustness analyses. Section 7 concludes.

\section{$2 \quad$ Related Literature}

Our study contributes to the literature in various disciplines that have analysed whether - and to what extent - retention determines later school completion and affects the probabilities of dropping out of school.

There is extensive educational research on the determinants of high school dropout, largely based on survey data. Many of these studies find numerous individual characteristics associated with above average rates of dropout. Socioeconomic status (usu- 
ally measured by parental education, occupational status, or income) is one of the most consistent explanatory factors (Alexander and Kabbani, 2001; Rumberger, 1995, 2004). Moreover, different generations of migrant children and male students (Pharris-Ciurej, Hirschman, and Willhoft, 2012) and adolescents from single parent families and those that experience more residential mobility are shown to have a higher risk of dropping out of school (McLanahan and Sandefur, 1994; Rumberger and Larson, 1998). School-related characteristics are revealed as determinants of dropout over and above individual and family-related motives (Dalton, Glennie, and Ingels, 2009; Rumberger, 2004). Among these and several other factors that explain early school leaving, grade retention is often referred to as a strong predictor of school dropout.

Studies on dropouts consistently find that repeating a grade is positively associated with leaving school before graduation (e.g. Bowers, 2010; Bowers et al., 2012; De Witte, Cabus, Thyssen, Groot, and van den Brink, 2013; Janosz, LeBlanc, Boulerice, and Tremblay, 1997; Jimerson, 1999, 2001; Jimerson et al., 2002; Plank and A., 2005; Roderick, 1994; Rumberger and Larson, 1998; Stearns et al., 2007; Temple, Reynolds, and Ou, 2004). One of these studies (Stearns et al., 2007) illustrates that various school resources affect differently the association between elementary school retention and high school dropouts for white, black, and Latino students in the US.

Regarding the possible explanations for the positive association between retention and dropouts, some scholars have conjectured that it may reflect: (1) the difficulty that overage retained students may face in integrating themselves into peer and school cultures (Plank and A., 2005; Roderick, 1994), (2) the self-esteem frustration associated with the failure sentiment, the stigma of being unintelligent, and lagging behind, which can increase the likelihood of leaving school permanently, rather than just temporarily (Alexander and Kabbani, 2001; Plank and A., 2005), (3) the psychological and behavioural disengagement from school due to loss of social capital that students draw from their relationships with teachers, parents, and peers (Alexander and Kabbani, 2001; Lamote, Speybroeck, Van Den Noortgate, and Van Damme, 2013; Stearns and Glennie, 2006), (4) the (subconscious) response of teachers to the retention status, which may make them expect and demand less school achievement from retained students and put less effort into reaching them (De Witte et al., 2013; Jimerson et al., 2002; Stearns et al., 2007), and (5) the long-term trajectory of low grades or poor school performance (Bowers and Sprott, 2012).

An important caveat is that these studies can only report correlations and not causal estimates. Since practical constraints make retention experimental designs difficult to implement, most of these studies can only conduct statistic association analyses or build structural models to test the effect of grade retention on dropouts while controlling for other covariates, especially achievement. Although correlations are informative, important confounders may bias such estimates. Retention is defined very differently across the studies, e.g. identifying over-age students for their grade, asking students if they have ever been retained, examining retention school records, or restricting a definition of retention to specific grade levels. This leads to differences in precision and specificity across the studies due to the retention definition, as well as which grade level was included in the definition and how dropout was defined in each study. A second caveat is that researchers have not assessed the possibility that the strength of the association between retention and dropout may differ, depending on the timing of retention. This is an important problem, given suggestive evidence that various predictors of dropping out vary in strength and significance at different stages of high school but also evidence that retention has a heterogeneous effect on the school performance of students, depending on the timing of 
retention and the time since retention elapses (Fruehwirth, Navarro, and Takahashi, 2016; Stearns and Glennie, 2006).

Last, it is worth noting the existing gap in this research especially in the context of developing countries, where dropping out of school is an even more pronounced phenomenon. Related studies in the Latin-American context often look at trends in dropout but not the reasons behind it. The literature does not offer explanations to the dropout phenomenon explicitly, nor to the trends observed during the past decades (e.g. Busso et al., 2013; Cabrol, 2002; Di Gropello, 2006; Ikeda and García, 2014).

Three articles in the economics literature are closest to our study. First, Eide and Showalter (2001) use an instrumental variable for retention, based on exogenous variation across states in kindergarten entry dates, to evaluate the effect of retention on students' dropout rates and labour market earnings. Their results for white students suggest that grade retention may have some benefit to students by lowering dropout rates; however, their IV estimates are statistically indistinguishable from zero. For black students, the IV approach gave very poor first-stage results. Their own conclusion is that the IV estimates are not conclusive neither informative enough.

Second, Jacob and Lefgren (2009) use plausibly exogenous variation in retention - at grades 6 and 8 - generated by a test-based promotion policy in Chicago to assess the longrun effects of retention on high school completion. They find that retention among younger students (grade 6) does not affect the likelihood of high school completion but retaining low-achieving eighth grade students in elementary school increases the probability that these students will drop out of high school. According to their study, it appears that the differential effect across grade level is driven by the fact that students retained in earlier grades have more opportunities to catch up with their peers and, conversely, students who narrowly missed retention in earlier grades have more opportunities to 'fall back' in subsequent years. The main difference of our study with Jacob and Lefgren's (2009) research is that instead of a regression discontinuity design that relies on the specific margin at which retention was increased by the new tests thresholds for students to be promoted to the next grade, we can analyse the dropout rates at several moments of the distribution of students retention, at all grades, since the policy change we exploit affected treated students heterogeneously in the full range of subjects not conditioned to changes in any test or achievement results, which we believe remained unaffected before and after the reform.

Third, Manacorda (2012) studies the effects of retention in secondary schools (grades 7 to 9) in Uruguay on dropout rates and school attainment, exploiting a discontinuity established by a rule of automatic grade failure for pupils with more than three failed subjects at the end of the school year. Using administrative longitudinal microdata, this analysis reveals that grade failure induces students to drop out at the end of the school year when failure occurs, which has long-lasting negative effects on their school attainment. Apart from the same advantage of not restricting our analysis only to the specific margin of the discontinuity, as mentioned earlier, we expand the results of Manacorda's (2012) article in two more ways. First, we do not face the discontinuity-related concern that assignment around the threshold of three failed subjects might not be as good as random due to the strategic behaviour of better-performing students or possible manipulation of final scores by teachers to promote students with better latent outcomes. Second, we have several years of information before and after the retention reform we exploit, whereas Manacorda (2012) only has two years of data on failed subjects, information that is not available at the end of the school year but only at an intermediate term. This 
retention measure is not precise since students with three or fewer failed subjects by the intermediate term might have eventually failed and some students with four or more failed subjects at their mid-term could have eventually passed. Our administrative source of data contains actual students' retention results by the end of each grade in each school cycle.

Finally, it is worth to briefly mention that the growing literature on early school leaving indicates that dropout has profound social and economic consequences for students, their families, and their communities. Several studies suggest that school dropouts, compared with their graduated peers, are more frequently associated with higher rates of and longterm unemployment, poverty, bleak health prospects, sustained dependence on public assistance, single parenthood (in females), political and social apathy, (juvenile) crime and lower overall lifetime earnings and life expectancy (e.g. Bowers et al., 2012; De Witte et al., 2013; Psacharopoulos, 2007; Rumberger, 2011; Rumberger and Lamb, 2003; Swanson, 2004).

\section{Background}

\subsection{The Colombian Educational System}

Colombia has an eleven-year system of elementary and secondary education, consisting of five years of compulsory elementary education (grade 1 to 5 ), four years of compulsory lower secondary education (grade 6 to 9 ) and two years of non-compulsory upper secondary education (grade 10 to 11$).{ }^{4}$ The regular age of entry to the first grade is six years. Therefore, if children are not retained and do not interrupt their school career, they complete lower secondary education at ages 14-15 and upper secondary education when they are 16-17 years old.

The educational system in Colombia is a comprehensive school system with no tracking at any grade. ${ }^{5}$ Completion of the lower secondary cycle leads to a Certificate of Basic Baccalaureate Studies (Certificado de Estudios de Bachillerato Básico). Upon completion of the grade 11 of secondary school, all students must pass a national standardised exam (SABER11) to be awarded the title of Baccalaureate (Titulo de Bachiller), which gives access to higher education. This credential is equivalent to a US high-school diploma.

Although constitutional regulations in Colombia establish that elementary and lower secondary education are free and compulsory, the capacity of the system is in practice insufficient to accommodate full enrolment. In addition, dropout and inadequate students' progress in lower secondary education remains a bottleneck for enrolment. Net enrolment rates at all levels of secondary education increased from 64.1 percent in 2004 to 79.7 percent in 2013. However, enrolment levels vary widely across the country, particularly between rural and urban areas, as shown in Figure 1 (OECD, 2016).

\footnotetext{
${ }^{4}$ Elementary and secondary education in Colombia are offered in two school calendars: Calendar "A" that runs from February until November, and calendar "B" from September to June. Most schools $(92 \%)$ in the country operate in calendar A. Formal education is also offered by schools in three different class-schedules: a morning schedule, an afternoon schedule, and a full-day schedule. Students opt or are allocated by the school to attend either one of these. Most students in secondary education attend school either in the morning or the afternoon schedule (78\%).

${ }^{5}$ The Ministry of Education regulates all levels of education for both public and private schools.
} 
Figure 1: Students who remain enrolled in education

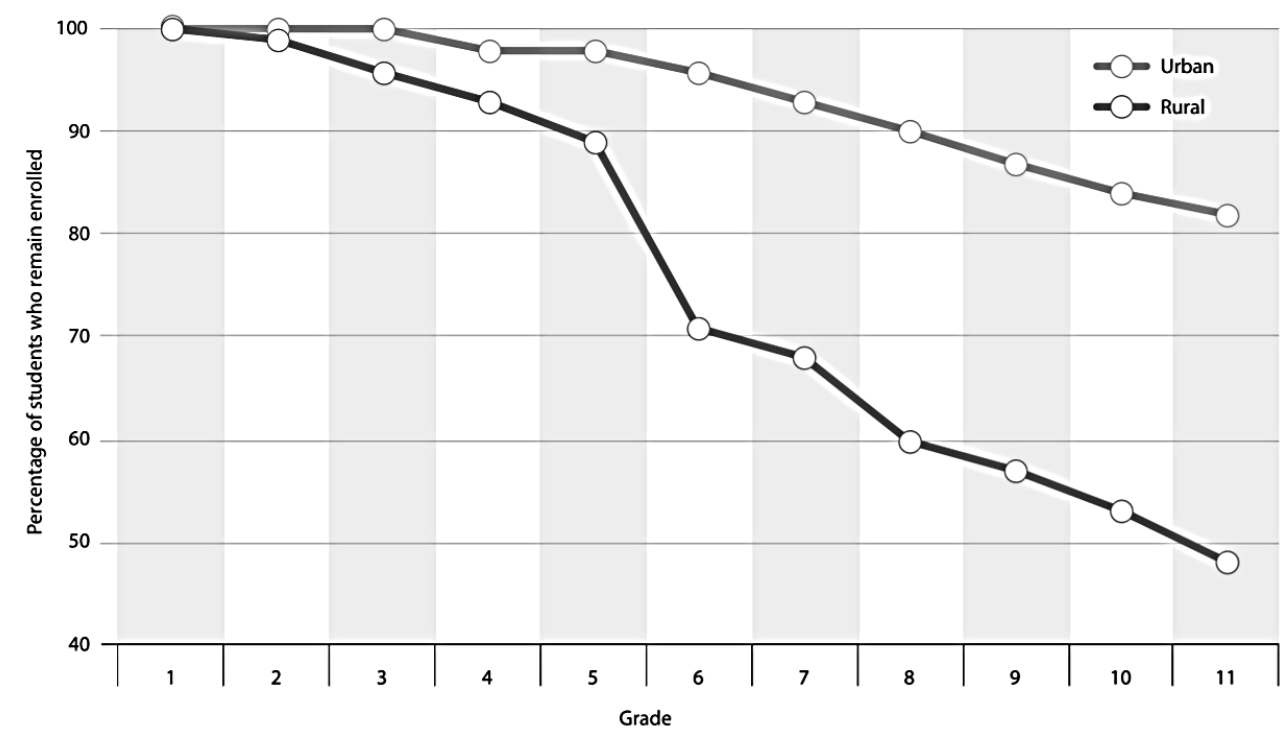

Notes: Source: OECD, Education in Colombia Highlights 2016. Data correspond to year 2008.

\subsection{The Free Retention Policy (FRP) reform}

In 2002, by mandate of the Ministry of Education (Decree 230 of 2002), schools were each year restricted to retain up to a maximum of 5 percent of their students. This retention policy was implemented to reduce costs attributed to higher retention rates (i.e. low performance, low motivation, etcetera) without compromising the quality of education provided by the system (Martínez and Herrera, 2002). According to the policy mandate, a student should be retained if at least one of the following three circumstances holds: i) the student received an unsatisfactory performance evaluation in three or more school subjects in the current school year, ii) the student received an unsatisfactory performance evaluation in math and/or language courses during the current and two previous grades, or iii) the student failed to attend at least 25 percent of all school activities during the current school year. However, schools were required to adjust their evaluation standards to comply with the law, which forced them to promote at least 95 percent of all their students each year.

While the 5-percent retention rule was considered as moderately successful in increasing school enrolment, the incentives to underperform at school, as perceived by schools and teachers, led the Ministry of Education to revoke this retention restriction. ${ }^{6}$ In February 2009, the 5-percent retention restriction was ended by the Ministry of Education through a new regulation mandate (Decree 1290 of 2009), allowing schools from 2010 onwards to retain as many students as they considered necessary, and thereby giving them more discretion in their evaluation and promotion strategies. We use the term Free Retention Policy (FRP) reform to refer to this policy change. Overall, this reform increased students' retention rates across all grades of secondary education from 4.3 percent to 7.7 percent, on average, in all schools in the country.

\footnotetext{
${ }_{6}$ Ministry of Education, Press Release April 17, 2009.
} 


\section{Empirical Strategy}

To estimate the effects of higher grade retention on school dropout rates, we use a difference-in-differences approach that exploits variation in retention rates at the school level, as induced by the FRP reform in Colombia. Since similar schools reacted differently to the policy change, our approach compares the dropout rates by grade in secondary school before and after the FRP reform, between schools where retention rates increased a lot (i.e. the treatment group) and schools where retention rates remained relatively constant across both periods (i.e. the control group).

We also generate a categorical heterogeneous treatment variable. Based on the change in schools' retention rates before and after the reform, as previously explained, we divide the schools population into quartiles to identify four groups: the lowest 25 percentile is defined as the control group and the other three quartiles represent more and less intensely treated groups - high, mid and low treated schools. Figure 4 shows the retention rates across time for these heterogeneously treated groups. We observe that retention rates among control schools barely changed: there was a slight decrease of $0.23 \mathrm{pp}$ after the FRP reform. During the same period, low-treated, mid-treated and high-treated schools experienced increases in their grade retention rates of $1.82 \mathrm{pp}, 4.29 \mathrm{pp}$ and 9.72 pp respectively. ${ }^{7}$

Figure 2: Retention rates by treatment status

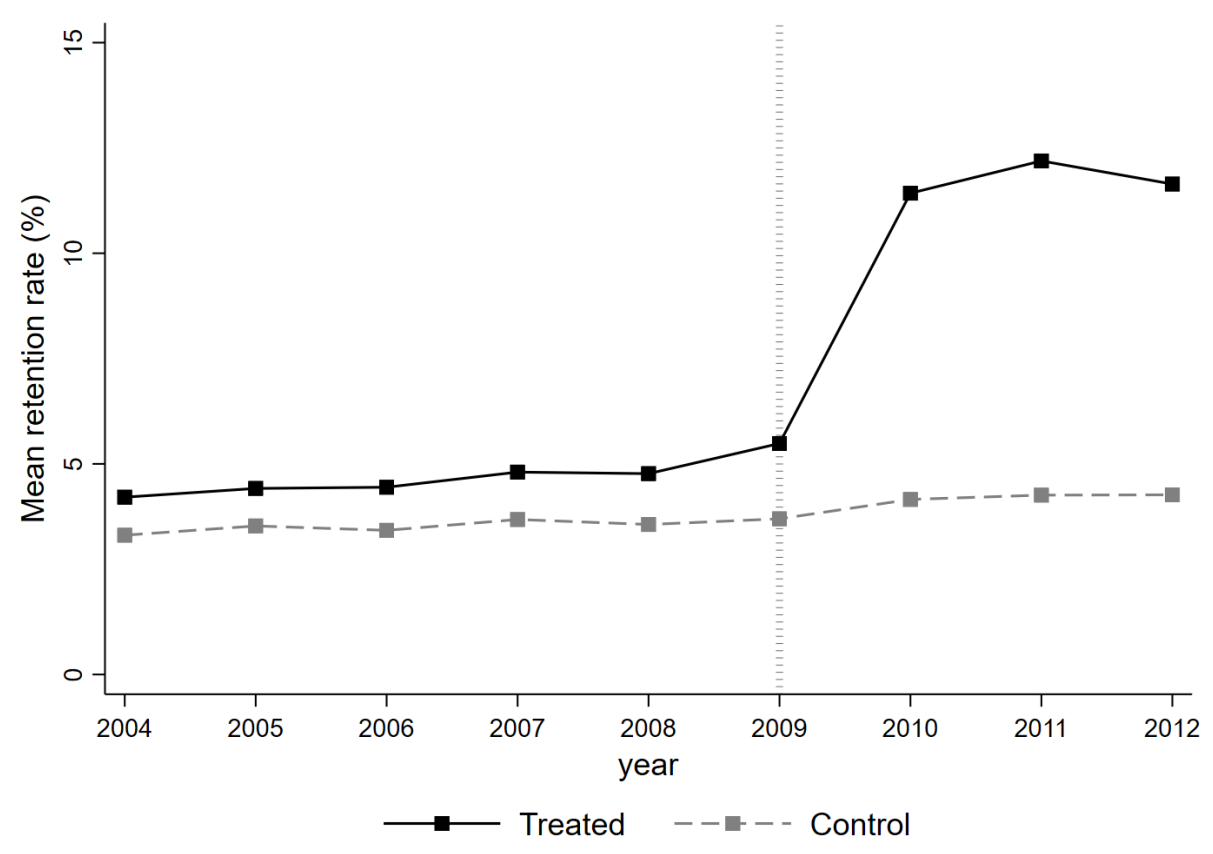

Notes: This figure shows school average retention rates in year $t$ for treated and control schools. Averages include all students in grades 6 to 11.

\footnotetext{
${ }^{7}$ We observe a similar pattern for male and female students, although increases in retention are more pronounced among male students. While female retention rates changed after the FRP reform by $0.11 \mathrm{pp}, 0.68 \mathrm{pp}, 1.71 \mathrm{pp}$, and $4.07 \mathrm{pp}$ for control, low-treated, mid-treated and high-treated schools respectively; male retention rates changed by $-0.12 \mathrm{pp}, 1.14 \mathrm{pp}, 2.59 \mathrm{pp}$, and $5.65 \mathrm{pp}$ for the corresponding treatment groups.
} 
Figure 3: Retention rates by grade

(a) grade 6

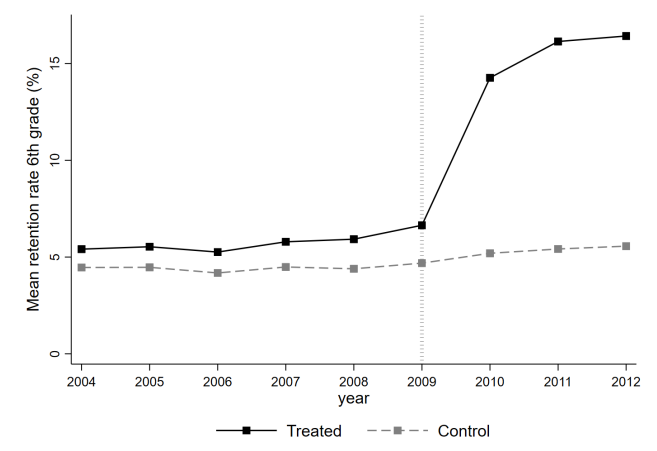

(d) grade 9

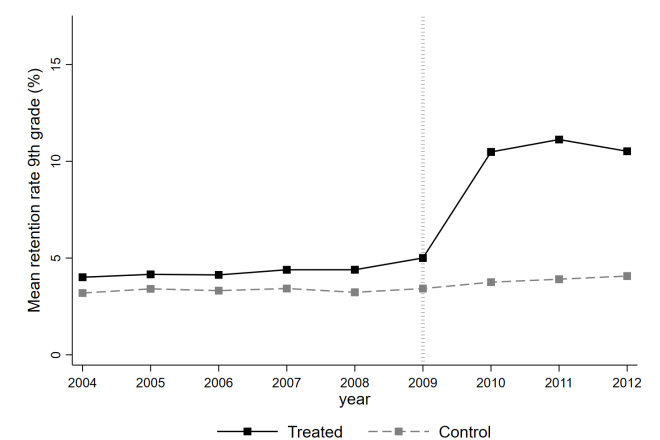

(b) grade 7

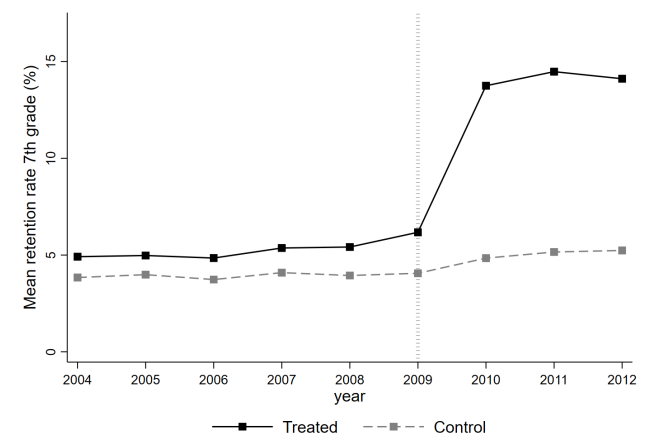

(e) grade 10

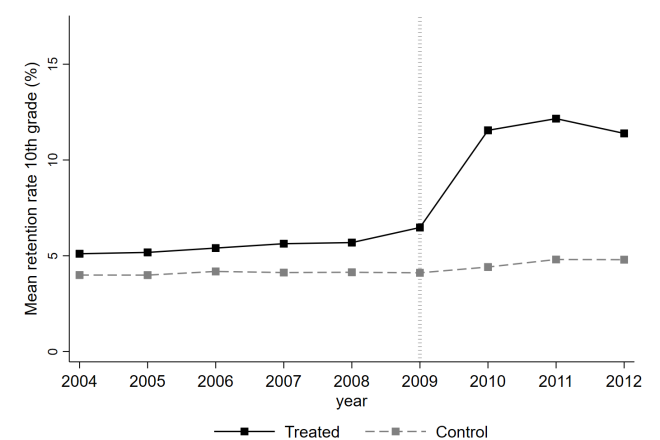

(c) grade 8

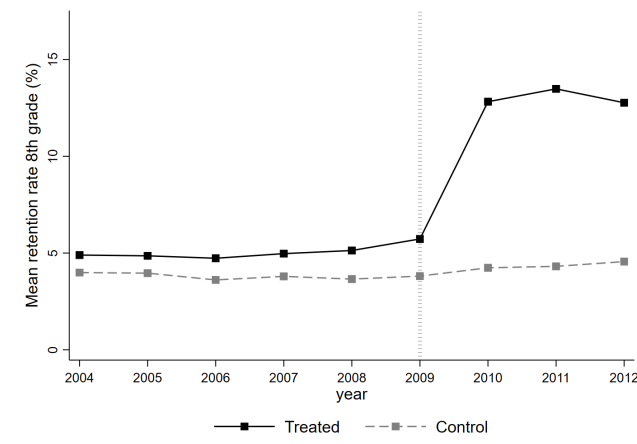

(f) grade 11

Notes: This figure shows school average retention rates in year $t$ including all students in each grade by treated and control schools. 
Figure 4: Retention rates by heterogeneous treatment status

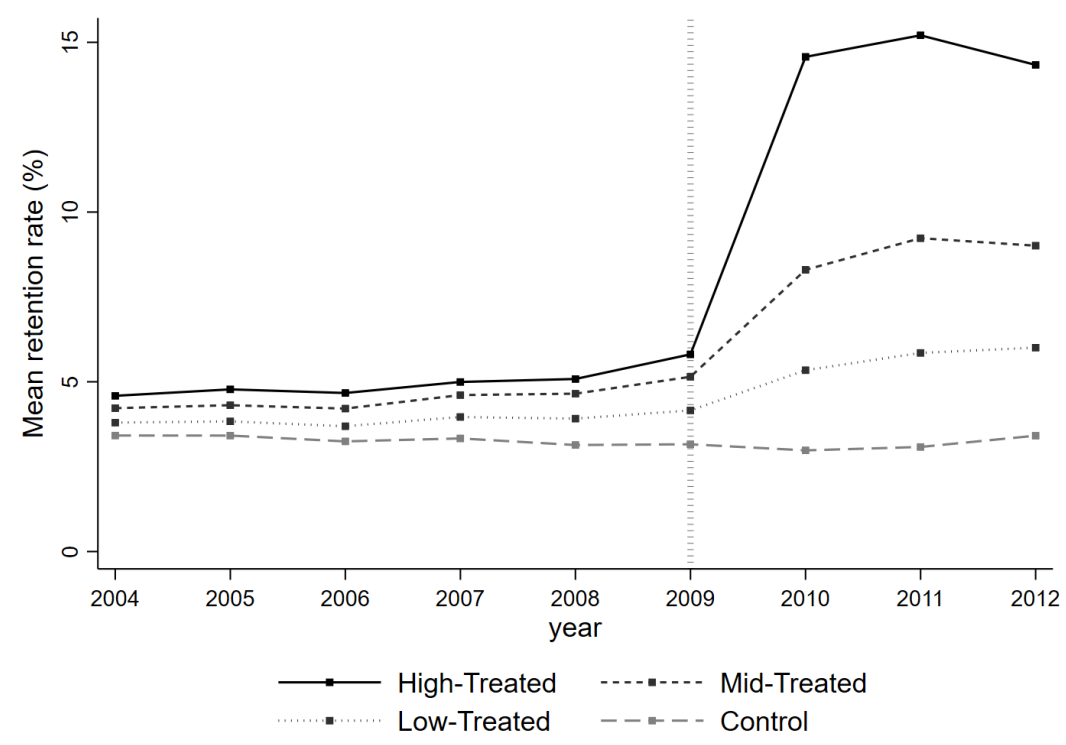

Notes: This figure shows school average retention rates in year $t$ for three heterogeneous treatment groups and the control group of schools. Averages include all students in grades 6 to 11.

We will distinguish between two outcomes as the effects of the reform. First, we consider end-of-year dropout rates $\left(Y D_{\text {sgt }}\right.$ ), referring to the proportion of pupils from a cohort enrolled in a given grade, who concluded the school year but were retained, and did not register in the educational system to repeat the failed grade. Since this is the rate of retained students who stop their school education in the same year of retention, we measure end-of-year dropout rates in year $t$ as the outcome of retention rates during the same year $t$. Second, we consider early dropout rates $\left(E D_{\text {sgt }}\right)$ that refer to the proportion of students in each grade who abandoned the educational system without concluding the school year. This is the dropout rate among all students enrolled in year $t+1$, including those non-retained the preceding year and those repeating the failed grade. Although this output considers the full enrolled population of students, it gives some indication of the potential spill-over effects of retention on non-retained students, since by data construction, it discounts already the retained dropouts during the preceding academic year. Therefore, early dropout rates in year $t$ are measured as the outcome of retention rates in year $t-1$. Because we cannot identify students who permanently leave education and those who just interrupt their studies for at least a year and later return to school, both outcomes can only be interpreted as short-term (one year) effects of retention.

Our basic difference-in-differences models can then be expressed as:

$$
\begin{gathered}
Y D_{s g t}=\alpha_{s g}+\delta_{t}+\gamma_{s g}\left[\alpha_{s g} \times L T\right]+\theta_{1 s t}\left[\operatorname{Group}_{s} \times F R P_{t}\right]+\beta X_{s g t}+\varepsilon_{s g t} \\
E D_{s g t}=\alpha_{s g}+\delta_{t}+\gamma_{s g}\left[\alpha_{s g} \times L T\right]+\theta_{2 s t}\left[\operatorname{Group}_{s} \times F R P_{t-1}\right]+\beta X_{s g t}+\varepsilon_{s g t}
\end{gathered}
$$

where $Y D_{\text {sgt }}$ is the end-of-year dropout rate and $E D_{\text {sgt }}$ the early dropout rate, as explained in the previous paragraph. $\mathrm{s}$ indexes school, $\mathrm{g}$ indexes grade (from 6 to 11), $t$ indexes year. FRP is a dummy variable equal to 1 if the observation is from the period after the FRP reform (and 0 if the observation is from the period before the FRP reform). Group 
is the treatment variable that takes value 1 for schools in the treated group, and zero for schools in the control group in our basic binary treatment specification; and a categorical variable that takes values from 1 to 4 corresponding to control, low-treated, mid-treated, and high-treated schools respectively. We estimate the model with and without a set of covariates for school, grade, teachers, and students' characteristics $X$, as described later in Table 1. All our estimations include year-fixed effects $(\delta)$, school-grade fixed effects $(\alpha)$ and school-grade specific linear trends $(\gamma)$. All standard errors are clustered at the school-grade level to ensure that we account for potential serial correlation, as indicated in the difference-in-differences literature (Bertrand, Duflo, and Mullainathan, 2004). The models are weighted by the total number of students per year and school-grade.

Because of our treatment-control schools classification, $\theta_{s t}$ are best interpreted as intention-to-treat effects (ITT). To obtain the average treatment effect on the treated (ATT) interpretation, we rescale the resulting coefficients by the difference in the retention rates between treated and control schools before and after the FRP reform. It is also important to note that our approach defines control and treatment groups (and more and less intensely treated groups) based on variation in retention rates by school over the sample period. Thus, the validity of our empirical design depends on the variation in retention rates being orthogonal to expected changes in dropout rates. We will investigate whether this key identifying assumption holds, estimating the following two specifications, taking advantage of the several years of data we have for the period before the reform:

$$
\begin{aligned}
& Y D_{s g t}=\alpha_{s g}+\delta_{t}+\gamma_{s g}\left[\alpha_{s g} \times L T\right]+\sum_{t=2005}^{2012} \theta_{4 t}\left[\text { Group }_{s} \times \delta_{t}\right]+\beta X_{s g t}+\varepsilon_{s g t} \\
& E D_{s g t}=\alpha_{s g}+\delta_{t}+\gamma_{s g}\left[\alpha_{s g} \times L T\right]+\sum_{t=2004}^{2013} \theta_{3 t}\left[\text { Group }_{s} \times \delta_{t}\right]+\beta X_{s g t}+\varepsilon_{s g t}
\end{aligned}
$$

With equations (3) and (4), we basically test for the assumption that treatment and control schools shared a common trend in end-of-year dropout and early dropout rates before the FRP reform, and that these trends would have remained the same if the retention policy would not have been changed. Therefore, the null hypothesis of interest here is that pre-treatment differences in trends $\left(\theta_{t}\right)$ between treated and control schools are not significantly different from zero. ${ }^{8}$ As we will elabourate later, we cannot reject such hypotheses at conventional significance levels in the case of early dropout rates $\left(E D_{s g t}\right)$; however, we find that it is due to a significant and robust anticipatory effect in year 2010 that needs to be accounted for in the estimation of our main results.

In addition to specifications (3) and (4), we also perform several placebo tests, in which we assume that the FRP reform was introduced in different years before or after it was implemented. We examine whether such placebo reforms have any effects on our outcomes of interest. By not being able to reject the null hypothesis that such effects are significantly equal to zero in each of the estimated placebo cases, we can confirm that the estimated effects on end-of-year and early dropout rates can be attributed to the FRP reform only.

\footnotetext{
8 That is, $\theta_{2005}=\theta_{2006}=\theta_{2007}=\theta_{2008}=\theta_{2019}=0, \theta_{2004}$ being the base year of comparison in equation (3.3) for $Y D_{s g t}$ and $\theta_{2006}=\theta_{2007}=\theta_{2008}=\theta_{2009}=\theta_{2010}=0, \theta_{2005}$ being the base year of comparison in equation (3.4) for $E D_{s g t}$.
} 


\section{$5 \quad$ Data and Descriptive Statistics}

\subsection{Data}

This study is based on information from 2004 to 2013 contained in the schools' national census, an administrative database that the Colombian Ministry of Education releases for public use through the National Administrative Department of Statistics (DANE). This census contains several school and organisational data that all schools in the country are compelled to report at the grade level on a yearly basis. We use information on the number of students by grade that are retained by the end of the school year, and those who abandon school before the school year ends (early dropouts). In addition, we are able to compute the number of retained students in year $t$ that did not enrol in the educational system in year $t+1$, which will give us insight in the percentage of retained students that do not continue with their school studies (end-of-year dropout rates). For retention and early dropout rates we can distinguish between male and female students; however, because of data limitations, we cannot analyse gender differences for end-of-year dropout rates. We use additional information on several student, teacher and school characteristics as covariates.

Our unit of analysis is a school-grade-year combination for all schools that offer secondary education in the country. The estimation sample includes schools i) that offer education exclusively in Calendar A (February to November), ii) did not change this calendar during the period 2004-2013, iii) had no missing values on retention rates, dropout rates, and school covariates, and iv) reported information on retention rates at least one year before and one year after the FRP reform. The resulting dataset consists of an unbalanced panel of 9,449 schools, which in total contains 52,037 school-grade combinations and 368,433 schools-grade-year observations across the 2004-2013 period.

The major advantage of these administrative records is the ability to track the number of students by grade who exit from the universe of enrolled students from one year to the next. The second advantage is that the transfer of students between schools is accounted separately; hence, our dropout rates are purely the share of students who do not continue with their education. However, as mentioned in our empirical strategy, we can only identify the short-term (one-year) effects of retention on dropouts since we cannot distinguish between those who left school permanently or just temporarily.

As we can observe in Panel (a) of Figure 5, before the FRP reform, the average retention rates of students in grade 6 to grade 11 were kept at or below 5 percent, according to the law restriction. Panel (b) of the figure shows that retention rates nearly doubled for all grades from grade 6 to 10 after the reform. Only at grade 11, the last level of secondary education, retention rates were below 2 percent before the reform, increasing by just 1 percentage point after the reform.

Figure 5 also shows that end-of-year dropout rates by grade were slightly less than half of the retention rates before the reform. This means that, between 2004 and 2009, less than fifty percent of the retained students in each grade dropped out of school by the end of the year of their retention. With the increase of retention rates after the reform, all end-of-year dropout rates in the period 2010-2012 more than doubled, with the only exception of grade 11. Finally, regarding early dropout rates in year $t+1$, Figure 2 reveals that even before the reform those rates were high and close to 6 percent. These dropout rates, however, decreased after the FRP reform by nearly 1 percentage point in each grade. 
Figure 5: Retention and dropout rates by grade

(a) 2004-2009

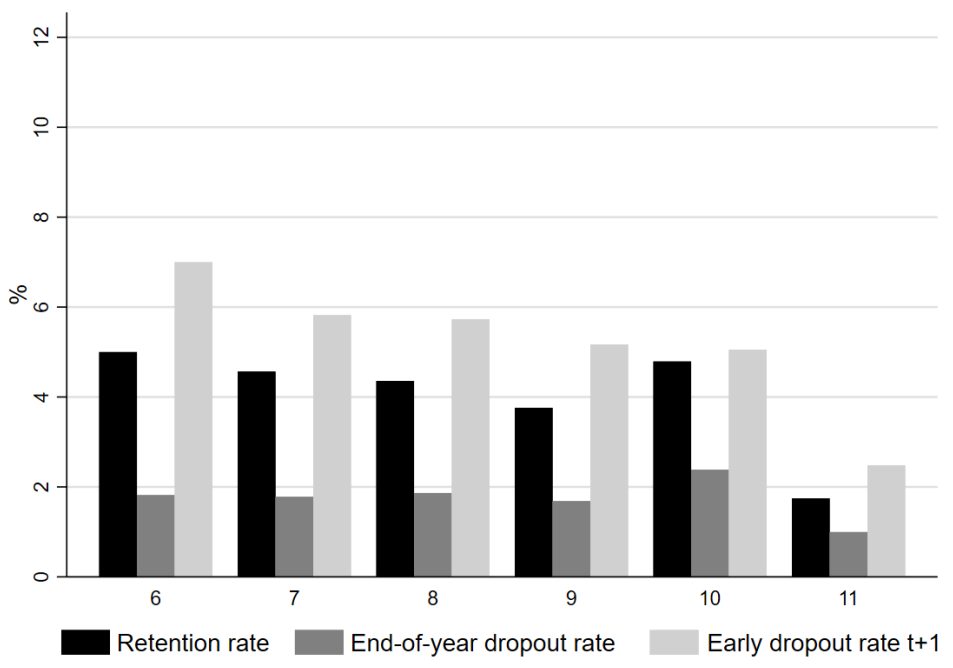

(b) $2010-2012$

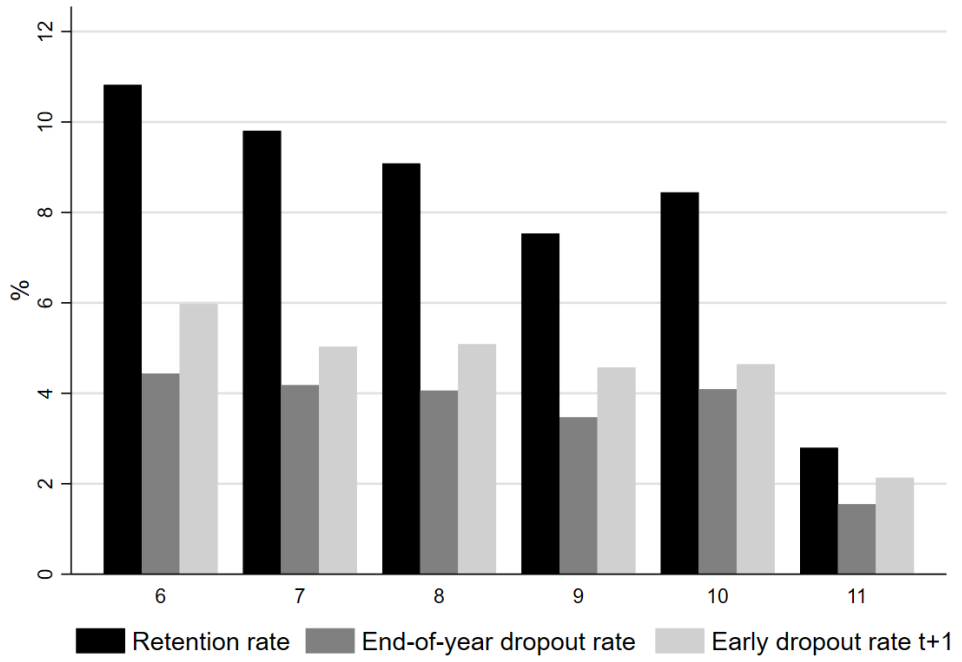

More interestingly, when we compare the average retention and dropout rates between treated and control schools, we find first suggestive evidence of a positive effect of increased retention on end-of-year dropout rates. As figure 6 shows, whereas end-of-year dropout rates in control schools remained almost the same before and after the reform, these rates grew by approximately 3.5 percentage points in treated schools between the same two periods. The descriptive evidence on early dropout rates is, however, not that clear. Although early dropout rates among schools in the treatment group decreased less than they did in control schools between the periods before and after the reform, the difference seems to be very small. Estimation results in Section 3.6 will reveal whether this difference holds in our difference-in-differences setting. 
Figure 6: Retention and dropout rates by treatment status

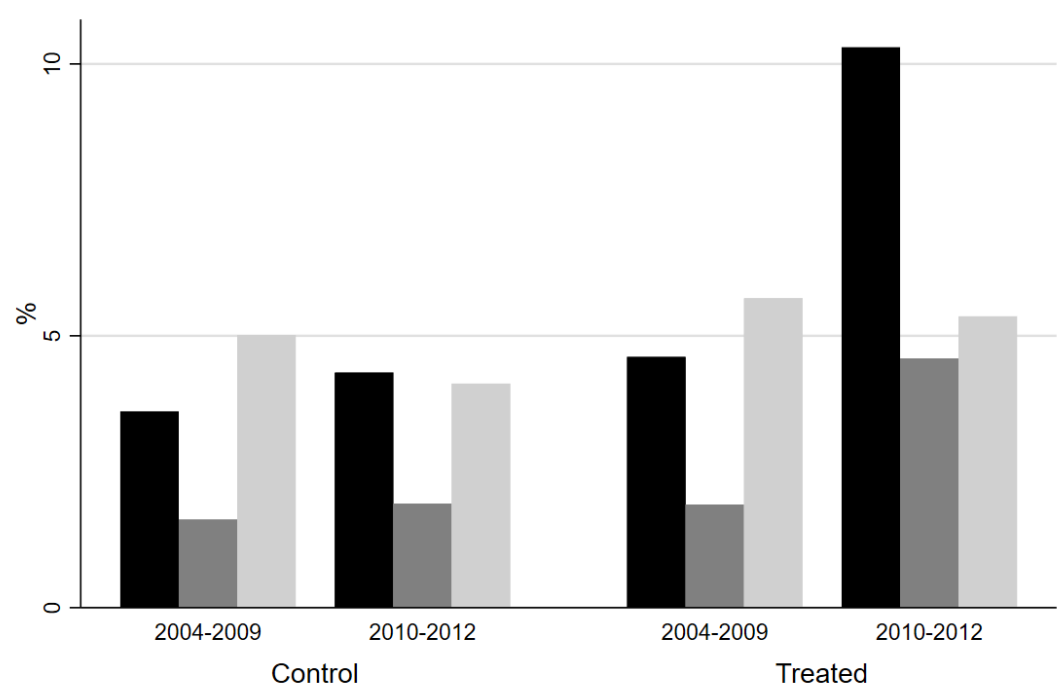

Retention rate $\quad$ End-of-year dropout rate $\quad$ Early dropout rate $t+1$ 
Table 1: Pre-treatment summary statistics

\begin{tabular}{|c|c|c|c|c|c|c|}
\hline & \multirow{2}{*}{$\begin{array}{l}\text { Control } \\
\text { Mean }\end{array}$} & \multirow{2}{*}{$\begin{array}{c}\text { Treated } \\
\text { Mean }\end{array}$} & \multicolumn{2}{|c|}{ All } & \multicolumn{2}{|c|}{ Difference $(\mathrm{C})-(\mathrm{T})$} \\
\hline & & & Min & Max & $\mathrm{b}$ & $\mathrm{se}$ \\
\hline Retention rate & 3.66 & 4.64 & 0 & 100 & $-0.98^{* * *}$ & 0.03 \\
\hline Male retention rate & 2.28 & 2.94 & 0 & 100 & $-0.66^{* * *}$ & 0.02 \\
\hline Female retention rate & 1.38 & 1.70 & 0 & 100 & $-0.32^{* * *}$ & 0.01 \\
\hline End-of-year dropout rate $t$ & 1.62 & 1.91 & -298 & 100 & $-0.29^{* * *}$ & 0.03 \\
\hline Share of repeaters $t+1$ & 2.03 & 2.64 & 0 & 100 & $-0.61^{* * *}$ & 0.03 \\
\hline Early dropout rate $t+1$ & 4.82 & 5.66 & 0 & 100 & $-0.85^{* * *}$ & 0.04 \\
\hline Male early dropout rate $t+1$ & 2.61 & 3.09 & 0 & 100 & $-0.48^{* * *}$ & 0.02 \\
\hline Female early dropout rate $t+1$ & 2.21 & 2.57 & 0 & 100 & $-0.37^{* * *}$ & 0.02 \\
\hline \multicolumn{7}{|l|}{ Covariates } \\
\hline$\overline{\text { Average age }}$ & 14.07 & 14.19 & 9 & 20 & $-0.12^{* *}$ & 0.05 \\
\hline Share of female students & 50.94 & 50.61 & 0 & 100 & 0.34 & 0.22 \\
\hline Share of subsidised students & 4.61 & 4.43 & 0 & 100 & 0.18 & 0.21 \\
\hline Share of students from ethnic minorities & 5.10 & 5.13 & 0 & 100 & -0.03 & 0.25 \\
\hline Share of students victims of armed conflict & 1.32 & 1.44 & 0 & 100 & -0.12 & 0.18 \\
\hline Share of students with disabilities & 1.02 & 1.01 & 0 & 100 & 0.01 & 0.02 \\
\hline Share of students with exceptional abilities & 0.85 & 0.84 & 0 & 73 & 0.01 & 0.01 \\
\hline Rural school & 0.34 & 0.33 & 0 & 1 & -0.01 & 0.02 \\
\hline Private school & 0.28 & 0.22 & 0 & 1 & $0.06^{* * *}$ & 0.01 \\
\hline Non-traditional teaching school & 0.11 & 0.09 & 0 & 1 & 0.02 & 0.02 \\
\hline Number of class schedules & 1.58 & 1.74 & 1 & 5 & $-0.16^{* *}$ & 0.06 \\
\hline Number of groups per grade & 1.98 & 2.49 & 1 & 45 & $-0.51^{* *}$ & 0.19 \\
\hline Average class size & 28.89 & 30.15 & 1 & 202 & -1.26 & 0.94 \\
\hline Total students per grade & 57.20 & 75.26 & 1 & 1,204 & $-18.06^{* * *}$ & 1.03 \\
\hline Total students per school & 412.14 & 524.90 & 4 & 6,330 & $-112.75^{* * *}$ & 5.95 \\
\hline Share of teachers with pedagogical education & 86.19 & 87.42 & 0 & 100 & -1.23 & 0.81 \\
\hline Share of teachers with tertiary education & 94.79 & 95.88 & 0 & 100 & -1.09 & 0.63 \\
\hline Share of teachers under new pay-scale & 37.97 & 40.31 & 0 & 100 & $-2.34^{*}$ & 1.09 \\
\hline Students per teacher & 20.33 & 21.70 & 1 & 263 & $-1.37^{* *}$ & 0.51 \\
\hline Students per administrative personnel & 77.55 & 80.98 & 1 & 5,166 & -3.43 & 2.46 \\
\hline Students per medical personnel & 197.19 & 208.02 & 1 & 5,166 & -10.83 & 6.96 \\
\hline Observations & 90,248 & 93,478 & & 83,726 & & \\
\hline School-grades & 24,970 & 25,985 & & 50,952 & & \\
\hline Schools & 4,668 & 4,741 & & 9,409 & & \\
\hline
\end{tabular}




\subsection{Descriptive Statistics}

Table 1 shows pre-treatment summary statistics for our outcome variables, retention rates, and the set of covariates included in our models for both the treatment and control group of schools. First, we observe that between 2004 and 2009 in the treatment group, retention rates were about 1 percentage point higher than in the control group, suggesting that the schools most relieved by the treatment had retention rates closer to the 5 percent limit set by the law. As expected, the average percentage of repeaters in each grade in year $t+1$ was higher in the treatment group as well. Second, we observe that both end-ofyear dropout rates and early dropout rates were also slightly higher among schools in the treatment group prior to the reform.

Our difference-in-differences approach identifies the effects of retention by comparing the change in dropout rates before and after the FRP reform among treatment and control schools. Table 1 shows that the treatment and control schools have fairly similar characteristics. Interestingly, there are no noticeable differences in the share of female students in the grades of the treatment and control-group schools, nor is there significant disparity in the share of subsidised students, or the share of students from ethnic minorities, with disabilities or exceptional abilities, or the share of students documented as victims of the armed conflict. Moreover, the difference in the share of rural and urban schools, the percentage of schools that apply non-traditional teaching methods, the share of teachers with tertiary and pedagogical education as well as the number of students per medical and administrative personnel do not significantly differ between treated and control schools. Further, there are no substantial differences in the percentage of teachers hired under the new pay-scale regulation introduced in Colombia in 2002. ${ }^{9}$

There are, however, some notable significant differences between treatment and comparison schools. First, although the difference in average age of students and number of class schedules per school are statistically significant with 95 percent of confidence, the size of these differences is that small that they are not economically significant: students in treatment and control schools are on average 14 years old, and schools in treatment and control groups offer education in either one or two class schedules. Most importantly, in the treatment group the share of private schools is 6 percentage points lower than in the control group. This is not surprising since the expansion of retention rates is likely to be stronger in public schools where retention rates before the reform were more restricted and strictly controlled by the government as public funds are conditioned to the annual information reported by schools. In addition, it might be related to the higher socio-economic status of students in private schools, which could make retention rates less likely to increase after the reform.

In relation to the proportion of public and private schools in treatment and control groups, we also observe significant differences in the total number of students per grade and school as well as in the number of groups per grade. This might be due to the discreteness to increase retention after the reform; retention rates are more likely to increase in larger than smaller schools, and in Colombia public schools tend to be larger, on average, than private schools. Since the characteristic of private or public school does not change over time in our sample, these significant differences will most probably be picked up by the school-grade fixed effects and school-grade specific linear trends. It

\footnotetext{
${ }^{9}$ In 2002, by mandate of the Ministry of Education (Decree 1278 de 2002) the career and pay scale of public-school teachers was reformed through the introduction of a selective entry test and further quality incentives. The regulation applied only to newly hired teachers, creating a mix of new-pay-scale regulation and old-pay-scale regulation teachers in Colombian schools.
} 
is also important to note in this respect that the average number of students per class does not differ between treated and control schools, despite the significant differences previously mentioned. Finally, to further investigate the robustness of our results with respect to time-varying school characteristics, we will run the regressions both without any covariates and with the rich set of school-grade specific time-varying covariates indicated in Table 1. As will be shown in Section 6, the inclusion of covariates does not affect the positive sign or the size of our estimates.

\subsection{Common Trends: Graphical evidence}

The key identifying assumption of any difference-in-differences model is the common trend assumption. In our case this means that, conditional on school-grade fixed effects and the set of time-varying covariates, there are no unobserved characteristics of a school-grade that vary over time and are correlated with school retention rate increases and future changes in the schools' dropout rates.

As we showed in the preceding section, the treatment and control schools are very similar in their pre-reform characteristics. Despite this, it might be the case that timevarying factors that are correlated with dropout rates evolve differently in treated schools as compared to control schools and thus bias the estimates. To address this concern, we investigate whether treatment and control schools show the same trend in both our outcomes of interest during the pre-treatment period. In this section, we perform a first graphic check of the common trend and in Section 6 we will show the results of the regressions tests defined in equations (3) and (4).

Figure 7 shows the average dropout rates across time for treated and control schools. First, the graph in panel (a) provides suggestive evidence of a common trend between treated and control schools during the pre-treatment period regarding end-of-year dropout rates. There seems to be a small anticipatory effect one year prior to the treatment: if students that concluded the school year but were retained at the end of 2009 knew that the next year the probabilities of retention were going to be even higher, those at the lower end of the ability distribution or those who were less confident about their academic success they might have felt discouraged to repeat the grade and dropped out of school. The graph in Panel (a) of Figure 7 also suggests a substantial positive effect of retention on end-of-year dropout rates among the retained students. Figure A3 in the Appendix indicates that the same conclusion holds if we use the heterogeneous treatment groups low-treated, mid-treated, and high-treated. The effect of higher retention on end-of-year dropout rates seems to increase proportionally to the intensity of the treatment.

Second, Panel (b) of Figure 7 suggests the existence of a common trend for early dropout rates during the pre-reform period (2005-2010), except for year 2010. This exception is likely to be an anticipatory effect of the FRP reform: since enrolled students were aware since the beginning of the year that the probabilities of being retained were going to be much higher than in the past, those at the lower end of the ability distribution or those who were less confident about their school success might have made the decision of dropping out of school before the termination of the school year. Panel (b) of Figure 7 also suggests a positive effect of retention on early dropout rates; the difference in early dropout rates between treated and control schools in the pre-reform period increases consistently after 2010. ${ }^{10}$ As shown in Figure A5 in the Appendix, the same

\footnotetext{
${ }^{10}$ Figure A4 in the Appendix suggests that the common trend in early dropout rates between treated and control schools also holds among female and male students, separately. Even though male early
} 
inferences hold when using the heterogeneous treatment variable instead of the binary variable. The effect of higher retention on early dropouts seems to be linear; there is no apparent effect among low-treated schools whereas the effect is positive and increasing among mid-treated and high-treated schools respectively.

Graphically, we can also observe some differences between grades. Figure 8 shows the graphical tests of the common trend for end-of-year dropout rates by grade. This figure suggests once more the existence of a common trend at each grade between control and treated schools for the period 2004-2009. The small anticipatory effect appears here as well, except in grade 6 where no anticipatory effect seemed to have occurred. Figure 8 is preliminary descriptive evidence of a substantial positive effect of higher retention on end-of-year dropout rates among retained students in all grades, even in grades 10 and 11. This effect, however, appears to be stronger at earlier grades, and smallest at grade 11.

Finally, Figure 9 shows the average early dropout rates across time by grade. In general, the figure indicates that common trends hold in each grade between control and treated schools during the pre-treatment period. The anticipatory effect only seemed to have occurred from grade 6 to grade 9 . The figure also indicates that early dropout rates are larger at earlier grades and that the grade 11 is the grade with the lowest percentage of dropouts across time. The effect of retention on dropout rates seems to be positive and strongest at the first level of secondary education (grade 6) whereas there does not seem to be any effect at grades 10 and 11 .

dropout rates were slightly higher than female dropout rates during the entire period, the figure shows the potential positive effect of retention on early dropout rates to be similar among female and male students: the difference between control and treated groups nearly doubled after the FRP reform. The figure also suggests that the anticipatory effect of the reform in 2010 was more pronounced among male than female students. 
Figure 7: Dropout rates by treatment status

(a) End-of-year dropout rates $t$

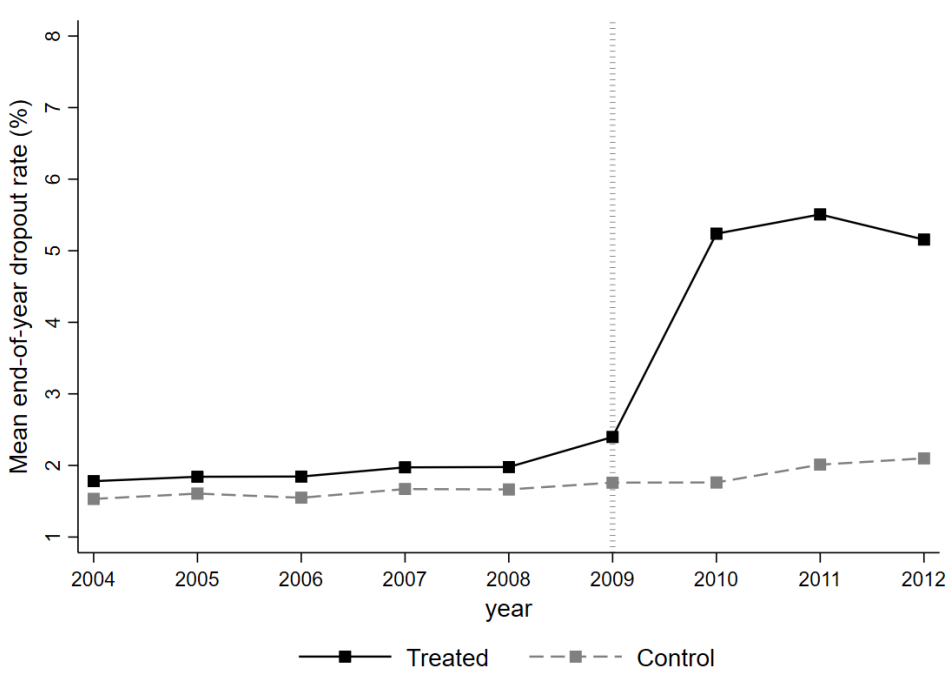

(b) Early dropout rates $t+1$

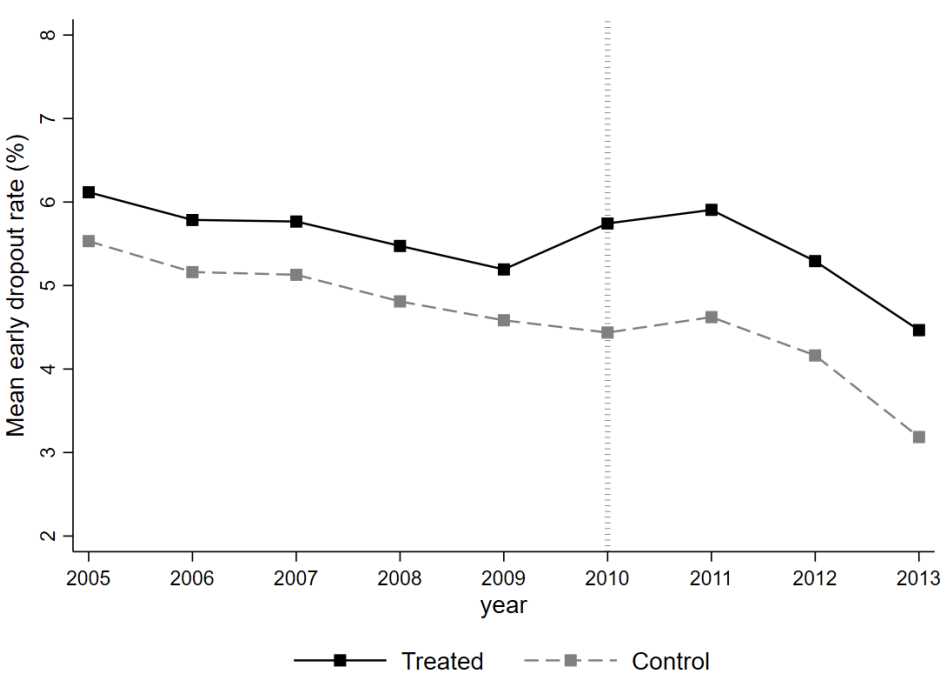

Notes: This figure shows the average dropout rates across time for treated and control schools. Averages include all students in grades 6 to 11. 
Figure 8: End-of-year dropout rates by grade $t$

(a) grade 6

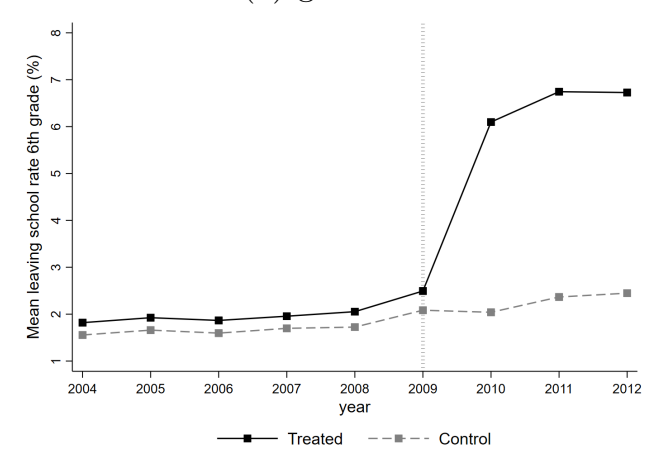

(d) grade 9

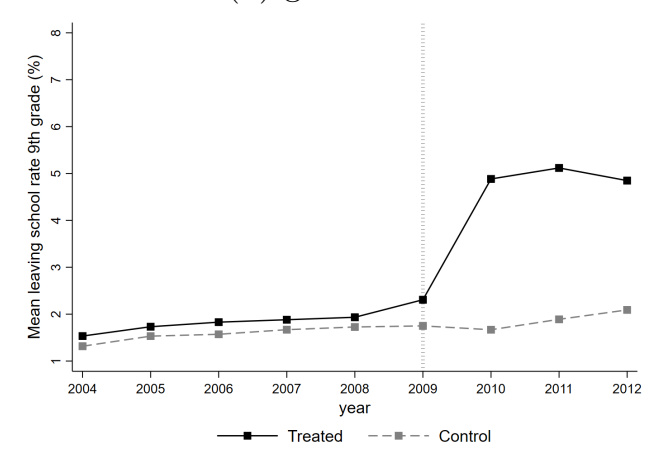

(b) grade 7

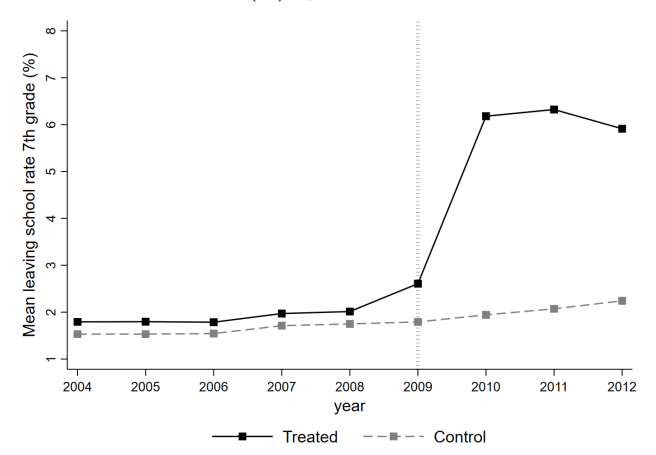

(e) grade 10

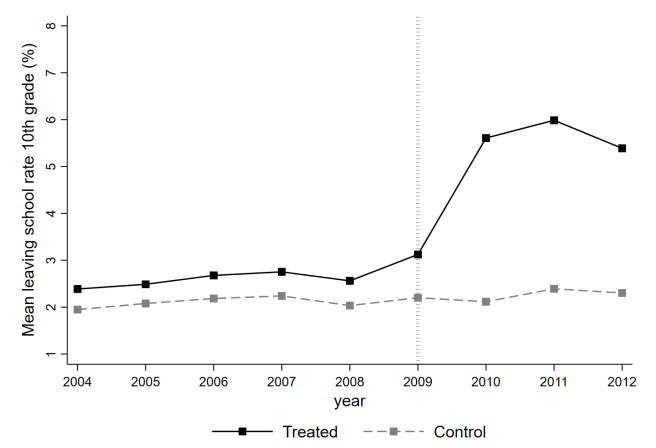

(c) grade 8

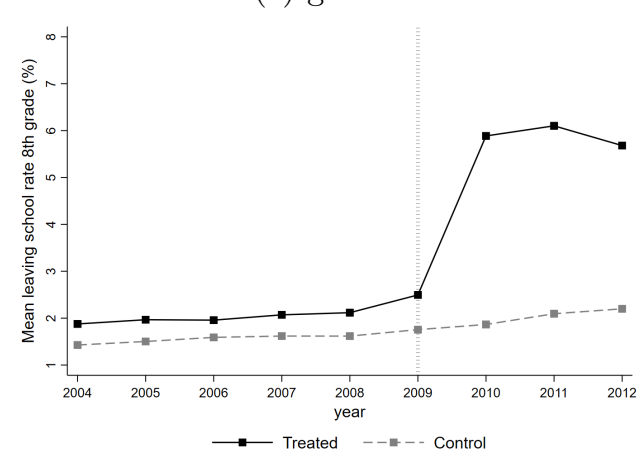

(f) grade 11

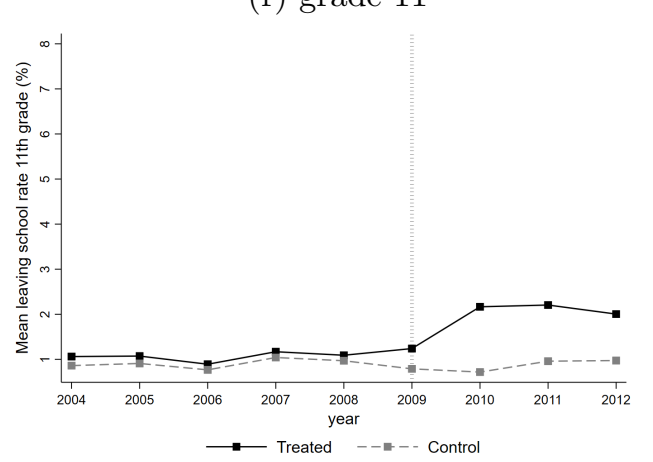

Notes: This figure shows school average end-of-year dropout rates in year $t$ including all students in each grade by treated and control schools. 
Figure 9: Early dropout rates by grade $t+1$

(a) grade 6

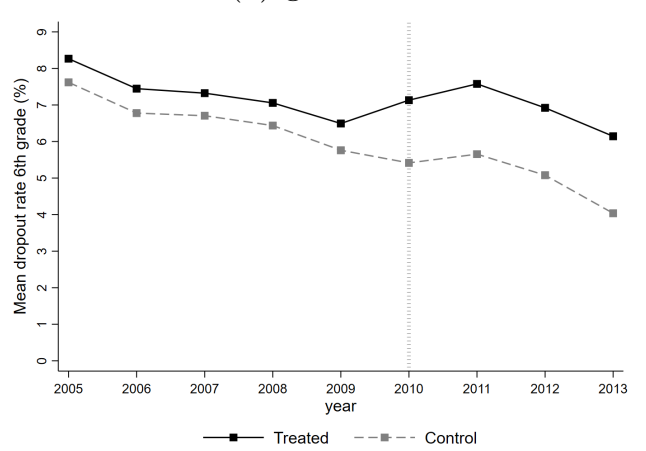

$\stackrel{N}{\sim}$
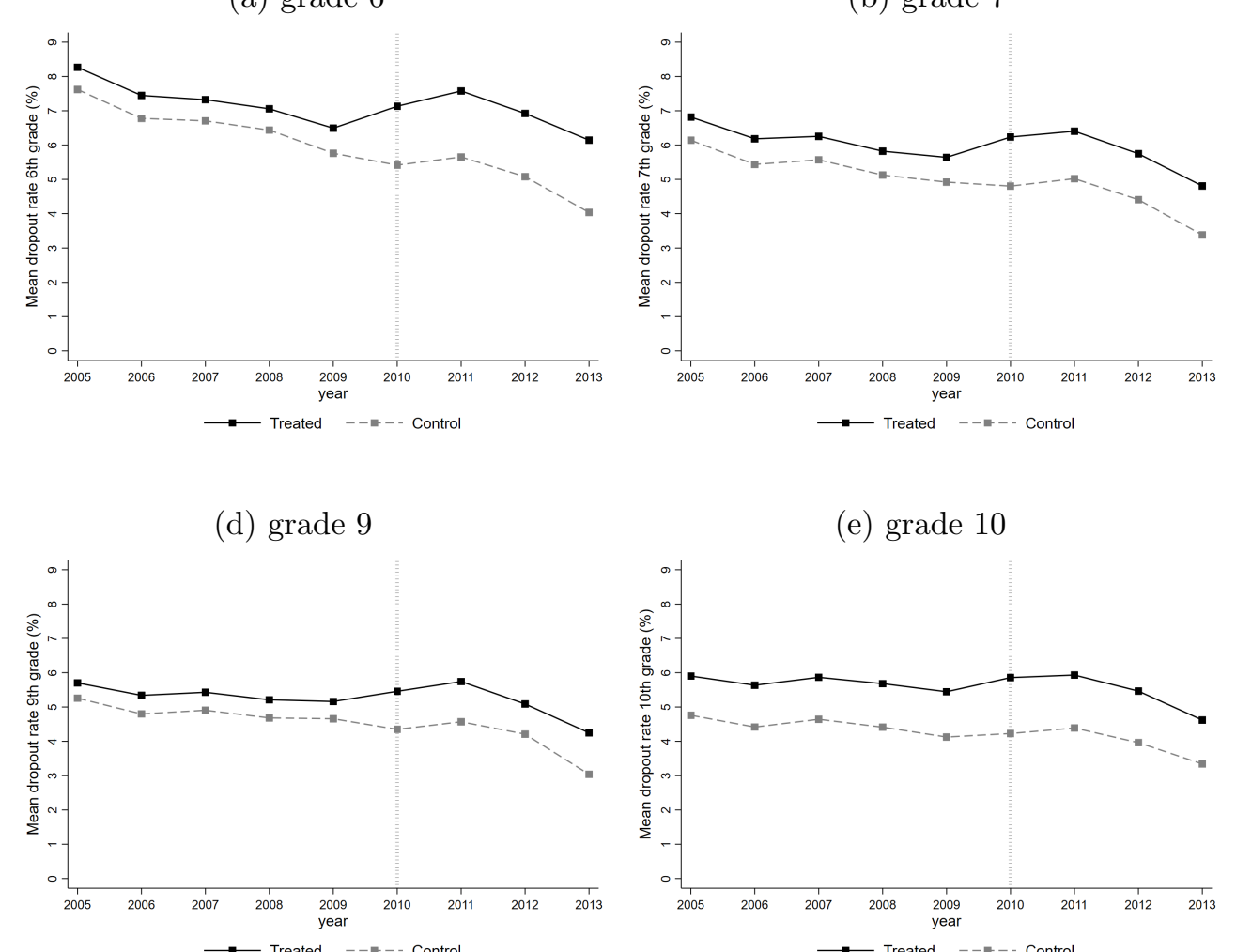

(e) grade 10

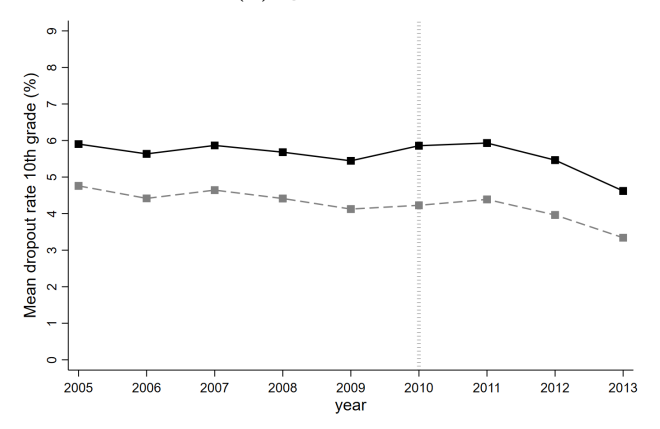

(c) grade 8

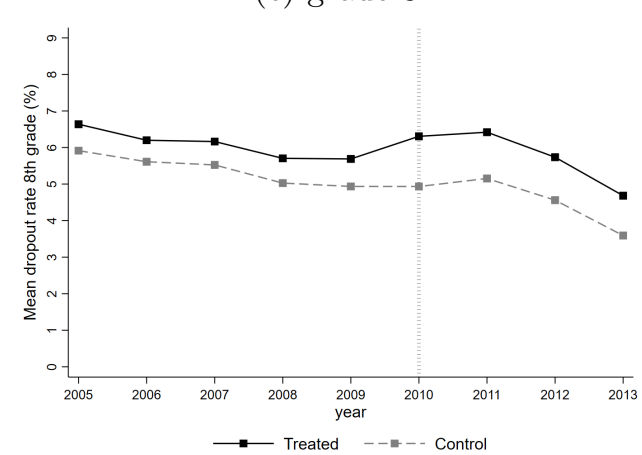

(f) grade 11

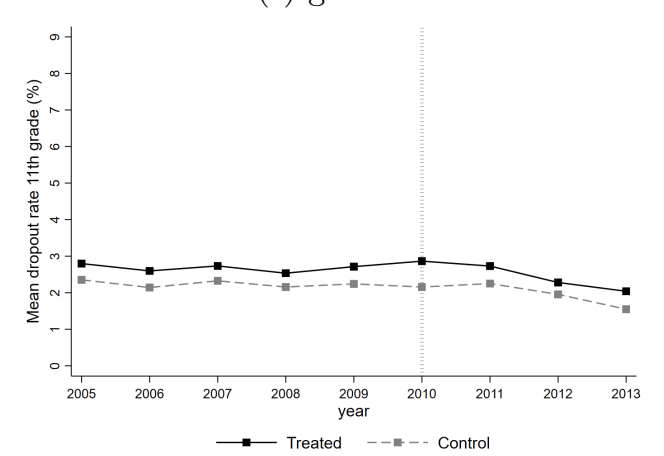

Notes: This figure shows school average early dropout rates in year $t+1$ including all students in each grade by treated and control schools. 


\section{Results}

\subsection{End-of-year dropout rates: Testing the common trend as- sumption and anticipatory effect}

A precondition for the validity of the difference-in-differences estimator is that the treatment is not implemented based on pre-existing differences in outcomes between treatment and control groups. The graphical evidence presented in the previous section suggests the existence of such common trend in early dropout rates between treated and control schools before the implementation of the FRP. However, the graphs also suggest the existence of an anticipatory effect, which could affect our main estimations, given the fact that the reform was announced one year before it came into force.

In this section, we present the results of the difference-in-differences common trend regressions for end-of-year dropout rates. This refers to the proportion of pupils from a cohort enrolled in a given grade, who concluded the school year but were retained, and did not register in the educational system to repeat the failed grade. As explained in Section 4 , since this is the rate of students who stop their school education in the same year of retention, we measure end-of-year dropout rates in year $t$ as the outcome of retention rates during the same year $t .^{11}$

Table 2: Common trend test - End-of-year dropout rate $t$

\begin{tabular}{lcc}
\hline \hline & $(1)$ & $(2)$ \\
\hline Pre-treatment trends & & \\
Treated $\times 2005$ & -0.091 & -0.155 \\
& $(0.114)$ & $(0.108)$ \\
Treated $\times 2006$ & 0.053 & -0.009 \\
& $(0.110)$ & $(0.103)$ \\
Treated $\times 2007$ & 0.059 & -0.018 \\
& $(0.117)$ & $(0.111)$ \\
Treated $\times 2008$ & 0.088 & 0.016 \\
& $(0.117)$ & $(0.113)$ \\
Treated $\times 2009$ & $0.310^{* *}$ & $0.231^{*}$ \\
& $(0.124)$ & $(0.121)$ \\
FRP trends & & \\
Treated $\times 2010$ & $3.163^{* * *}$ & $3.065^{* * *}$ \\
& $(0.147)$ & $(0.144)$ \\
Treated $\times 2011$ & $3.173^{* * *}$ & $3.061^{* * *}$ \\
& $(0.145)$ & $(0.139)$ \\
Treated $\times 2012$ & $2.790^{* * *}$ & $2.720^{* * *}$ \\
& $(0.152)$ & $(0.146)$ \\
Covariates & & \\
Schools & No & Yes \\
School-grades & 9,782 & 9,449 \\
Observations & 53,867 & 52,037 \\
Adjusted $R^{2}$ & 389,775 & 368,433 \\
\hline & 0.171 & 0.183 \\
\hline
\end{tabular}

Notes: ${ }^{*} p<0.10,{ }^{* *} p<0.05,{ }^{* * *} p<0.01$. Robust standard errors in parentheses, clustered at the at the school-grade level. Where indicated, the estimations control for all the variables listed in Table 1 as covariates. All estimations are weighted by the total number of students per school per year and include year-fixed effects, school-grade fixed effects, and school-grade specific linear trends.

\footnotetext{
$\overline{11}$ Because of data limitations, as mentioned earlier in Section 5.1, for this outcome of end-of-year dropout rates we cannot distinguish between male and female students; therefore, gender analyses are not possible.
} 
In Table 2 we show the common trend estimates for end-of-year dropout rates before and after the FRP reform, as described in equation (3). As required, the pre-treatment trends from 2005 to 2008 are not significantly different from the baseline year 2004; the corresponding coefficients are in fact close to zero. On the contrary, the post-treatment trends from 2010 to 2012 are all statistically significant and positive. The size of these estimates suggests an important positive impact of the FRP reform of approximately 3 percentage points higher end-of-year dropout rates among the retained students.

However, it is also important to note that the coefficient for the pre-treatment trend in year 2009 differs with 90 percent of confidence from the baseline. Although the size of this coefficient is very small in comparison with the subsequent post-treatment trend estimates, it suggests the possibility of an anticipatory effect in end-of-year dropout rates in year 2009. When using the heterogeneous treatment variable instead of the binary indicator, as shown in Table A1 in the Appendix, we observe that the marginal anticipatory effect in end-of-year dropout rates is entirely driven by schools in the high-treated group. In addition, these results in Table A1 show that the pre-treatment trends are also similar between the control and different-intensity treated schools. Finally, the FRP trends estimates in this table suggest that the effect of the reform on end-of-year dropouts is linear to the intensity of treatment.

Table 3: Placebo tests - End-of-year dropout rate ${ }_{t}$

\begin{tabular}{|c|c|c|c|c|c|c|}
\hline \multirow{3}{*}{ Treated $\times$ FakeFRP 2005} & \multirow{2}{*}{\multicolumn{2}{|c|}{$\begin{array}{l}\text { Including year } 2009 \\
(1)\end{array}$}} & \multirow{2}{*}{\multicolumn{2}{|c|}{$\begin{array}{l}\text { Excluding year } 2009 \\
(3)\end{array}$}} & \multicolumn{2}{|c|}{ Year > 2009} \\
\hline & & & & & & (6) \\
\hline & $\begin{array}{c}0.009 \\
(0.062)\end{array}$ & $\begin{array}{c}0.006 \\
(0.067)\end{array}$ & $\begin{array}{l}-0.026 \\
(0.064)\end{array}$ & $\begin{array}{c}-0.013 \\
(0.069)\end{array}$ & & \\
\hline Treated $\times$ FakeFRP 2006 & $\begin{array}{c}0.071 \\
(0.053)\end{array}$ & $\begin{array}{c}0.038 \\
(0.068)\end{array}$ & $\begin{array}{c}0.028 \\
(0.056)\end{array}$ & $\begin{array}{l}-0.026 \\
(0.070)\end{array}$ & & \\
\hline Treated $\times$ FakeFRP 2007 & $\begin{array}{c}0.030 \\
(0.053)\end{array}$ & $\begin{array}{l}0.029 \\
(0.068)\end{array}$ & $\begin{array}{l}-0.040 \\
(0.057)\end{array}$ & $\begin{array}{l}-0.061 \\
(0.063)\end{array}$ & & \\
\hline Treated $\times$ FakeFRP 2008 & $\begin{array}{l}0.126^{* *} \\
(0.052)\end{array}$ & $\begin{array}{l}0.138^{* *} \\
(0.056)\end{array}$ & $\begin{array}{c}0.053 \\
(0.063)\end{array}$ & $\begin{array}{c}0.031 \\
(0.066)\end{array}$ & & \\
\hline Treated $\times$ FakeFRP 2009 & $\begin{array}{c}0.187^{* * *} \\
(0.063)\end{array}$ & $\begin{array}{c}0.189^{* * *} \\
(0.065)\end{array}$ & & & & \\
\hline Treated $\times$ FakeFRP 2011 & & & & & $\begin{array}{c}0.322 \\
(0.251)\end{array}$ & $\begin{array}{c}0.230 \\
(0.250)\end{array}$ \\
\hline Treated $\times$ FakeFRP 2012 & & & & & $\begin{array}{l}-0.322 \\
(0.250)\end{array}$ & $\begin{array}{l}-0.230 \\
(0.251)\end{array}$ \\
\hline Covariates & No & Yes & No & Yes & No & Yes \\
\hline Schools & 9,777 & 9,409 & 9,777 & 9,409 & 9,777 & 9,409 \\
\hline School-grades & 52,674 & 50,109 & 51,356 & 48,995 & 48,063 & 46,179 \\
\hline Observations & 233,819 & 201,385 & 195,105 & 179,687 & 131,440 & 126,563 \\
\hline
\end{tabular}

Notes: ${ }^{*} p<0.10,{ }^{* *} p<0.05,{ }^{* * *} p<0.01$. Robust standard errors in parentheses, clustered at the at the school-grade level. Where indicated, the estimations control for all the variables listed in Table 1 as covariates. All estimations are weighted by the total number of students per school per year and include year-fixed effects, school-grade fixed effects, and school-grade specific linear trends.

To further check for the potential existence of the anticipatory effect and the impact it could have on our main estimates, we run some additional placebo tests. We first assume artificially that the FRP reform was introduced in different years before it actually occurred and estimate equation (1) for the period 2004-2009. Table 3 shows the resulting estimates of this exercise in columns (1) and (2). We observe that the last two placebo 
coefficients are positive and significant, which means we cannot confirm the existence of a common trend in years 2008 and 2009.

Since we suspect an anticipatory effect in end-of-year dropout rates occurring in 2009, based on the previous common trend tests, in columns (3) and (4) of Table 3 we present the results of the same placebo tests excluding year 2009 from the sample. The results show again that excluding the year of the anticipatory effect leads to accept the null hypothesis of a common trend in all the necessary cases; the estimates from all placebo tests are then statistically zero, as required to be able to use a difference-in-differences strategy. Finally, in columns (5) and (6) of Table 3, we present the outcomes of the two possible placebo tests for the after-reform period (2010-2012), which also give the non-significant required estimates to be able to use our difference-in-differences approach. Given the results of this section, we consider the anticipatory effect in end-of-year dropout rates to be likely. We will therefore estimate our main difference-in-differences model (1) both including and excluding data from year 2009 and show the results in the next Section.

\subsection{End-of-year dropout rates: The effect of the FRP reform and increased retention}

Table 4 presents the baseline estimates of the FRP reform on end-of-year dropout rates among retained students at secondary school. As indicated in Section 4, we present our main results both excluding and including time variant school-grade specific covariates. All our estimations include year-fixed effects, school-grade fixed effects and school-grade specific linear trends. The models are weighted by the total number of students per year and school-grade and standard errors are always clustered at the school-grade level to ensure that we account for potential serial correlation.

Table 4: Effect of the FRP reform on end-of-year dropout rate ${ }_{t}$

\begin{tabular}{lcccc}
\hline \hline & \multicolumn{2}{c}{ Including year 2009 } & \multicolumn{2}{c}{ Excluding year 2009 } \\
& $(1)$ & $(2)$ & $(3)$ & $(4)$ \\
\hline Treated $\times$ FRP & $3.084^{* * *}$ & $3.084^{* * *}$ & $3.298^{* * *}$ & $3.427^{* * *}$ \\
& $(0.094)$ & $(0.106)$ & $(0.124)$ & $(0.149)$ \\
& & & & \\
Covariates & No & Yes & No & Yes \\
Schools & 9,777 & 9,409 & 9,777 & 9,409 \\
School-grades & 52,674 & 50,109 & 52,674 & 50,109 \\
Observations & 359,457 & 313,053 & 316,845 & 272,017 \\
Adjusted $R^{2}$ & 0.269 & 0.271 & 0.280 & 0.278 \\
\hline
\end{tabular}

Notes: ${ }^{*} p<0.10,{ }^{* *} p<0.05,{ }^{* * *} p<0.01$. Robust standard errors in parentheses, clustered at the at the school-grade level. Where indicated, the estimations control for all the variables listed in Table 1 as covariates. All estimations are weighted by the total number of students per school per year and include year-fixed effects, school-grade fixed effects, and school-grade specific linear trends.

Table 4 provides evidence of a large and significant positive effect of the FRP reform on the average end-of-year dropout rate of secondary school retained students. On average, the rate of students that abandoned education after being retained at the end of the school year was 3 percentage points larger in treated than in control schools after the implementation of the FRP reform. Including or excluding year 2009 from the estimations, as shown in columns (3) and (4) of Table 4, does not significantly change the results. 
Given the treatment classification and identification strategy we apply, our main estimates are best interpreted as intention-to-treat effects (ITT). To obtain the average treatment effects on the treated (ATT), we rescale these estimates by the effect of the FRP reform on retention rates. Table A2 in the Appendix presents the estimations of the latter effects. On average, after the FRP reform, retention in secondary schools increased by 7.2 percentage points. Based on the previous measures, we can conclude that the 7.2 percentage points increase in retention of secondary school students, as a product of the FRP reform, caused a rise in the dropout rate of retained students by the end of the school year of 3.1 percentage points. This means that approximately 40 percent of the additional retained students due to the reform decided not to continue with their secondary education, or at least interrupted their schooling temporarily, after learning they needed to repeat the grade.

To the best of our knowledge, there was not any other educational reform or regulation change around the same FRP period that could have affected dropout rates. Therefore, we discard the possibility that the difference in end-of-year dropout rates between treated and control schools after the FRP reform is caused by any other reason than the increase in students' retention. This is a very relevant finding that points to the undesirable effect of retention as it seems to discourage retained students to continue with their school development. This finding is consistent with the literature (e.g Jacob and Lefgren, 2009; Manacorda, 2012) that has found that grade failure induces students to drop out at the end of the school year when failure occurs.

\subsubsection{Heterogeneous effects by treatment intensity}

To provide further insights into the effects of retention on early dropouts during secondary education, we examine whether our estimate of main interest differs across schools that were treated with different intensity. For this analysis, we use the heterogeneous treatment groups as explained in Section 4. We first estimate the effects of the FRP reform on retention across low-treated, mid-treated and high-treated schools (see Table A3 in the Appendix), and then re-estimate equation (1) using this heterogeneous treatment variable instead of the binary indicator. The main results are presented in Table 5.

The results in Table 5 confirm our main finding of a large and significant positive effect of the FRP reform on end-of-year dropout rates, proportional to the extent of retention growth in schools. On average, dropout rates of retained students by the end of the school year in high-treated, mid-treated and low-treated schools increased respectively by 4.7 , 1.9 and 0.7 percentage points after the implementation of the FRP reform.

Rescaling these estimates to the effect of the FRP reform on retention increases, ${ }^{12}$ we can conclude that the effect of retention of end-of-year dropout rates among retained students is likely to be linear. This means that the largest dropout rates of retained students after the FRP reform was experienced by high-treated schools. In all treated schools, regardless of the retention rates increases after the FRP reform, on average, about 40 percent of the additionally retained students did not register to repeat the failed grade and did not continue with their education in the year following retention. This is at least a large undesirable temporary short-term effect of retention. Further research on the long-term effects of retention on dropping out of school is essential to unveil the full dimension of impacts that retention may have on retained students.

\footnotetext{
12 Table A3 in the Appendix shows the FRP reform increased retention in low-treated, mid-treated and high-treated schools by $1.6,4.4$, and 11.1 percentage points respectively.
} 
Table 5: Effect of the FRP reform on end-of-year dropout rate ${ }_{t}$

\begin{tabular}{lcccc}
\hline \hline & \multicolumn{2}{c}{ Including year 2009 } & \multicolumn{2}{c}{ Excluding year 2009 } \\
& $(1)$ & $(2)$ & $(3)$ & $(4)$ \\
\hline Low-treated × FRP & $0.744^{* * *}$ & $0.671^{* * *}$ & $0.682^{* * *}$ & $0.623^{* * *}$ \\
& $(0.118)$ & $(0.135)$ & $(0.160)$ & $(0.190)$ \\
Mid-treated $\times \mathrm{FRP}$ & $1.987^{* * *}$ & $1.920^{* * *}$ & $1.994^{* * *}$ & $1.992^{* * *}$ \\
& $(0.125)$ & $(0.141)$ & $(0.165)$ & $(0.198)$ \\
High-treated $\times \mathrm{FRP}$ & $4.696^{* * *}$ & $4.664^{* * *}$ & $4.982^{* * *}$ & $5.158^{* * *}$ \\
& $(0.141)$ & $(0.160)$ & $(0.179)$ & $(0.218)$ \\
& & & & \\
Covariates & $\mathrm{No}$ & Yes & No & Yes \\
Schools & 9,777 & 9,409 & 9,777 & 9,409 \\
School-grades & 52,674 & 50,109 & 52,674 & 50,109 \\
Observations & 359,457 & 313,053 & 316,845 & 272,017 \\
Adjusted $R^{2}$ & 0.272 & 0.274 & 0.282 & 0.281 \\
\hline
\end{tabular}

Notes: ${ }^{*} p<0.10,{ }^{* *} p<0.05,{ }^{* * *} p<0.01$. Robust standard errors in parentheses, clustered at the at the school-grade level. Where indicated, the estimations control for all the variables listed in Table 1 as covariates. All estimations are weighted by the total number of students per school per year and include year-fixed effects, school-grade fixed effects, and school-grade specific linear trends.

\subsubsection{Heterogeneous effects by grade}

Our main estimates could also differ by grade if students experience retention differently depending on the timing of retention along the secondary school cycle. We may expect that retention at earlier grades affects students' attitudes and future school perspectives more strongly than retention at later stages, therefore, leading to larger effects on retained students' dropouts at the beginning of secondary education. To test for these potential differences, we re-estimate equation (1) for each grade separately, from grade 6 to grade 11 of secondary education, using both the binary and the heterogeneous treatment variables. The resulting estimates are shown in Table 6 and Table 7 respectively.

First, when using the binary treatment indicator as shown in Table 6, we find that the overall positive effect of the FRP reform on end-of-year dropout rates is significant across all six grades. We also observe that the effects of retention on retained dropouts is stronger and of similar magnitude among students from grade 6 to grade 8 . This effect decreases slightly for retained students during grades 9 and 10 and it is smallest at grade 11, where retention increases after the FRP reform were also the smallest.

Nonetheless, when we rescale the estimates in Table 6 to the increases in retention due to the FRP reform (as shown in Table A4 in the Appendix), we find that the effect is quite uniform for students in grades $6,7,8$, and 10; but stronger if students are retained at the end of grade 9 and grade 11. After the implementation of the FRP reform, approximately 45 to 48 percent of students retained in grade 9 and grade 11 did not continue with their education after being retained. This finding indicates that retention has a tougher effect on students enrolled in the school year that would otherwise lead them to either (a) complete the lower secondary cycle and obtain the Certificate of Basic Baccalaureate Studies, that is, grade 9; or (b) complete and obtain the high-school diploma, that is, grade 11. This result suggests then that particular attention to retained students at these two specific grades is necessary since dropping out of school at these stages would not only be a high risk but would also imply the highest cost of retention due to the forgone opportunity for students to finalise either one of the two cycles of secondary education as well as the subsequent long-term forgone labour market gains such as earnings. 
Finally, when using the low-, mid-, and high-treatment variables, as shown in Table 7, we observe large heterogeneity in the effect of retention across grades of schools treated with different intensity. Taking into account the increases in grade retention induced by the FRP reform (shown in Table A4 in the Appendix), we can infer that at earlier grades (from grade 6 to grade 8), retention seems to affect end-of-year dropout rates linearly to the increases in retention: on average, after the implementation of the FRP reform, approximately 40 percent of students retained from grade 6 to grade 8 did not continue with their education after being retained.

However, retained students from grade 9 to grade 11 responded very differently in their decision of leaving school afterwards. These effects appear to be nonlinear, since retained students enrolled in grade 9 to grade 11 in mid-treated schools reacted with higher dropout rates (approximately 60 percent of retained students left school after retention) than similar students in high-treated schools where retention rates were even higher (approximately 48 percent of retained students left school after retention). This finding suggests that students retained at later stages of secondary education in a school environment where retention is less common can cause more harm to the future perspectives of those students than if they would have been in schools where retention was more pronounced or more likely to occur at the end of the school year. Further research into the effects of retention in different peer environment is therefore needed to better understand the decision of retained students about continuing or not with their schooling. 
Table 6: Effect of the FRP reform on end-of-year dropout rate by grade $t$

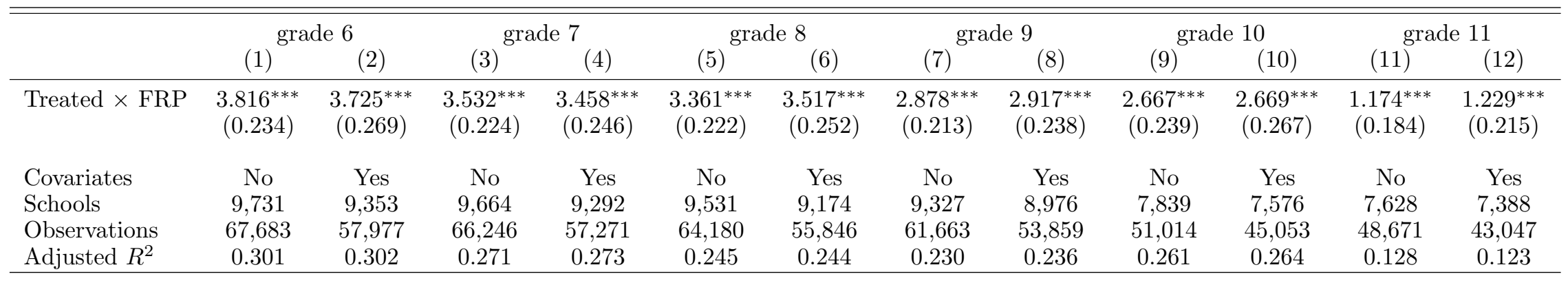

Notes: ${ }^{*} p<0.10,{ }^{* *} p<0.05,{ }^{* * *} p<0.01$. Robust standard errors in parentheses, clustered at the at the school-grade level. Where indicated, the estimations control for all the variables listed in Table 1 as covariates. All estimations are weighted by the total number of students per school per year and include year-fixed effects, school-grade fixed effects, and school-grade specific linear trends.

Table 7: Effect of the FRP reform on end-of-year dropout rate by grade ${ }_{t}$ - heterogeneous treatment

\begin{tabular}{|c|c|c|c|c|c|c|c|c|c|c|c|c|}
\hline & \multicolumn{2}{|c|}{ grade 6} & \multicolumn{2}{|c|}{ grade 7} & \multicolumn{2}{|c|}{ grade 8} & \multicolumn{2}{|c|}{ grade 9} & \multicolumn{2}{|c|}{ grade 10} & \multicolumn{2}{|c|}{ grade 11} \\
\hline & $(1)^{\circ}$ & (2) & $(3)$ & (4) & $(5)$ & (6) & $(7)^{-}$ & (8) & $(9)^{-}$ & (10) & $(11)^{\circ}$ & (12) \\
\hline Low-treated $\times$ FRP & $\begin{array}{c}1.091^{* * *} \\
(0.168)\end{array}$ & $\begin{array}{c}1.118^{* * *} \\
(0.177)\end{array}$ & $\begin{array}{c}0.923^{* * *} \\
(0.160)\end{array}$ & $\begin{array}{c}0.944^{* * *} \\
(0.168)\end{array}$ & $\begin{array}{c}0.955^{* * *} \\
(0.156)\end{array}$ & $\begin{array}{c}0.873^{* * *} \\
(0.163)\end{array}$ & $\begin{array}{c}1.064^{* * *} \\
(0.154)\end{array}$ & $\begin{array}{c}1.092^{* * *} \\
(0.160)\end{array}$ & $\begin{array}{c}1.026^{* * *} \\
(0.177)\end{array}$ & $\begin{array}{c}0.943^{* * *} \\
(0.183)\end{array}$ & $\begin{array}{c}0.481^{* * *} \\
(0.112)\end{array}$ & $\begin{array}{c}0.517^{* * *} \\
(0.124)\end{array}$ \\
\hline Mid-treated $\times$ FRP & $\begin{array}{c}2.766^{* * *} \\
(0.186)\end{array}$ & $\begin{array}{c}2.802^{* * *} \\
(0.196)\end{array}$ & $\begin{array}{c}2.442^{* * *} \\
(0.173)\end{array}$ & $\begin{array}{c}2.477^{* * *} \\
(0.182)\end{array}$ & $\begin{array}{c}2.350^{* * *} \\
(0.165)\end{array}$ & $\begin{array}{c}2.239^{* * *} \\
(0.172)\end{array}$ & $\begin{array}{c}2.330^{* * *} \\
(0.159)\end{array}$ & $\begin{array}{c}2.321^{* * *} \\
(0.164)\end{array}$ & $\begin{array}{c}2.269^{* * *} \\
(0.192)\end{array}$ & $\begin{array}{c}2.171^{* * *} \\
(0.194)\end{array}$ & $\begin{array}{c}0.656^{* * *} \\
(0.122)\end{array}$ & $\begin{array}{c}0.713^{* * *} \\
(0.132)\end{array}$ \\
\hline High-treated $\times$ FRP & $\begin{array}{c}5.720^{* * *} \\
(0.223)\end{array}$ & $\begin{array}{c}5.767^{* * *} \\
(0.233)\end{array}$ & $\begin{array}{c}5.306^{* * *} \\
(0.212)\end{array}$ & $\begin{array}{c}5.417^{* * *} \\
(0.217)\end{array}$ & $\begin{array}{c}5.041^{* * *} \\
(0.209)\end{array}$ & $\begin{array}{c}5.028^{* * *} \\
(0.214)\end{array}$ & $\begin{array}{c}4.347^{* * *} \\
(0.200)\end{array}$ & $\begin{array}{c}4.387^{* * *} \\
(0.206)\end{array}$ & $\begin{array}{c}4.552^{* * *} \\
(0.218)\end{array}$ & $\begin{array}{c}4.441^{* * * *} \\
(0.221)\end{array}$ & $\begin{array}{c}2.056^{* * *} \\
(0.158)\end{array}$ & $\begin{array}{c}2.092^{* * *} \\
(0.169)\end{array}$ \\
\hline Covariates & No & Yes & No & Yes & No & Yes & No & Yes & No & Yes & No & Yes \\
\hline Schools & 9,731 & 9,353 & 9,664 & 9,292 & 9,531 & 9,174 & 9,327 & 8,976 & 7,839 & 7,576 & 7,628 & 7,388 \\
\hline Observations & 64,330 & 60,058 & 63,097 & 59,325 & 61,377 & 57,964 & 59,202 & 56,085 & 49,440 & 47,087 & 47,351 & 45,170 \\
\hline Adjusted $R^{2}$ & 0.249 & 0.257 & 0.237 & 0.245 & 0.220 & 0.227 & 0.206 & 0.211 & 0.230 & 0.240 & 0.114 & 0.120 \\
\hline
\end{tabular}

Notes: ${ }^{*} p<0.10,{ }^{* *} p<0.05,{ }^{* * *} p<0.01$. Robust standard errors in parentheses, clustered at the at the school-grade level. Where indicated, the estimations control for all the variables listed in Table 1 as covariates. All estimations are weighted by the total number of students per school per year and include year-fixed effects, school-grade fixed effects, and school-grade specific linear trends. 


\subsection{Early dropout rates: Testing the common trend assumption and anticipatory effects}

In this section, we show a similar set of results than in Section 6.1 but for the second outcome of our interest, that is, early dropout rates in the year after retention.

Table 8 shows the common trend estimates for early dropout rates before and after the FRP reform. As required, the pre-treatment outcome trends from 2006 to 2009 are not significantly different from the baseline year 2005. In fact, these pre-treatment coefficients are very precise estimates of a zero difference in differences. Conversely, the trend estimates from 2011 to 2013 are all statistically significant and positive, although very small (lower than one percentage point) and decreasing over time. Overall, this result suggests a small positive impact of the FRP reform and increased retention on early dropout rates.

However, Table 8 also shows that the early dropout rates in 2010, which are the result of retention in the pre-treatment year 2009, significantly differ between treated and control schools by almost one percentage point. These estimates are statistically significant and of the same size either excluding or including covariates in the model; and hold when distinguishing between male and female students as well.

Table 8: Common trend tests - Early dropout rate ${ }_{t+1}$

\begin{tabular}{lcccccc}
\hline \hline & \multicolumn{2}{c}{ Dropout all } & \multicolumn{2}{c}{ Dropout males } & \multicolumn{2}{c}{ Dropout females } \\
& $(1)$ & $(2)$ & $(3)$ & $(4)$ & $(5)$ & $(6)$ \\
\hline Pre-treatment trends & & & & & & \\
Treated $\times 2006$ & 0.029 & 0.029 & 0.024 & 0.028 & 0.005 & 0.001 \\
& $(0.052)$ & $(0.053)$ & $(0.033)$ & $(0.034)$ & $(0.027)$ & $(0.027)$ \\
Treated $\times 2007$ & 0.038 & 0.031 & 0.041 & 0.036 & -0.003 & -0.005 \\
& $(0.053)$ & $(0.054)$ & $(0.036)$ & $(0.035)$ & $(0.027)$ & $(0.027)$ \\
Treated $\times 2008$ & 0.065 & -0.003 & 0.042 & -0.005 & 0.023 & 0.003 \\
& $(0.054)$ & $(0.055)$ & $(0.034)$ & $(0.034)$ & $(0.028)$ & $(0.028)$ \\
Treated $\times 2009$ & 0.023 & -0.003 & 0.031 & 0.021 & -0.008 & -0.024 \\
& $(0.053)$ & $(0.055)$ & $(0.033)$ & $(0.034)$ & $(0.027)$ & $(0.028)$ \\
Treated $\times 2010$ & $0.701^{* * *}$ & $0.652^{* * *}$ & $0.496^{* * *}$ & $0.451^{* * *}$ & $0.206^{* * *}$ & $0.201^{* * *}$ \\
& $(0.056)$ & $(0.058)$ & $(0.035)$ & $(0.036)$ & $(0.028)$ & $(0.029)$ \\
FRP trends & & & & & & \\
Treated $\times 2011$ & $0.915^{* * *}$ & $0.853^{* * *}$ & $0.605^{* * *}$ & $0.554^{* * *}$ & $0.311^{* * *}$ & $0.299^{* * *}$ \\
& $(0.057)$ & $(0.058)$ & $(0.035)$ & $(0.035)$ & $(0.029)$ & $(0.030)$ \\
Treated $\times 2012$ & $0.430^{* * *}$ & $0.458^{* * *}$ & $0.260^{* * *}$ & $0.274^{* * *}$ & $0.170^{* * *}$ & $0.184^{* * *}$ \\
& $(0.047)$ & $(0.047)$ & $(0.029)$ & $(0.029)$ & $(0.025)$ & $(0.026)$ \\
Treated $\times 2013$ & $0.384^{* * *}$ & $0.404^{* * *}$ & $0.229^{* * *}$ & $0.241^{* * *}$ & $0.155^{* * *}$ & $0.163^{* * *}$ \\
& $(0.045)$ & $(0.045)$ & $(0.028)$ & $(0.027)$ & $(0.024)$ & $(0.025)$ \\
Covariates & & & & & & \\
Schools & No & Yes & No & Yes & No & Yes \\
School-grades & 9,782 & 9,449 & 9,782 & 9,449 & 9,782 & 9,449 \\
Observations & 53,867 & 52,037 & 53,867 & 52,037 & 53,867 & 52,037 \\
Adjusted $R^{2}$ & 389,775 & 368,433 & 389,775 & 368,433 & 389,775 & 368,433 \\
\hline & 0.430 & 0.432 & 0.393 & 0.406 & 0.336 & 0.341 \\
\hline
\end{tabular}

Notes: ${ }^{*} p<0.10,{ }^{* *} p<0.05,{ }^{* * *} p<0.01$. Robust standard errors in parentheses, clustered at the at the school-grade level. Where indicated, the estimations control for all the variables listed in Table 1 as covariates. All estimations are weighted by the total number of students per school per year and include year-fixed effects, school-grade fixed effects, and school-grade specific linear trends.

As shown in Table A6 in the Appendix, this anticipatory effect is also evident when using the heterogeneous treatment variable instead of the binary variable. The anticipatory 
effect in 2010 is mostly driven by schools in the mid-treated and high-treated groups; although, there is a significant anticipatory effect in early dropout rates among male students in low-treated schools. Table A6 also confirms the validity of similar pre-treatment trends between the control and different-intensity treated schools. The effect of higher retention on early dropouts seems to be linear to the intensity of treatment; there is no apparent effect among low-treated schools whereas the effect is positive and increasing among mid-treated and high-treated schools respectively. These results suggest that the positive effect of retention on early dropout rates is strongest in high-treated schools and higher among male than female students.

Overall, we find a very robust indication of an anticipatory effect in early dropout rates one year prior to the reform implementation. As suggested by the common-trend tests, it is plausible that some students dropped out of school before concluding the school year as a reaction to the early announcement of the new law that would increase the likelihood of being retained in the following years.

To further check for the influence that such anticipatory effect could have on our main estimates, we run some additional placebo tests. First, we assume artificially that the FRP reform was introduced in different years before it actually occurred and estimate equation (2) for the period 2005-2010. The results are shown in Table 9. We observe that in all the five placebo tests performed, the estimated coefficients are positive and highly significant, regardless if we use the entire sample or the male and female students subsamples separately.

Table 9: Placebo tests pre-treatment, including year 2010 - Early dropout rate $t+1$

\begin{tabular}{lcccccc}
\hline \hline & \multicolumn{2}{c}{ Dropout all } & \multicolumn{2}{c}{ Dropout males } & \multicolumn{2}{c}{ Dropout females } \\
& $(1)$ & $(2)$ & $(3)$ & $(4)$ & $(5)$ & $(6)$ \\
\hline Treated $\times$ FakeFRP 2005 & $0.368^{* * *}$ & $0.358^{* * *}$ & $0.240^{* * *}$ & $0.207^{* * *}$ & $0.128^{* * *}$ & $0.151^{* * *}$ \\
& $(0.067)$ & $(0.067)$ & $(0.043)$ & $(0.043)$ & $(0.034)$ & $(0.034)$ \\
Treated $\times$ FakeFRP $_{2006}$ & $0.330^{* * *}$ & $0.319^{* * *}$ & $0.217^{* * *}$ & $0.186^{* * *}$ & $0.113^{* * *}$ & $0.133^{* * *}$ \\
& $(0.055)$ & $(0.056)$ & $(0.035)$ & $(0.035)$ & $(0.027)$ & $(0.028)$ \\
Treated $\times$ FakeFRP $_{2007}$ & $0.362^{* * *}$ & $0.319^{* * *}$ & $0.236^{* * *}$ & $0.190^{* * *}$ & $0.126^{* * *}$ & $0.129^{* * *}$ \\
& $(0.052)$ & $(0.052)$ & $(0.033)$ & $(0.033)$ & $(0.026)$ & $(0.026)$ \\
Treated $\times$ FakeFRP $_{2008}$ & $0.459^{* * *}$ & $0.444^{* * *}$ & $0.303^{* * *}$ & $0.270^{* * *}$ & $0.156^{* * *}$ & $0.174^{* * *}$ \\
& $(0.053)$ & $(0.054)$ & $(0.033)$ & $(0.034)$ & $(0.027)$ & $(0.027)$ \\
Treated $\times$ FakeFRP & & & \\
& $0.861^{* * *}$ & $0.836^{* * *}$ & $0.496^{* * *}$ & $0.463^{* * *}$ & $0.365^{* * *}$ & $0.373^{* * *}$ \\
& $(0.062)$ & $(0.063)$ & $(0.039)$ & $(0.040)$ & $(0.031)$ & $(0.031)$ \\
& & & & & & \\
Covariates & No & Yes & No & Yes & No & Yes \\
Schools & 9,777 & 9,409 & 9,777 & 9,409 & 9,777 & 9,409 \\
School-grades & 53,376 & 51,401 & 53,376 & 51,401 & 53,376 & 51,401 \\
Observations & 241,505 & 226,760 & 241,505 & 226,760 & 241,505 & 226,760 \\
\hline
\end{tabular}

Notes: ${ }^{*} p<0.10,{ }^{* *} p<0.05,{ }^{* * *} p<0.01$. Robust standard errors in parentheses, clustered at the at the school-grade level. Where indicated, the estimations control for all the variables listed in Table 1 as covariates. All estimations are weighted by the total number of students per school per year and include year-fixed effects, school-grade fixed effects, and school-grade specific linear trends.

This finding would pose a serious threat to our identification strategy, since it raises concerns about other potential confounding factors affecting early dropout rates in the pre-treatment period. However, since we suspect an anticipatory effect in early dropout rates in 2010, as suggested by the previous common trend tests, we run once more the same placebo tests of Table 9 excluding year 2010 from the sample. As shown in Table 10 , once we exclude the year of the anticipatory effect, all the estimates from the placebo 
tests are not significantly different from zero. This result not only confirms the required pre-treatment common trend but also confirms the occurrence of an anticipatory effect in early dropout rates in year 2010. Finally, in Table 11 we present the outcomes of the two possible placebo tests for the after-reform period (2011-2013), which also give non-significant estimates.

Given the results of our common trend and placebo analyses presented before, we consider that the sizable, robust and significant anticipatory effect in early dropout rates in 2010 needs to be excluded from our main difference-in-differences model (2) to be able to estimate correctly the effect of the FRP reform on early dropout rates. We proceed accordingly and show the main results in the next Section.

Table 10: Placebo tests pre-treatment, excluding year 2010 - Early dropout rate $t+1$

\begin{tabular}{lcccccc}
\hline \hline & \multicolumn{2}{c}{ Dropout all } & \multicolumn{2}{c}{ Dropout males } & \multicolumn{2}{c}{ Dropout females } \\
& $(1)$ & $(2)$ & $(3)$ & $(4)$ & $(5)$ & $(6)$ \\
\hline Treated × FakeFRP 2005 & 0.060 & 0.065 & 0.002 & 0.005 & 0.058 & 0.060 \\
& $(0.100)$ & $(0.101)$ & $(0.064)$ & $(0.064)$ & $(0.052)$ & $(0.053)$ \\
Treated × FakeFRP 2006 & -0.019 & 0.021 & -0.034 & -0.022 & 0.015 & 0.042 \\
& $(0.106)$ & $(0.109)$ & $(0.068)$ & $(0.069)$ & $(0.056)$ & $(0.057)$ \\
Treated $\times$ FakeFRP 2007 & -0.074 & -0.100 & -0.045 & -0.048 & -0.029 & -0.052 \\
& $(0.107)$ & $(0.108)$ & $(0.068)$ & $(0.069)$ & $(0.056)$ & $(0.057)$ \\
Treated × FakeFRP 2008 & 0.014 & -0.001 & 0.057 & 0.048 & -0.043 & -0.049 \\
& $(0.095)$ & $(0.098)$ & $(0.061)$ & $(0.062)$ & $(0.049)$ & $(0.051)$ \\
Covariates & & & & & & \\
Schools & No & Yes & No & Yes & No & Yes \\
School-grades & 9,777 & 9,409 & 9,777 & 9,409 & 9,777 & 9,409 \\
Observations & 52,325 & 50,952 & 52,325 & 50,952 & 52,325 & 50,952 \\
\hline & 196,020 & 183,726 & 196,020 & 183,726 & 196,020 & 183,726 \\
\hline
\end{tabular}

Notes: ${ }^{*} p<0.10,{ }^{* *} p<0.05,{ }^{* * *} p<0.01$. Robust standard errors in parentheses, clustered at the at the school-grade level. Where indicated, the estimations control for all the variables listed in Table 1 as covariates. All estimations are weighted by the total number of students per school per year and include year-fixed effects, school-grade fixed effects, and school-grade specific linear trends.

Table 11: Placebo tests FRP period - Early dropout rate ${ }_{t+1}$

\begin{tabular}{lcccccc}
\hline \hline & \multicolumn{2}{c}{ Dropout all } & \multicolumn{2}{c}{ Dropout males } & \multicolumn{2}{c}{ Dropout females } \\
& $(1)$ & $(2)$ & $(3)$ & $(4)$ & $(5)$ & $(6)$ \\
\hline Treated $\times$ FakeFRP $_{2011}$ & -0.21 & -0.174 & -0.107 & -0.078 & -0.103 & -0.096 \\
& $(0.144)$ & $(0.147)$ & $(0.091)$ & $(0.092)$ & $(0.074)$ & $(0.076)$ \\
Treated $\times$ FakeFRP $_{2012}$ & 0.21 & 0.174 & 0.107 & 0.078 & 0.103 & 0.096 \\
& $(0.144)$ & $(0.147)$ & $(0.091)$ & $(0.092)$ & $(0.074)$ & $(0.076)$ \\
& & & & & & \\
Covariates & No & Yes & No & Yes & No & Yes \\
Schools & 9,777 & 9,409 & 9,777 & 9,409 & 9,777 & 9,409 \\
School-grades & 53,396 & 51,273 & 53,396 & 51,273 & 53,396 & 51,273 \\
Observations & 144,827 & 137,087 & 144,827 & 137,087 & 144,827 & 137,087 \\
\hline
\end{tabular}

Notes: ${ }^{*} p<0.10,{ }^{* *} p<0.05,{ }^{* * *} p<0.01$. Robust standard errors in parentheses, clustered at the at the school-grade level. Where indicated, the estimations control for all the variables listed in Table 1 as covariates. All estimations are weighted by the total number of students per school per year and include year-fixed effects, school-grade fixed effects, and school-grade specific linear trends. 


\subsection{Early dropout rates: The effect of the FRP reform and increased retention}

Table 12 presents our baseline estimates of the effect of higher retention, as induced by the FRP reform, on early dropout rates at secondary school in the year after retention for all enrolled students, i.e. non-retained and retained students that decided to repeat the grade. As indicated in Section 4, these estimations are also weighted by the total number of students per year and include year-fixed effects, school-grade fixed effects, school-grade specific linear trends and standard errors clustered at the school-grade level.

The results in Table 12 provide evidence of a significant positive effect of the FRP reform on the average early dropout rate of secondary school students. Nevertheless, the effect of increased retention on early dropout seems to be rather small: on average, the dropout rate before the end of the school year in treated schools was 0.6 of a percentage point larger after the reform in comparison with control schools. This increase in dropouts was driven relatively equally by male and female students.

Table 12: Effect of the FRP reform on dropout rates $t+1$

\begin{tabular}{lcccccc}
\hline \hline & \multicolumn{2}{c}{ Dropout all } & \multicolumn{2}{c}{ Dropout males } & \multicolumn{2}{c}{$\begin{array}{c}\text { Dropout females } \\
(1)\end{array}$} \\
& $(2)$ & $(3)$ & $(4)$ & $(5)$ & $(6)$ \\
\hline Treated $\times \mathrm{FRP}_{t-1}$ & $0.621^{* * *}$ & $0.561^{* * *}$ & $0.335^{* * *}$ & $0.296^{* * *}$ & $0.287^{* * *}$ & $0.265^{* * *}$ \\
& $(0.051)$ & $(0.052)$ & $(0.031)$ & $(0.032)$ & $(0.026)$ & $(0.026)$ \\
& & & & & & \\
Covariates & No & Yes & No & Yes & No & Yes \\
Schools & 9,777 & 9,409 & 9,777 & 9,409 & 9,777 & 9,409 \\
School-grades & 53,720 & 51,759 & 53,720 & 51,759 & 53,720 & 51,759 \\
Observations & 344,797 & 325,689 & 344,797 & 325,689 & 344,797 & 325,689 \\
Adjusted $R^{2}$ & 0.376 & 0.378 & 0.346 & 0.360 & 0.285 & 0.292 \\
\hline
\end{tabular}

Notes: ${ }^{*} p<0.10,{ }^{* *} p<0.05,{ }^{* * *} p<0.01$. Robust standard errors in parentheses, clustered at the at the school-grade level. Where indicated, the estimations control for all the variables listed in Table 1 as covariates. All estimations are weighted by the total number of students per school per year and include year-fixed effects, school-grade fixed effects, and school-grade specific linear trends.

Rescaling the estimates of Table 12 by the effect of the FRP reform on retention rates (see Table A2 in the Appendix) suggests that a 10 percentage points rise in retention rates will increase early dropout rates by 0.8 of a percentage point in the year after retention. The effect seems to be similar between males and female students; a 10 percentage point increase in male (female) students' retention increases male (female) next year's dropouts before the completion of the school year by 0.75 (0.83) of a percentage point.

To the best of our knowledge, there was not any other educational reform or regulation change around the same FRP period that could have affected dropout rates. Therefore, we discard the possibility that difference in early dropout rates between treated and control schools after the FRP reform are caused by any other reason than the increase in students' retention. This finding is consistent with the previous empirical literature, as summarised in Section 2, that suggest that grade retention leads to higher school dropout rates. The size of the effect, however, seems to be initially small in economic terms, which could suggest that the undesirable effects of retention on dropouts could be in some cases offset by its positive effects, for instance, the effect of better school performance. 


\subsubsection{Heterogeneous effects by treatment intensity}

To provide further insights into the effects of retention on end-of-year dropouts at secondary school, we also analyse whether the estimates in Table 12 differ across schools that experience different intensity in the treatment. Following the same steps as in Section 6.2 , we now re-estimate equation (2) using the heterogeneous treatment variable instead of the binary indicator and show the results in Table 13.

The results in Table 13 confirm our main finding of a significant positive effect of the FRP reform on early dropouts at secondary school. Moreover, these results suggest this effect to be linear or proportional to the extent of retention growth: on average, the dropout rates before the end of the school year in high-treated, mid-treated and lowtreated schools were respectively 1, 0.4 and 0.2 percentage points higher after the reform in comparison with control schools. These positive effects of retention on dropping out of school were slightly larger among male than female students, particularly in the case of low-treated schools.

Table 13: Effect of the FRP reform on dropout rates $t_{t+1}$ - heterogeneous treatment

\begin{tabular}{lcccccc}
\hline \hline & \multicolumn{3}{c}{ Dropout all } & \multicolumn{2}{c}{ Dropout males } & \multicolumn{2}{c}{ Dropout } \\
& $(1)$ & $(2)$ & $(3)$ & $(4)$ & $(5)$ & $(6)$ \\
\hline Low-treated $\times \mathrm{FRP}_{t-1}$ & $0.186^{* * *}$ & $0.207^{* * *}$ & $0.152^{* * *}$ & $0.162^{* * *}$ & 0.034 & 0.045 \\
& $(0.068)$ & $(0.069)$ & $(0.041)$ & $(0.042)$ & $(0.036)$ & $(0.036)$ \\
Mid-treated $\times \mathrm{FRP}_{t-1}$ & $0.381^{* * *}$ & $0.368^{* * *}$ & $0.237^{* * *}$ & $0.225^{* * *}$ & $0.145^{* * *}$ & $0.143^{* * *}$ \\
& $(0.071)$ & $(0.073)$ & $(0.043)$ & $(0.044)$ & $(0.039)$ & $(0.039)$ \\
High-treated $\times \mathrm{FRP}_{t-1}$ & $1.004^{* * *}$ & $0.934^{* * *}$ & $0.572^{* * *}$ & $0.527^{* * *}$ & $0.432^{* * *}$ & $0.407^{* * *}$ \\
& $(0.072)$ & $(0.074)$ & $(0.044)$ & $(0.045)$ & $(0.037)$ & $(0.037)$ \\
Covariates & & & & & & \\
Schools & $\mathrm{No}$ & Yes & $\mathrm{No}$ & Yes & No & Yes \\
School-grades & 9,777 & 9,409 & 9,777 & 9,409 & 9,777 & 9,409 \\
Observations & 53,720 & 51,759 & 53,720 & 51,759 & 53,720 & 51,759 \\
Adjusted $R^{2}$ & 344,797 & 325,689 & 344,797 & 325,689 & 344,797 & 325,689 \\
& 0.376 & 0.378 & 0.346 & 0.360 & 0.285 & 0.292 \\
\hline
\end{tabular}

Notes: ${ }^{*} p<0.10,{ }^{* *} p<0.05,{ }^{* * *} p<0.01$. Robust standard errors in parentheses, clustered at the at the school-grade level. Where indicated, the estimations control for all the variables listed in Table 1 as covariates. All estimations are weighted by the total number of students per school per year and include year-fixed effects, school-grade fixed effects, and school-grade specific linear trends.

As previously mentioned, Table A3 in the Appendix shows that the FRP reform increased retention in low-treated, mid-treated and high-treated schools by 1.6, 4.4, and 11.1 percentage points, respectively. Among male students, the same effects were 0.9, 2.3, and 6.3 percentage points whereas for female students' retention increased by $0.7,2.0$ and 4.9 percentages points. Thus, rescaling the estimates obtained in Table 13 to the corresponding increases in retention, reinforces the conclusion from the previous section that an increase of one percentage point in retention rises early dropout rates linearly by approximately 0.09 percentage point in the year after retention. This means, the strongest effect on dropout rates was experienced among high-treated schools.

The effect of retention on dropouts, however, seems to differ between male and female students when taking into consideration the heterogeneous treatment intensity across schools. Our findings suggest that the slight increase in retention rates among all lowtreated schools only affected male early dropouts and did not have any effect on female students. Similarly, whereas a one percentage point higher retention amongst mid- 
treated schools led to an increase of one percentage point in male dropout rates, female dropout rates only increased by 0.06 percentage points. Nevertheless, amongst hightreated schools, the scaled effect of retention on early dropouts is similar for male and female students. Although the effect of the FRP reform on male dropout rates was slightly higher ( 0.6 percentage point) than for females ( 0.4 percentage point), this effect is proportional to the higher increase in males' retention (6.3 percentage points) in comparison with the increase in female retention rates (4.9 percentage points).

\subsubsection{Heterogeneous effects by grade}

In this last section, we test for potential differences in the effect of retention on early dropout rates across grades. For instance, it could be that retention at early grades affects more strongly students' attitudes and future perspectives than retention at later stages, which could lead to heterogeneous motivations and responses in terms of dropping out of school. To test for this hypothesis, we re-estimate equation (2) for each grade separately, from grade 6 to grade 11, using both the binary and the heterogeneous treatment variables. The results are shown in Table 14 and Table 15, respectively.

First, when using the binary treatment indicator as shown in Table 14, we find that indeed the overall positive effect of the FRP reform on early dropout rates is stronger the earlier the grade, and that there is not any significant effect during the last two years of secondary education, i.e. grades 10 and 11. Rescaling these estimates to the increase in retention due to the FRP reform (See Table A4 in the Appendix) confirms that the effect of our interest is strongest at grade 6: a 10 percentage points increase in students' retention during the first year of secondary school increases early dropouts at grade 6 , one year after, by 1.1 percentage points. This effects gradually decreases over grades until grade 9 , when a 10 percentage points increase in students' retention rises early dropouts by 0.6 of a percentage point. Moreover, we observe in Table 14 that the effects of the FRP reform are, in all grades, consistently higher for male students than for female students, nevertheless, proportional to the larger increases in males' retention across all grades as well.

Second, when using the low-, mid-, and high-treatment variables, as shown in Table 15, we observe large heterogeneity in the effect of the FRP reform across grades of schools treated with different intensity. For instance, the slight increase in retention amongst low-treated schools only had a marginal positive effect on early dropouts in grade 6 , while all other grades seemed to be unaffected. Within mid-treated schools, the positive effect of the reform on students' dropouts appears to be significant only from grade 6 to grade 8. Students in grades 9 and 10 did not seem to react to the law change.

Surprisingly, the results for grade 11 of mid-treated schools suggest a small marginal negative effect on dropouts. Finally, the positive effect on high-treated schools is confirmed to be the largest in all grades, except grades 10 and 11, where the increase in retention induced by the reform did not affect students' early dropouts. This effect across hightreated schools is also greater the earlier the grade.

More interestingly, some gender differences become evident. Table 15 and Table A5 in the Appendix reveal that amongst low-treated schools, for example, the small positive effect of retention on early dropouts in grade 6 is driven entirely by male students, although the increase in retention was very similar for both males and females. Within mid-treated schools, the effect of retention on dropping out of school in grades 7 and 8 is almost the same between males and females, even though males' retention rates were approximately one percentage point higher among males. Conversely, at grade 6 the same effect is 
twice the size for male students in comparison with female students; nonetheless, this seems to be proportional to retention rates, which affected males more strongly than females in grade 6 . In the case of high-treated schools, the effects vary as well. For students in grade 9, the reform affected male and female dropouts in a very similar magnitude, even though again males' retention was approximately one percentage point higher than females' retention. The effect on students' dropouts from grade 6 to grade 8 , however, appears to be proportional to the larger retention rates among male students in comparison to females after the FRP reform. Finally, there is a striking small negative effect of the reform on dropouts that is significant for grade 11 males in low- and midtreated schools only. This is surprising since the reform, according to Table A5 in the Appendix, did not have any effect on retention for this group of students. This might have been a clever response from students in male-only schools that expected correctly the FRP reform to affect students' retention in other grades except for grade 11, given the historically low retention rates at this level, so their incentives to finish the last year of secondary school could have marginally increased. 
Table 14: Effect of the FRP reform on dropout rates $t+1$ by grade

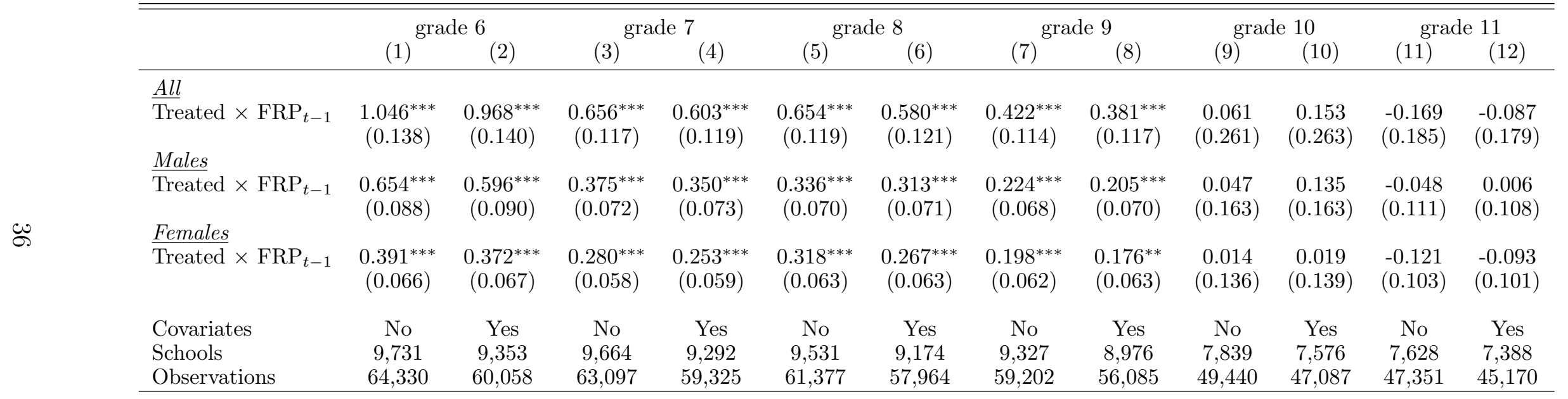

Notes: ${ }^{*} p<0.10,{ }^{* *} p<0.05,{ }^{* * *} p<0.01$. Robust standard errors in parentheses, clustered at the at the school-grade level. Where indicated, the estimations control for all the variables listed in Table 1 as covariates. All estimations are weighted by the total number of students per school per year and include year-fixed effects, school-grade fixed effects, and school-grade specific linear trends. 
Table 15: Effect of the FRP reform on dropout rates ${ }_{t+1}$ by grade - heterogeneous treatment

\begin{tabular}{|c|c|c|c|c|c|c|c|c|c|c|c|c|}
\hline & \multicolumn{2}{|c|}{ grade 6} & \multicolumn{2}{|c|}{ grade 7} & \multicolumn{2}{|c|}{ grade 8} & \multicolumn{2}{|c|}{ grade 9} & \multicolumn{2}{|c|}{ grade 10} & \multicolumn{2}{|c|}{ grade 11} \\
\hline & $(1)^{+x}$ & $(2)$ & $(3)^{8+\infty}$ & $(4)$ & $(5)^{8+20}$ & $(6)$ & $(7)^{8-1}$ & $(8)$ & $(9)^{2}$ & $(10)$ & $(11)^{-2}$ & (12) \\
\hline \multicolumn{13}{|l|}{ All } \\
\hline Low-treated $\times \mathrm{FRP}_{t-1}$ & $\begin{array}{l}0.380^{* *} \\
(0.181)\end{array}$ & $\begin{array}{l}0.327^{*} \\
(0.185)\end{array}$ & $\begin{array}{c}0.172 \\
(0.161)\end{array}$ & $\begin{array}{c}0.204 \\
(0.164)\end{array}$ & $\begin{array}{c}0.160 \\
(0.163)\end{array}$ & $\begin{array}{c}0.158 \\
(0.166)\end{array}$ & $\begin{array}{c}0.058 \\
(0.152)\end{array}$ & $\begin{array}{c}0.085 \\
(0.156)\end{array}$ & $\begin{array}{c}0.207 \\
(0.347)\end{array}$ & $\begin{array}{c}0.239 \\
(0.355)\end{array}$ & $\begin{array}{l}-0.307 \\
(0.247)\end{array}$ & $\begin{array}{l}-0.303 \\
(0.241)\end{array}$ \\
\hline Mid-treated $\times \mathrm{FRP}_{t-1}$ & $\begin{array}{c}0.813^{* * *} \\
(0.195)\end{array}$ & $\begin{array}{c}0.704^{* * *} \\
(0.202)\end{array}$ & $\begin{array}{l}0.379^{* *} \\
(0.160)\end{array}$ & $\begin{array}{l}0.402^{* *} \\
(0.164)\end{array}$ & $\begin{array}{l}0.430^{* *} \\
(0.172)\end{array}$ & $\begin{array}{l}0.402^{* *} \\
(0.176)\end{array}$ & $\begin{array}{c}0.148 \\
(0.157)\end{array}$ & $\begin{array}{c}0.139 \\
(0.160)\end{array}$ & $\begin{array}{l}-0.113 \\
(0.375)\end{array}$ & $\begin{array}{c}0.040 \\
(0.379)\end{array}$ & $\begin{array}{l}-0.502^{*} \\
(0.255)\end{array}$ & $\begin{array}{l}-0.459^{*} \\
(0.235)\end{array}$ \\
\hline High-treated $\times \mathrm{FRP}_{t-1}$ & $\begin{array}{c}1.622^{* * *} \\
(0.197)\end{array}$ & $\begin{array}{c}1.380^{* * *} \\
(0.202)\end{array}$ & $\begin{array}{c}1.051^{* * *} \\
(0.168)\end{array}$ & $\begin{array}{c}0.996^{* * *} \\
(0.171)\end{array}$ & $\begin{array}{c}0.997^{* * *} \\
(0.169)\end{array}$ & $\begin{array}{c}0.904^{* * *} \\
(0.174)\end{array}$ & $\begin{array}{c}0.695^{* * *} \\
(0.157)\end{array}$ & $\begin{array}{c}0.660^{* * *} \\
(0.164)\end{array}$ & $\begin{array}{c}0.416 \\
(0.363)\end{array}$ & $\begin{array}{c}0.493 \\
(0.365)\end{array}$ & $\begin{array}{l}-0.219 \\
(0.253)\end{array}$ & $\begin{array}{l}-0.127 \\
(0.247)\end{array}$ \\
\hline \multicolumn{13}{|l|}{ Males } \\
\hline$\overline{\text { Low-treated } \times \mathrm{FRP}_{t-1}}$ & $\begin{array}{c}0.323^{* * *} \\
(0.115)\end{array}$ & $\begin{array}{l}0.282^{* *} \\
(0.119)\end{array}$ & $\begin{array}{c}0.147 \\
(0.099)\end{array}$ & $\begin{array}{c}0.164 \\
(0.100)\end{array}$ & $\begin{array}{c}0.148 \\
(0.094)\end{array}$ & $\begin{array}{c}0.147 \\
(0.096)\end{array}$ & $\begin{array}{c}0.028 \\
(0.093)\end{array}$ & $\begin{array}{c}0.035 \\
(0.096)\end{array}$ & $\begin{array}{c}0.272 \\
(0.220)\end{array}$ & $\begin{array}{c}0.281 \\
(0.224)\end{array}$ & $\begin{array}{c}-0.301^{* *} \\
(0.149)\end{array}$ & $\begin{array}{c}-0.302^{* *} \\
(0.146)\end{array}$ \\
\hline Mid-treated $\times \mathrm{FRP}_{t-1}$ & $\begin{array}{c}0.575^{* * *} \\
(0.120)\end{array}$ & $\begin{array}{c}0.465^{* * *} \\
(0.124)\end{array}$ & $\begin{array}{l}0.201^{* *} \\
(0.096)\end{array}$ & $\begin{array}{l}0.200^{* *} \\
(0.098)\end{array}$ & $\begin{array}{l}0.225^{* *} \\
(0.096)\end{array}$ & $\begin{array}{l}0.211^{* *} \\
(0.099)\end{array}$ & $\begin{array}{c}0.043 \\
(0.095)\end{array}$ & $\begin{array}{c}0.038 \\
(0.098)\end{array}$ & $\begin{array}{c}0.098 \\
(0.237)\end{array}$ & $\begin{array}{c}0.219 \\
(0.237)\end{array}$ & $\begin{array}{c}-0.352^{* *} \\
(0.149)\end{array}$ & $\begin{array}{c}-0.295^{* *} \\
(0.143)\end{array}$ \\
\hline High-treated $\times \mathrm{FRP}_{t-1}$ & $\begin{array}{c}1.057^{* * *} \\
(0.126)\end{array}$ & $\begin{array}{c}0.861^{* * *} \\
(0.129)\end{array}$ & $\begin{array}{c}0.552^{* * *} \\
(0.102)\end{array}$ & $\begin{array}{c}0.522^{* * *} \\
(0.103)\end{array}$ & $\begin{array}{c}0.580^{* * *} \\
(0.096)\end{array}$ & $\begin{array}{c}0.552^{* * *} \\
(0.099)\end{array}$ & $\begin{array}{c}0.348^{* * *} \\
(0.096)\end{array}$ & $\begin{array}{c}0.322^{* * *} \\
(0.101)\end{array}$ & $\begin{array}{c}0.301 \\
(0.226)\end{array}$ & $\begin{array}{c}0.341 \\
(0.231)\end{array}$ & $\begin{array}{l}-0.137 \\
(0.155)\end{array}$ & $\begin{array}{l}-0.087 \\
(0.151)\end{array}$ \\
\hline \multicolumn{13}{|l|}{ Females } \\
\hline$\overline{\text { Low-treated } \times \mathrm{FRP}_{t-1}}$ & $\begin{array}{c}0.057 \\
(0.089)\end{array}$ & $\begin{array}{c}0.044 \\
(0.089)\end{array}$ & $\begin{array}{c}0.025 \\
(0.083)\end{array}$ & $\begin{array}{c}0.040 \\
(0.084)\end{array}$ & $\begin{array}{c}0.012 \\
(0.094)\end{array}$ & $\begin{array}{c}0.011 \\
(0.095)\end{array}$ & $\begin{array}{c}0.029 \\
(0.087)\end{array}$ & $\begin{array}{c}0.050 \\
(0.088)\end{array}$ & $\begin{array}{l}-0.065 \\
(0.186)\end{array}$ & $\begin{array}{l}-0.042 \\
(0.192)\end{array}$ & $\begin{array}{l}-0.006 \\
(0.144)\end{array}$ & $\begin{array}{l}-0.001 \\
(0.143)\end{array}$ \\
\hline Mid-treated $\times \mathrm{FRP}_{t-1}$ & $\begin{array}{l}0.238^{* *} \\
(0.105)\end{array}$ & $\begin{array}{l}0.239^{* *} \\
(0.109)\end{array}$ & $\begin{array}{l}0.178^{* *} \\
(0.083)\end{array}$ & $\begin{array}{l}0.182^{* *} \\
(0.085)\end{array}$ & $\begin{array}{l}0.206^{* *} \\
(0.100)\end{array}$ & $\begin{array}{l}0.192^{* *} \\
(0.098)\end{array}$ & $\begin{array}{c}0.105 \\
(0.086)\end{array}$ & $\begin{array}{c}0.102 \\
(0.086)\end{array}$ & $\begin{array}{l}-0.211 \\
(0.199)\end{array}$ & $\begin{array}{l}-0.179 \\
(0.205)\end{array}$ & $\begin{array}{l}-0.150 \\
(0.139)\end{array}$ & $\begin{array}{l}-0.165 \\
(0.137)\end{array}$ \\
\hline High-treated $\times \mathrm{FRP}_{t-1}$ & $\begin{array}{c}0.564^{* * *} \\
(0.091)\end{array}$ & $\begin{array}{c}0.519^{* * *} \\
(0.092)\end{array}$ & $\begin{array}{c}0.499^{* * *} \\
(0.085)\end{array}$ & $\begin{array}{c}0.474^{* * *} \\
(0.087)\end{array}$ & $\begin{array}{c}0.417^{* * *} \\
(0.096)\end{array}$ & $\begin{array}{c}0.352^{* * *} \\
(0.098)\end{array}$ & $\begin{array}{c}0.347^{* * *} \\
(0.084)\end{array}$ & $\begin{array}{c}0.339^{* * *} \\
(0.086)\end{array}$ & $\begin{array}{c}0.115 \\
(0.194)\end{array}$ & $\begin{array}{c}0.121 \\
(0.197)\end{array}$ & $\begin{array}{l}-0.082 \\
(0.140)\end{array}$ & $\begin{array}{l}-0.039 \\
(0.140)\end{array}$ \\
\hline Covariates & No & Yes & No & Yes & No & Yes & No & Yes & No & Yes & No & Yes \\
\hline Schools & 9,731 & 9,353 & 9,664 & 9,292 & 9,531 & 9,174 & 9,327 & 8,976 & 7,839 & 7,576 & 7,628 & 7,388 \\
\hline Observations & 64,330 & 60,058 & 63,097 & 59,325 & 61,377 & 57,964 & 59,202 & 56,085 & 49,440 & 47,087 & 47,351 & 45,170 \\
\hline
\end{tabular}

Notes: ${ }^{*} p<0.10,{ }^{* *} p<0.05,{ }^{* * *} p<0.01$. Robust standard errors in parentheses, clustered at the at the school-grade level. Where indicated, the estimations control for all the variables listed in Table 1 as covariates. All estimations are weighted by the total number of students per school per year and include year-fixed effects, school-grade fixed effects, and school-grade specific linear trends. 


\section{Conclusions}

We have estimated the causal effects of grade retention on school dropout rates in secondary schools, distinguishing between (1) the end-of-year effect for retained students in the same year of retention and (2) the effect in the year after retention for all pupils that were enrolled in each grade. We have analysed the heterogeneity of these effects depending on the timing at which retention occurs by estimating the impact of retention on dropouts at each grade of secondary education from grade 6 to grade 11 .

We highlight two major findings. First, a remarkably large positive effect of grade retention on end-of-year dropout rates among retained students and a positive, however relatively small, effect of grade failure on consecutive dropout rates among all students enrolled in the year after retention. Second, we show significant heterogeneity in both effects depending on the timing of retention along the secondary education cycle: the effects of grade failure on early dropout rates are stronger when retention takes place at the earlier grades whereas the effect among retained students is strongest if retention occurs at grade 9 and grade 11, precisely the grades where successful completion entitles the students to receive the lower secondary school certificate and the high-school diploma respectively.

These results account for the endogeneity of the selection into retention by estimating a difference-in-differences model that exploits variation in retention rates induced by a policy change with respect to retention in Colombia. Until 2009, schools were each year restricted by national regulation to retain up to a maximum of 5 percent of their students. This retention restriction was ended by the Free Retention Policy (FRP) reform, which allowed schools from 2010 onwards to retain as many students as they considered appropriate.

We provide robust evidence of a significant positive effect of increased retention on the dropout rate of retained students during secondary school. The finding that approximately 40 percent of retained students do not continue with their secondary education - or at least, interrupt their studies temporarily - due to the experience of being retained is a very relevant insight that points to the undesirable effect of retention that seems to discourage retained students to continue with their human capital development. This finding is consistent with the literature (e.g Jacob and Lefgren, 2009; Manacorda, 2012) that has found that grade failure induces students to drop out at the end of the school year when failure occurs.

Notably, we also show that the overall positive effect of retention on dropout rates for the full cohort of students is stronger in the earlier grades of secondary school and that there is not any significant effect during the last two years of high school. These results highlight that the strongest dropout effect early in the academic year takes place during the year of transition from primary to secondary education, i.e. grade 6 . This implies, in light of the human capital literature, that earlier investments to remedy skill deficits might be much more effective than later attempts to repair such deficits. This result suggests that schools and policy makers should pay particular attention to grade 6 groups where the proportion of repeater students is relatively high: given that among these groups dropping early out of school is a higher risk for both repeaters and non-repeaters, schools principals and teachers and also policy makers can design alternative interventions such as early class repetition or reinforcement and/or reallocation of students to more similar groups.

Conversely, the retention effect on the dropout rates of retained students is strongest if students are retained at the end of grade 9 and grade 11, suggesting that particular 
attention to retained students at these two specific grades is necessary from schools principals, regulators and policy makers since leaving school at these stages would imply the highest costs of retention due to the forgone opportunity for students to finalise either one of the two cycles of secondary education and receive the corresponding certificate as well as the potential long-term forgone labour market gains. In line with the literature, the fact that this effect is stronger at grade 9 and grade 11, where successful completion would otherwise entitle the students to receive a diploma, could be linked to a more severe self-esteem frustration associated with the failure sentiment and the psychological and behavioural disengagement from school, which in turn can increase the likelihood of leaving school permanently, rather than just temporarily (Alexander and Kabbani, 2001; Lamote et al., 2013; Plank and A., 2005; Stearns and Glennie, 2006).

Finally, we provide empirical evidence of the heterogeneity and (non)linearity of the main effects with regard to the treatment intensity by distinguishing between students in schools that reacted more or less to the policy reform. Although we find most of our main effects to be linear to schools' retention growth, we observe that retained students from grade 9 to 11 in mid-treated schools had greater dropout rates than similar students in high-treated schools where retention rates were even higher. This last finding suggests that students retained at later stages of secondary education in a school environment where retention is not a common outcome can cause more harm to the future perspectives of those students than if they would have been in schools where retention was more pronounced or a more likely result at the end of the school year.

This study complements the literature on school retention by enriching our understanding of whether the performance gains and losses of retention can be outweighed by lower costs of school dropout or strengthened by higher costs of school dropout. The findings of our study contribute to the evaluation of the costs and benefits of retention practices for society. It is important to take the effects of retention for retained and non-retained students into consideration, analysing both the positive and negative effects retention may have not only on school performance but also on the decisions of continuing with their secondary school studies until graduation. Because we cannot identify students who permanently leave education and those who just interrupt their studies temporarily to return later to school, our results should be interpreted cautiously as the short-term (one year) effects of retention. For instance, it could be possible that some dropout students enrol into (part-time) adult education instead of standard secondary education, and therefore the dropout effects in the long run would differ with the options taken after retention and dropping out of school. Further research on the long-term effects of retention on dropping out of school is then essential to unveil the full dimension of impacts that retention may have on retained students.

This study also emphasises the importance of developing a more holistic approach to assess the effects of retention. To answer the question of whether - and when - lowachieving students should be required or not to repeat a failed grade, we need to take into consideration the extent to which grade retention affects not only the retained or repeating individuals but also the extent to which grade repeaters may affect their classmates when they repeat the grade in the following year and the specifics of the context that could mitigate the undesirable effects of grade retention or intensify its positive effects on the human capital development of pupils.

Our findings suggest that we must carefully assess the costs and benefits of grade retention policies for different types of students and at different moments during the school cycle. Although this study particularly focuses on the dropout costs of retention, a 
more holistic approach should also include the potential benefits if retention leads to better performance at exams or later in the labour market. This study has also suggested that there are differences between the processes of dropping out early and dropping out late that would be hidden by considering all dropouts together. Therefore, research applying a more holistic approach will benefit the decision-making process regarding retention policies at the country and school levels.

More accurate procedures to identify the risks and benefits of grade retention for different students in different school contexts will help schools' awareness of the extent to which they need to retain students or provide instead interventions of a different kind. These are crucial decisions knowing that retaining students is highly predictive of dropout even if not all dropouts are retained, and an important consideration when attempting to decrease dropout rates. This could imply either a trade-off or a double challenge for policy makers and schools in developing countries, where skill development is crucial for social mobility but also where school dropout is a very serious issue given the limitations in realising the universalisation of schooling. 
Appendices 
Figure A1: Retention rates by treatment status and sex

(a) Male students

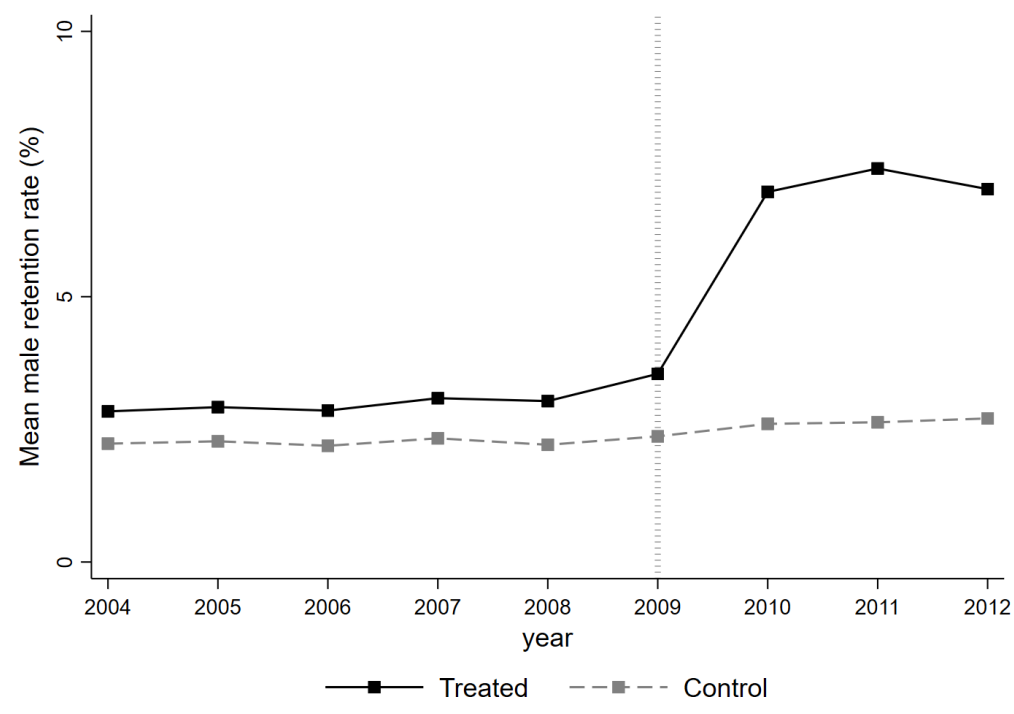

(b) Female students

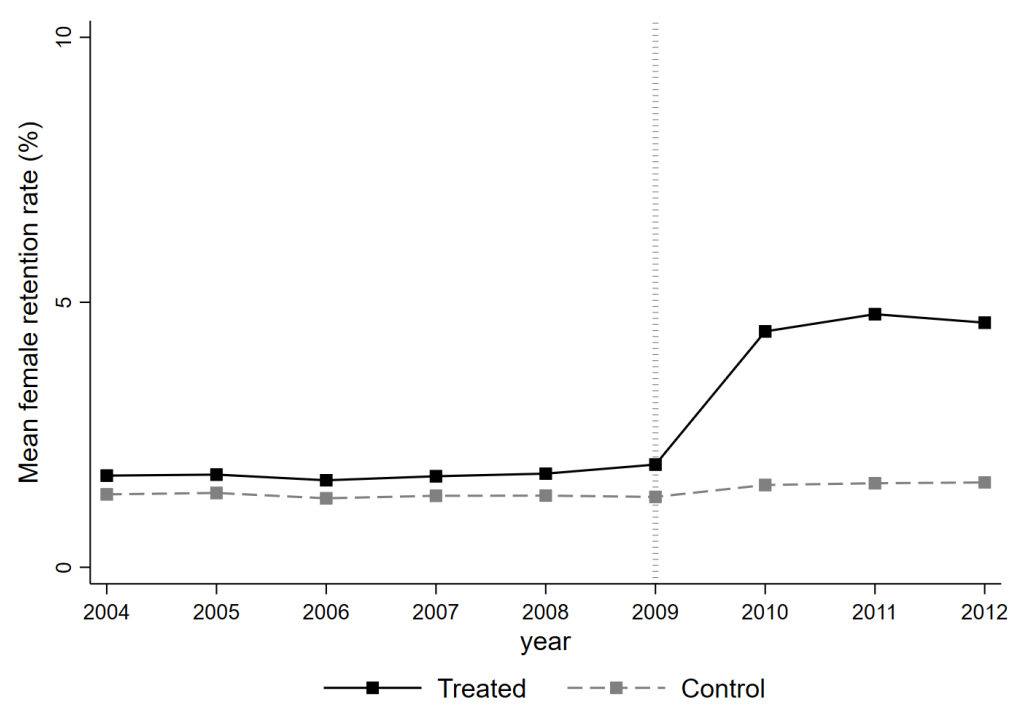

Notes: This figure shows school average retention rates in year $t$ for treated and control schools. Averages include grade 6 to grade 11. Panel (a) shows averages for male students and panel (b) for females students. 
Figure A2: Retention rates by heterogeneous treatment status and sex

(a) Male students

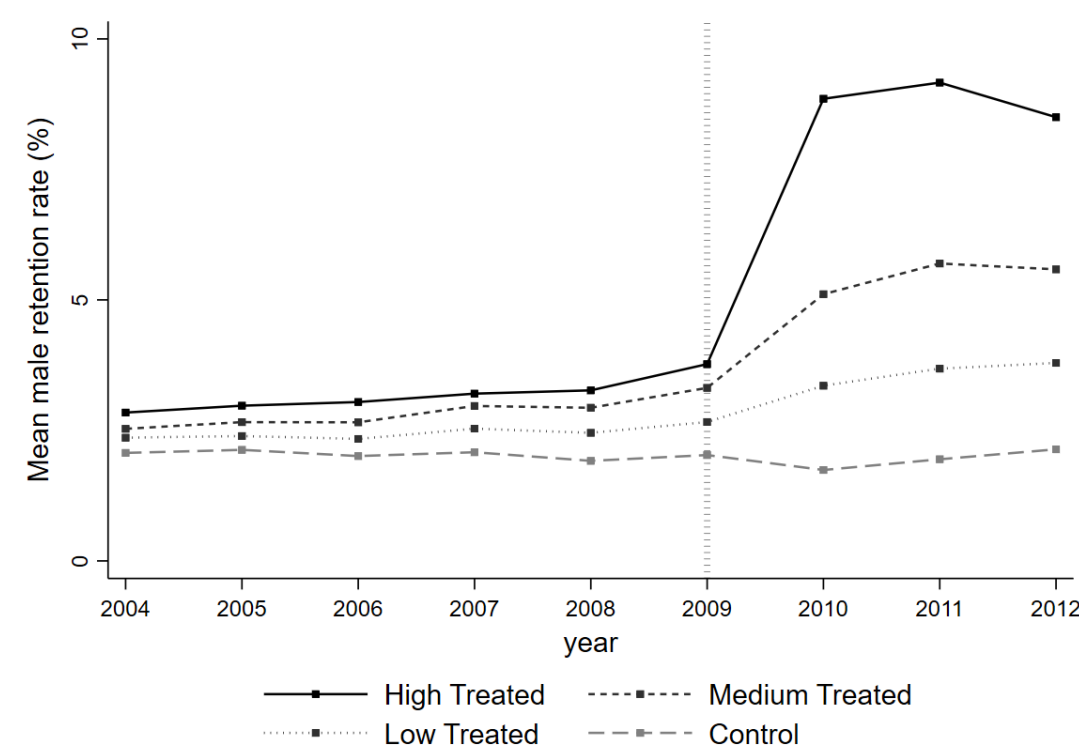

(b) Female students

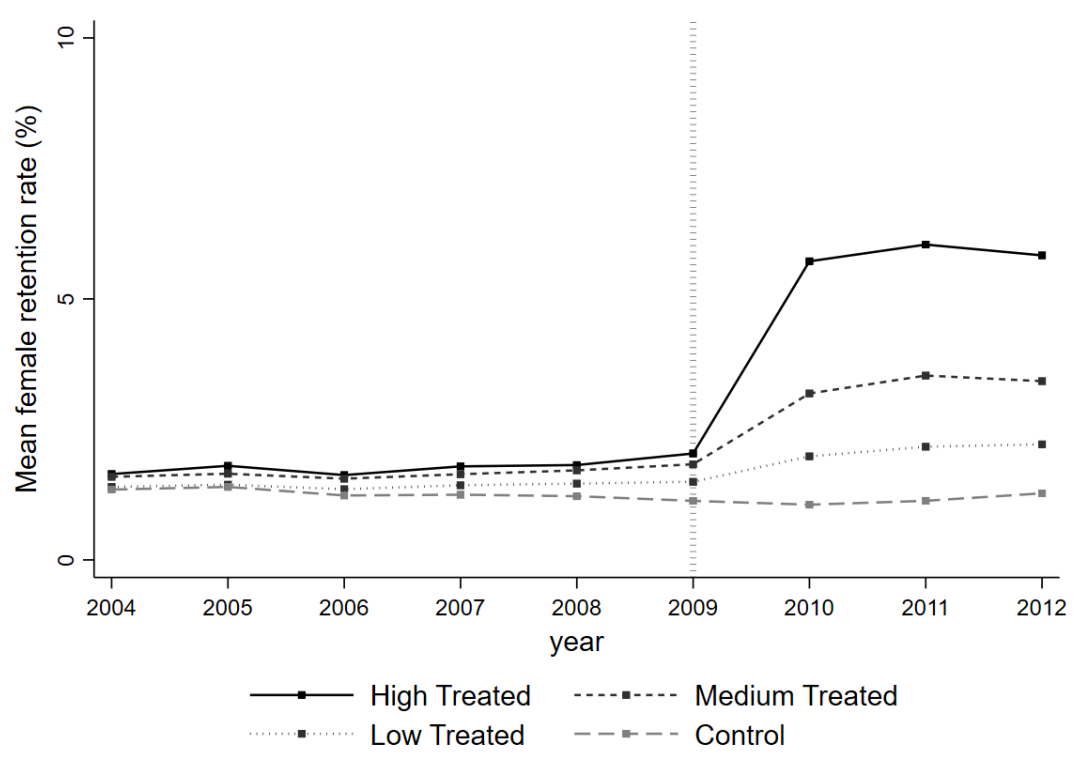

Notes: This figure shows school average retention rates in year $t$ for control and heterogeneously treated schools. Averages include grade 6 to grade 11. Panel (a) shows averages for male students and panel (b) for females students. 
Figure A3: End-of-year dropout rate ${ }_{t}$ by heterogeneous treatment status

(a) High-treated vs. Control

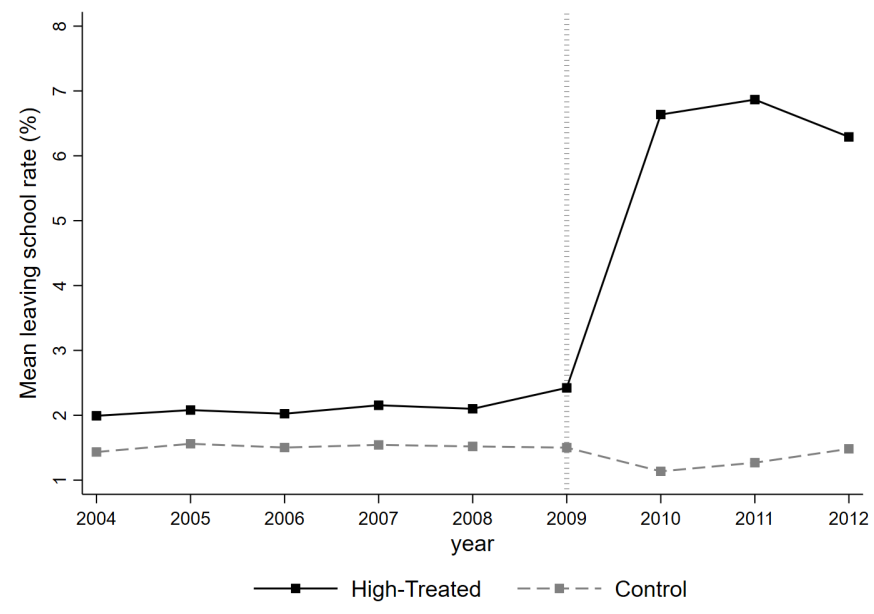

(b) Mid-treated vs. Control

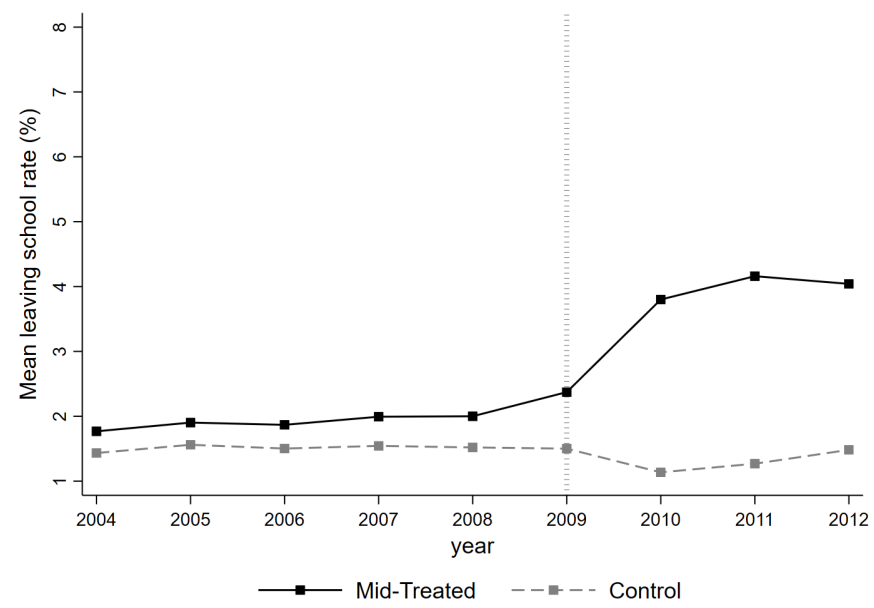

(c) Low-treated vs. Control

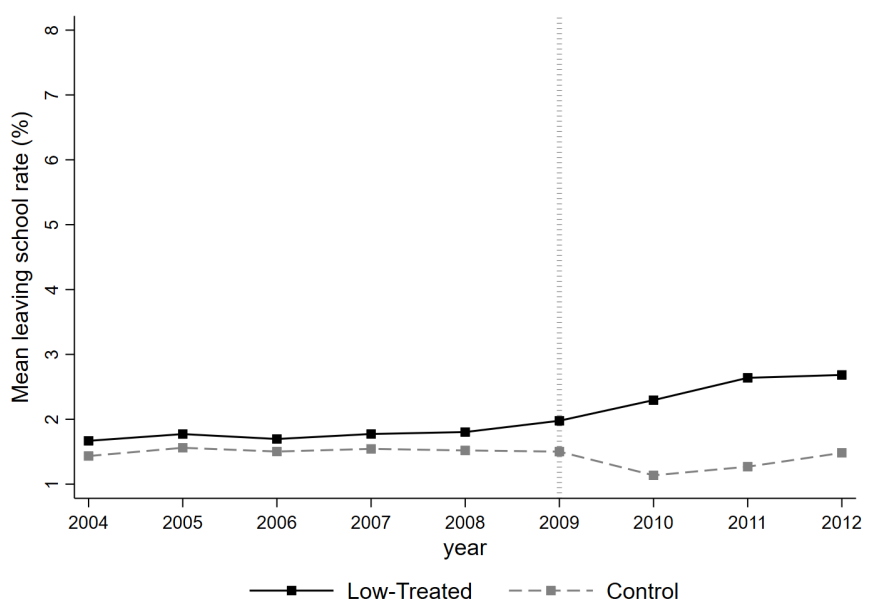

Notes: This figure shows school average end-of-year dropout rates in year $t$ for control and heterogeneously treated schools. Averages include grade 6 to grade 11. 
Figure A4: Early dropout rates ${ }_{t+1}$ by treatment status and sex

(a) Male students

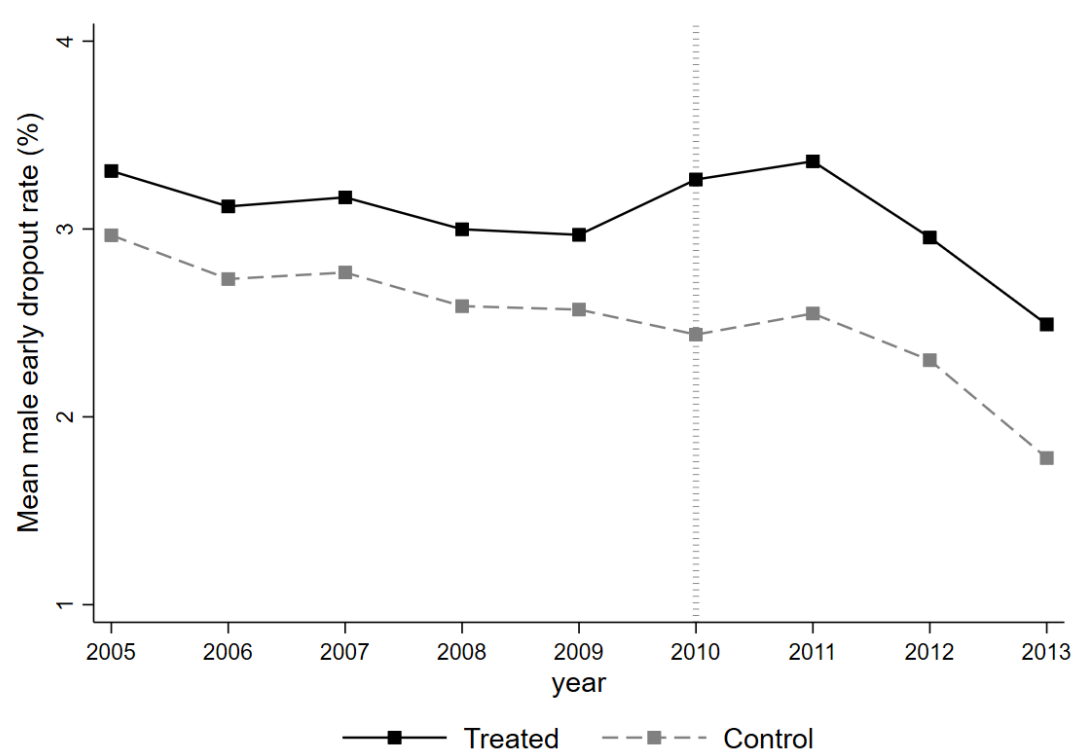

(b) Female students

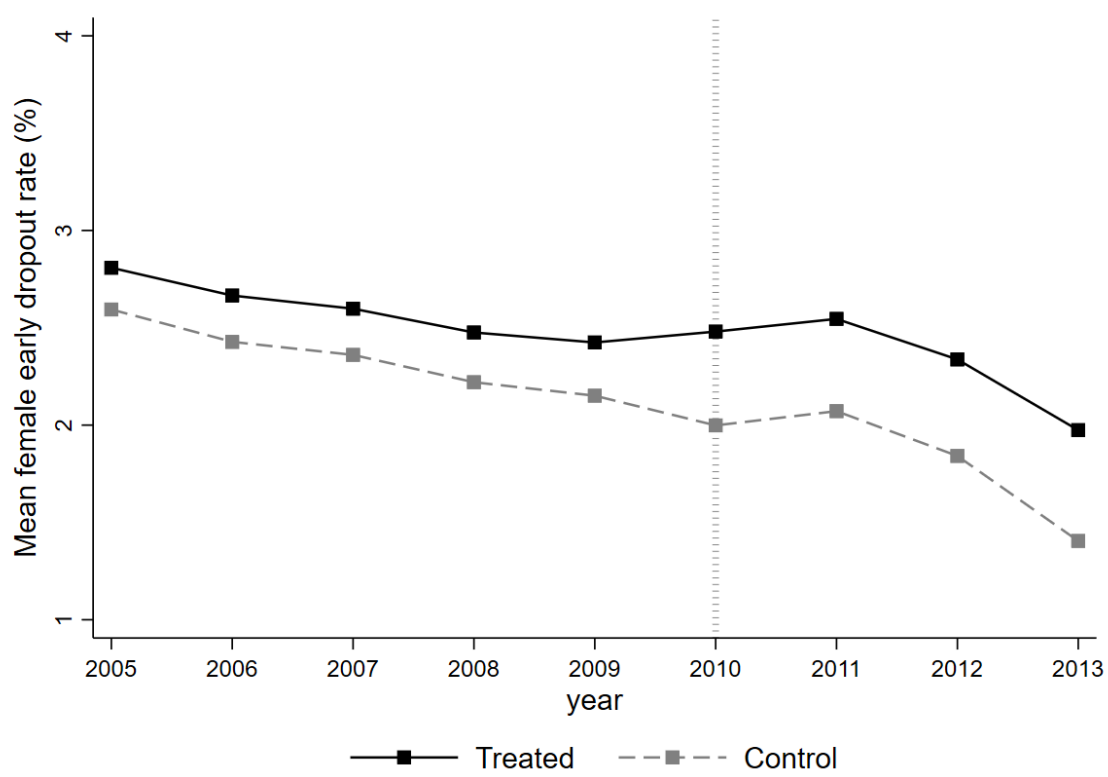

Notes: This figure shows school average early dropout rated rates in year $t+1$ for treated and control schools. Averages include grade 6 to grade 11. Panel (a) shows averages for male students and panel (b) for females students. 
Figure A5: Early dropout rate ${ }_{t+1}$ by heterogeneous treatment status

(a) High-treated vs. Control

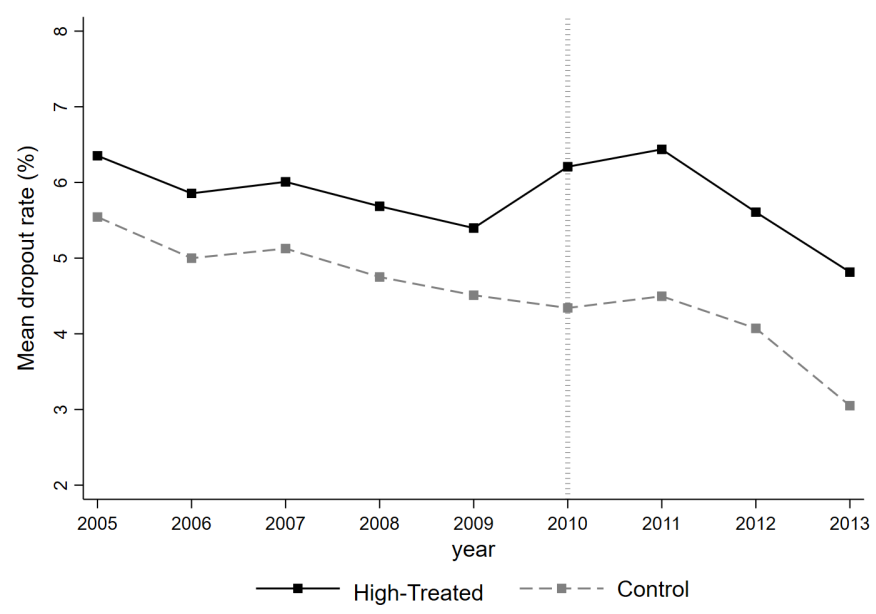

(b) Mid-treated vs. Control

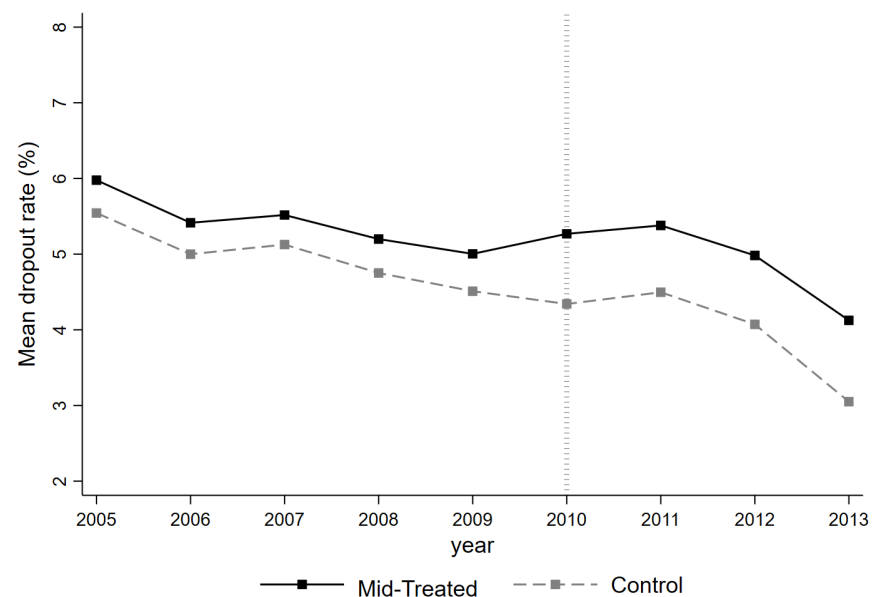

(c) Low-treated vs. Control

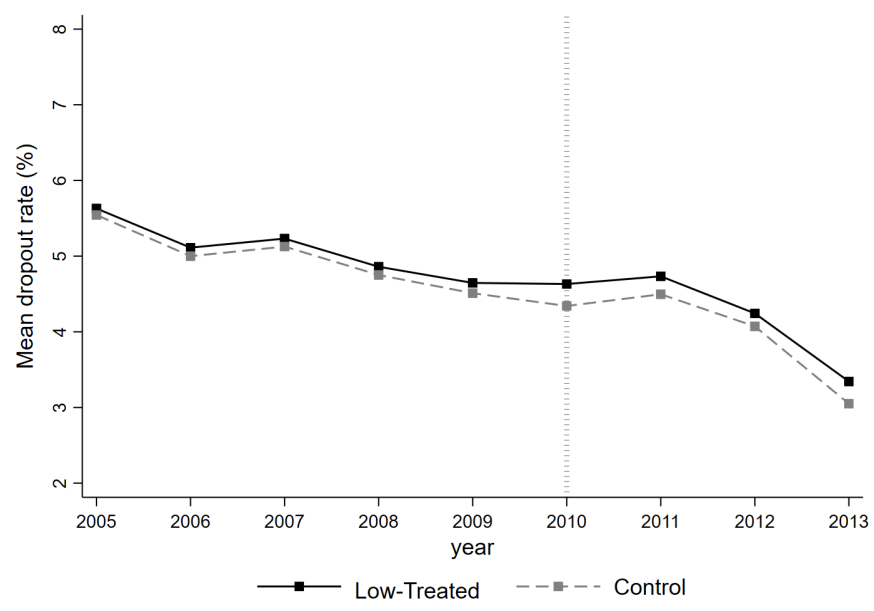

Notes: This figure shows school average early dropout rates in year $t+1$ for control and heterogeneously treated schools. Averages include grade 6 to grade 11. 
Table A1: Common trend test - End-of-year dropout rate ${ }_{t}$ heterogenous treatment

\begin{tabular}{|c|c|c|}
\hline & (1) & $(2)$ \\
\hline \multicolumn{3}{|l|}{ Pre-treatment trends } \\
\hline Low-treated $\times 2005$ & $\begin{array}{c}0.052 \\
(0.187)\end{array}$ & $\begin{array}{l}-0.148 \\
(0.210)\end{array}$ \\
\hline Low-treated $\times 2006$ & $\begin{array}{l}0.032 \\
(0.193)\end{array}$ & $\begin{array}{l}-0.115 \\
(0.204)\end{array}$ \\
\hline Low-treated $\times 2007$ & $\begin{array}{l}0.076 \\
(0.210)\end{array}$ & $\begin{array}{l}-0.135 \\
(0.182)\end{array}$ \\
\hline Low-treated $\times 2008$ & $\begin{array}{l}0.148 \\
(0.193)\end{array}$ & $\begin{array}{l}-0.019 \\
(0.206)\end{array}$ \\
\hline Low-treated $\times 2009$ & $\begin{array}{c}0.174 \\
(0.198)\end{array}$ & $\begin{array}{l}-0.029 \\
(0.187)\end{array}$ \\
\hline Mid-treated $\times 2005$ & $\begin{array}{l}-0.039 \\
(0.187)\end{array}$ & $\begin{array}{l}-0.178 \\
(0.222)\end{array}$ \\
\hline Mid-treated $\times 2006$ & $\begin{array}{c}0.196 \\
(0.192)\end{array}$ & $\begin{array}{l}-0.096 \\
(0.217)\end{array}$ \\
\hline Mid-treated $\times 2007$ & $\begin{array}{l}0.146 \\
(0.207)\end{array}$ & $\begin{array}{l}-0.128 \\
(0.204)\end{array}$ \\
\hline Mid-treated $\times 2008$ & $\begin{array}{c}0.219 \\
(0.194)\end{array}$ & $\begin{array}{l}-0.109 \\
(0.187)\end{array}$ \\
\hline Mid-treated $\times 2009$ & $\begin{array}{l}0.280 \\
(0.205)\end{array}$ & $\begin{array}{c}0.338 \\
(0.211)\end{array}$ \\
\hline High-treated $\times 2005$ & $\begin{array}{l}-0.021 \\
(0.183)\end{array}$ & $\begin{array}{c}0.036 \\
(0.187)\end{array}$ \\
\hline High-treated $\times 2006$ & $\begin{array}{c}0.038 \\
(0.198)\end{array}$ & $\begin{array}{c}0.031 \\
(0.194)\end{array}$ \\
\hline High-treated × 2007 & $\begin{array}{l}-0.158 \\
(0.212)\end{array}$ & $\begin{array}{l}-0.179 \\
(0.201)\end{array}$ \\
\hline High-treated × 2008 & $\begin{array}{l}0.125 \\
(0.192)\end{array}$ & $\begin{array}{l}0.067 \\
(0.190)\end{array}$ \\
\hline High-treated × 2009 & $\begin{array}{l}0.501^{* *} \\
(0.198)\end{array}$ & $\begin{array}{l}0.373^{*} \\
(0.206)\end{array}$ \\
\hline \multicolumn{3}{|l|}{ FRP trends } \\
\hline$\overline{\text { Low-treated }} \times 2010$ & $\begin{array}{c}0.985^{* * *} \\
(0.211)\end{array}$ & $\begin{array}{c}0.754^{* * *} \\
(0.198)\end{array}$ \\
\hline Low-treated $\times 2011$ & $\begin{array}{c}1.154^{* * *} \\
(0.192)\end{array}$ & $\begin{array}{c}0.897^{* * *} \\
(0.191)\end{array}$ \\
\hline Low-treated $\times 2012$ & $\begin{array}{c}1.024^{* * *} \\
(0.220)\end{array}$ & $\begin{array}{c}0.803^{* * *} \\
(0.204)\end{array}$ \\
\hline Mid-treated $\times 2010$ & $\begin{array}{c}2.350^{* * *} \\
(0.222)\end{array}$ & $\begin{array}{c}1.971^{* * *} \\
(0.206)\end{array}$ \\
\hline Mid-treated $\times 2011$ & $\begin{array}{c}2.572^{* * * *} \\
(0.209)\end{array}$ & $\begin{array}{c}2.138^{* * *} \\
(0.211)\end{array}$ \\
\hline Mid-treated $\times 2012$ & $\begin{array}{c}2.403^{* * *} \\
(0.243)\end{array}$ & $\begin{array}{c}1.994^{* * *} \\
(0.233)\end{array}$ \\
\hline High-treated $\times 2010$ & $\begin{array}{c}4.976^{* * *} \\
(0.282)\end{array}$ & $\begin{array}{c}5.007^{* * *} \\
(0.281)\end{array}$ \\
\hline High-treated $\times 2011$ & $\begin{array}{c}5.006^{* * * *} \\
(0.251)\end{array}$ & $\begin{array}{c}4.988^{* * * *} \\
(0.254)\end{array}$ \\
\hline High-treated $\times 2012$ & $\begin{array}{l}4.404^{* * * *} \\
(0.275)\end{array}$ & $\begin{array}{c}4.455^{* * *} \\
(0.262)\end{array}$ \\
\hline Covariates & No & Yes \\
\hline Schools & 9,782 & 9,449 \\
\hline School-grades & 53,867 & 52,037 \\
\hline Observations & 389,775 & 368,433 \\
\hline Adjusted $R^{2}$ & 0.232 & 0.240 \\
\hline
\end{tabular}

Notes: ${ }^{*} p<0.10,{ }^{* *} p<0.05,{ }^{* * *} p<0.01$. Robust standard errors in parentheses, clustered at the at the school-grade level. Where indicated, the estimations control for all the variables listed in Table 1 as covariates. All estimations are weighted by the total number of students per school per year and include year-fixed effects, school-grade fixed effects, and school-grade specific linear trends. 
Table A2: Effect of the FRP reform on retention rates and share of repeaters

\begin{tabular}{|c|c|c|c|c|c|c|c|c|}
\hline & \multicolumn{2}{|c|}{$\begin{array}{l}\text { Grade retention } \\
\text { all }\end{array}$} & \multicolumn{2}{|c|}{$\begin{array}{l}\text { Grade retention } \\
\text { males }\end{array}$} & \multicolumn{2}{|c|}{$\begin{array}{l}\text { Grade retention } \\
\text { females }\end{array}$} & \multicolumn{2}{|c|}{$\begin{array}{l}\text { Share of repeaters } \\
\qquad t+1\end{array}$} \\
\hline & $(1)$ & $(2)$ & $(3)$ & $(4)$ & $(5)$ & $(6)$ & $(7)$ & $(8)$ \\
\hline Treated $\times$ FRP & $\begin{array}{c}7.197^{* * *} \\
(0.130)\end{array}$ & $\begin{array}{c}7.269^{* * *} \\
(0.135)\end{array}$ & $\begin{array}{c}4.015^{* * *} \\
(0.086)\end{array}$ & $\begin{array}{c}4.050^{* * *} \\
(0.088)\end{array}$ & $\begin{array}{c}3.182^{* * *} \\
(0.067)\end{array}$ & $\begin{array}{c}3.219^{* * *} \\
(0.069)\end{array}$ & $\begin{array}{c}4.002^{* * *} \\
(0.118)\end{array}$ & $\begin{array}{c}3.980^{* * *} \\
(0.119)\end{array}$ \\
\hline & & & $\mathrm{Nc}$ & & $\mathrm{N}$ & & Nc & $\mathrm{Ye}$ \\
\hline & & & & & & & & \\
\hline & 53 & & 53,7 & & 53,7 & 51,7 & 53,720 & 51,759 \\
\hline & 344,797 & 325,6 & 344,797 & 325,689 & 344,797 & 325,689 & 344,797 & 325,689 \\
\hline Adjusted $R^{2}$ & 0.522 & 0.528 & 0.489 & 0.496 & 0.480 & 0.484 & 0.449 & 0.456 \\
\hline
\end{tabular}

Notes: ${ }^{*} p<0.10,{ }^{* *} p<0.05,{ }^{* * *} p<0.01$. Robust standard errors in parentheses, clustered at the at the school-grade level. Where indicated, the estimations control for all the variables listed in Table 1 as covariates. All estimations are weighted by the total number of students per school per year and include year-fixed effects, school-grade fixed effects, and school-grade specific linear trends. 
Table A3: Effect of the FRP reform on retention rates and share of repeaters - heterogeneous treatment

\begin{tabular}{lccccccccc}
\hline \hline & \multicolumn{2}{c}{$\begin{array}{c}\text { Grade retention } \\
\text { all }\end{array}$} & \multicolumn{2}{c}{$\begin{array}{c}\text { Grade retention } \\
\text { males }\end{array}$} & \multicolumn{2}{c}{$\begin{array}{c}\text { Grade retention } \\
\text { females }\end{array}$} & \multicolumn{2}{c}{ Share of repeaters } \\
& $(1)$ & $(2)$ & $(3)$ & $(4)$ & $(5)$ & $(6)$ & $(7)$ & $(8)$ \\
\hline Low-treated $\times$ FRP & $1.734^{* * *}$ & $1.603^{* * *}$ & $0.968^{* * *}$ & $0.866^{* * *}$ & $0.765^{* * *}$ & $0.737^{* * *}$ & $0.827^{* * *}$ & $0.903^{* * *}$ \\
& $(0.162)$ & $(0.163)$ & $(0.110)$ & $(0.110)$ & $(0.086)$ & $(0.088)$ & $(0.143)$ & $(0.145)$ \\
Mid-treated $\times$ FRP & $4.426^{* * *}$ & $4.361^{* * *}$ & $2.394^{* * *}$ & $2.332^{* * *}$ & $2.033^{* * *}$ & $2.029^{* * *}$ & $2.317^{* * *}$ & $2.318^{* * *}$ \\
& $(0.169)$ & $(0.170)$ & $(0.116)$ & $(0.116)$ & $(0.089)$ & $(0.091)$ & $(0.150)$ & $(0.152)$ \\
High-treated $\times$ FRP & $11.140^{* * *}$ & $11.139^{* * *}$ & $6.273^{* * *}$ & $6.250^{* * *}$ & $4.867^{* * *}$ & $4.889^{* * *}$ & $6.146^{* * *}$ & $6.178^{* * *}$ \\
& $(0.188)$ & $(0.190)$ & $(0.124)$ & $(0.124)$ & $(0.098)$ & $(0.101)$ & $(0.171)$ & $(0.171)$ \\
& & & & & & & & \\
Covariates & No & Yes & No & Yes & No & Yes & No & Yes \\
Schools & 9,777 & 9,409 & 9,777 & 9,409 & 9,777 & 9,409 & 9,777 & 9,409 \\
School-grades & 53,720 & 51,759 & 53,720 & 51,759 & 53,720 & 51,759 & 53,720 & 51,759 \\
Observations & 344,797 & 325,689 & 344,797 & 325,689 & 344,797 & 325,689 & 344,797 & 325,689 \\
Adjusted $R^{2}$ & 0.531 & 0.536 & 0.496 & 0.503 & 0.486 & 0.490 & 0.453 & 0.460 \\
\hline
\end{tabular}

Notes: ${ }^{*} p<0.10,{ }^{* *} p<0.05,{ }^{* * *} p<0.01$. Robust standard errors in parentheses, clustered at the at the school-grade level. Where indicated, the estimations control for all the variables listed in Table 1 as covariates. All estimations are weighted by the total number of students per school per year and include year-fixed effects, school-grade fixed effects, and school-grade specific linear trends. 
Table A4: Effect of the FRP reform on retention rates by grade

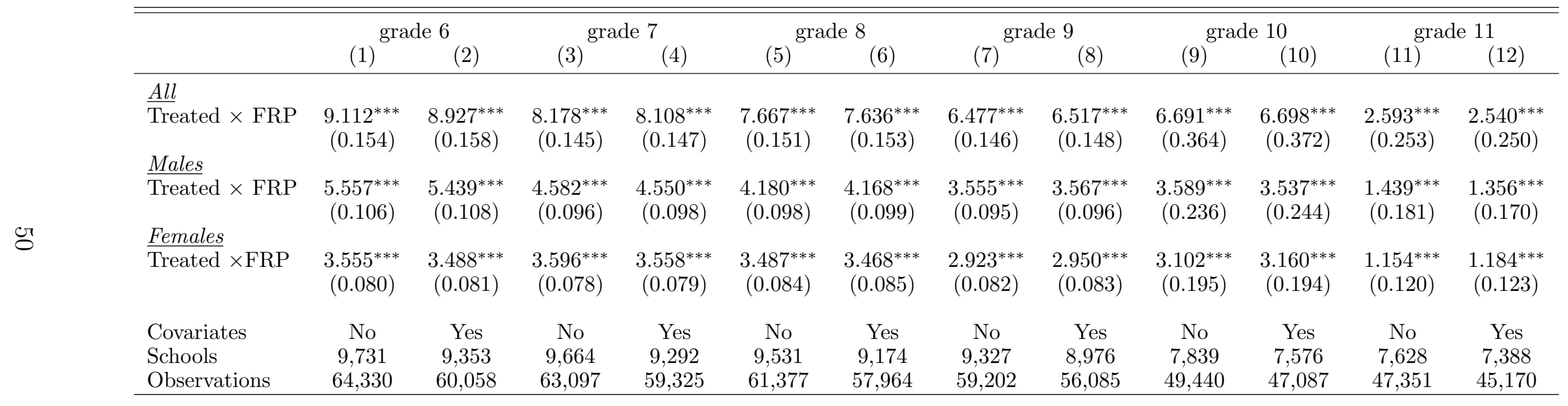

Notes: ${ }^{*} p<0.10,{ }^{* *} p<0.05,{ }^{* * *} p<0.01$. Robust standard errors in parentheses, clustered at the at the school-grade level. Where indicated, the estimations control for all the variables listed in Table 1 as covariates. All estimations are weighted by the total number of students per school per year and include year-fixed effects, school-grade fixed effects, and school-grade specific linear trends. 
Table A5: Effect of the FRP reform on retention rates by grade - heterogenous treatment

\begin{tabular}{|c|c|c|c|c|c|c|c|c|c|c|c|c|}
\hline & \multicolumn{2}{|c|}{ grade 6} & \multicolumn{2}{|c|}{ grade 7} & \multicolumn{2}{|c|}{ grade 8} & \multicolumn{2}{|c|}{ grade 9} & \multicolumn{2}{|c|}{ grade 10} & \multicolumn{2}{|c|}{ grade 11} \\
\hline & $(1)^{+\infty}$ & $(2)$ & $(3)^{+3 x}$ & (4) & $(5)^{8-1}$ & $(6)$ & $(7)^{8-2}$ & $(8)$ & $(9)$ & $(10)$ & $(11)$ & $(12)$ \\
\hline \multicolumn{13}{|l|}{ All } \\
\hline Low-treated $\times \mathrm{FRP}$ & $\begin{array}{l}2.64^{* * *} \\
(0.138)\end{array}$ & $\begin{array}{l}2.63^{* * *} \\
(0.143)\end{array}$ & $\begin{array}{l}2.44^{* * *} \\
(0.127)\end{array}$ & $\begin{array}{l}2.43^{* * *} \\
(0.132)\end{array}$ & $\begin{array}{l}2.29^{* * *} \\
(0.138)\end{array}$ & $\begin{array}{l}2.27^{* * *} \\
(0.141)\end{array}$ & $\begin{array}{l}2.35^{* * *} \\
(0.134)\end{array}$ & $\begin{array}{l}2.35^{* * *} \\
(0.139)\end{array}$ & $\begin{array}{l}1.08^{* *} \\
(0.455)\end{array}$ & $\begin{array}{l}0.94^{* *} \\
(0.454)\end{array}$ & $\begin{array}{c}0.26 \\
(0.342)\end{array}$ & $\begin{array}{c}0.06 \\
(0.292)\end{array}$ \\
\hline Mid-treated $\times$ FRP & $\begin{array}{l}6.54^{* * *} \\
(0.150)\end{array}$ & $\begin{array}{l}6.51^{* * *} \\
(0.154)\end{array}$ & $\begin{array}{l}5.81^{* * *} \\
(0.141)\end{array}$ & $\begin{array}{l}5.79^{* * *} \\
(0.146)\end{array}$ & $\begin{array}{l}5.41^{* * *} \\
(0.142)\end{array}$ & $\begin{array}{l}5.39^{* * *} \\
(0.143)\end{array}$ & $\begin{array}{l}4.77^{* * *} \\
(0.150)\end{array}$ & $\begin{array}{l}4.81^{* * *} \\
(0.154)\end{array}$ & $\begin{array}{l}3.95^{* * *} \\
(0.465)\end{array}$ & $\begin{array}{l}3.74^{* * *} \\
(0.466)\end{array}$ & $\begin{array}{l}1.04^{* * *} \\
(0.368)\end{array}$ & $\begin{array}{l}0.88^{* * *} \\
(0.324)\end{array}$ \\
\hline High-treated $\times$ FRP & $\begin{array}{c}13.82^{* * *} \\
(0.203)\end{array}$ & $\begin{array}{c}13.59^{* * *} \\
(0.213)\end{array}$ & $\begin{array}{c}12.62^{* * *} \\
(0.187)\end{array}$ & $\begin{array}{c}12.55^{* * *} \\
(0.194)\end{array}$ & $\begin{array}{c}11.87^{* * *} \\
(0.201)\end{array}$ & $\begin{array}{c}11.85^{* * *} \\
(0.204)\end{array}$ & $\begin{array}{c}10.32^{* * *} \\
(0.196)\end{array}$ & $\begin{array}{c}10.40^{* * *} \\
(0.200)\end{array}$ & $\begin{array}{l}9.92^{* * *} \\
(0.528)\end{array}$ & $\begin{array}{l}9.88^{* * *} \\
(0.527)\end{array}$ & $\begin{array}{l}4.05^{* * *} \\
(0.392)\end{array}$ & $\begin{array}{l}3.85^{* * *} \\
(0.349)\end{array}$ \\
\hline \multicolumn{13}{|l|}{ Males } \\
\hline$\overline{\text { Low-treated } \times \mathrm{FRP}}$ & $\begin{array}{l}1.72^{* * *} \\
(0.101)\end{array}$ & $\begin{array}{l}1.72^{* * *} \\
(0.104)\end{array}$ & $\begin{array}{l}1.39^{* * *} \\
(0.094)\end{array}$ & $\begin{array}{l}1.37^{* * *} \\
(0.097)\end{array}$ & $\begin{array}{l}1.29^{* * *} \\
(0.097)\end{array}$ & $\begin{array}{l}1.29^{* * *} \\
(0.099)\end{array}$ & $\begin{array}{l}1.33^{* * *} \\
(0.094)\end{array}$ & $\begin{array}{l}1.34^{* * *} \\
(0.097)\end{array}$ & $\begin{array}{c}0.48 \\
(0.313)\end{array}$ & $\begin{array}{c}0.39 \\
(0.313)\end{array}$ & $\begin{array}{c}0.12 \\
(0.278)\end{array}$ & $\begin{array}{c}-0.09 \\
(0.207)\end{array}$ \\
\hline Mid-treated $\times$ FRP & $\begin{array}{l}4.12^{* * *} \\
(0.115)\end{array}$ & $\begin{array}{l}4.08^{* * *} \\
(0.118)\end{array}$ & $\begin{array}{l}3.29^{* * *} \\
(0.107)\end{array}$ & $\begin{array}{l}3.27^{* * *} \\
(0.109)\end{array}$ & $\begin{array}{l}3.02^{* * *} \\
(0.102)\end{array}$ & $\begin{array}{l}3.01^{* * *} \\
(0.103)\end{array}$ & $\begin{array}{l}2.69^{* * *} \\
(0.105)\end{array}$ & $\begin{array}{l}2.69^{* * *} \\
(0.107)\end{array}$ & $\begin{array}{l}2.01^{* * *} \\
(0.321)\end{array}$ & $\begin{array}{l}1.85^{* * *} \\
(0.322)\end{array}$ & $\begin{array}{c}0.52^{*} \\
(0.290)\end{array}$ & $\begin{array}{c}0.31 \\
(0.222)\end{array}$ \\
\hline High-treated $\times$ FRP & $\begin{array}{l}8.45^{* * *} \\
(0.142)\end{array}$ & $\begin{array}{l}8.32^{* * *} \\
(0.148)\end{array}$ & $\begin{array}{l}7.06^{* * *} \\
(0.128)\end{array}$ & $\begin{array}{l}7.03^{* * *} \\
(0.132)\end{array}$ & $\begin{array}{l}6.47^{* * *} \\
(0.132)\end{array}$ & $\begin{array}{l}6.47^{* * *} \\
(0.134)\end{array}$ & $\begin{array}{l}5.65^{* * *} \\
(0.127)\end{array}$ & $\begin{array}{l}5.70^{* * *} \\
(0.130)\end{array}$ & $\begin{array}{l}5.30^{* * *} \\
(0.340)\end{array}$ & $\begin{array}{l}5.21^{* * *} \\
(0.340)\end{array}$ & $\begin{array}{l}2.26^{* * *} \\
(0.306)\end{array}$ & $\begin{array}{l}2.04^{* * *} \\
(0.242)\end{array}$ \\
\hline \multicolumn{13}{|l|}{ Females } \\
\hline$\overline{\text { Low-treated } \times \text { FRP }}$ & $\begin{array}{l}0.92^{* * *} \\
(0.079)\end{array}$ & $\begin{array}{l}0.91^{* * *} \\
(0.081)\end{array}$ & $\begin{array}{l}1.05^{* * *} \\
(0.075)\end{array}$ & $\begin{array}{l}1.06^{* * *} \\
(0.077)\end{array}$ & $\begin{array}{l}0.99^{* * *} \\
(0.080)\end{array}$ & $\begin{array}{l}0.99^{* * *} \\
(0.081)\end{array}$ & $\begin{array}{l}1.03^{* * *} \\
(0.087)\end{array}$ & $\begin{array}{l}1.01^{* * *} \\
(0.089)\end{array}$ & $\begin{array}{c}0.59^{* *} \\
(0.246)\end{array}$ & $\begin{array}{c}0.55^{* *} \\
(0.243)\end{array}$ & $\begin{array}{c}0.15 \\
(0.142)\end{array}$ & $\begin{array}{c}0.16 \\
(0.144)\end{array}$ \\
\hline Mid-treated $\times$ FRP & $\begin{array}{l}2.43^{* * *} \\
(0.090)\end{array}$ & $\begin{array}{l}2.43^{* * *} \\
(0.092)\end{array}$ & $\begin{array}{l}2.51^{* * *} \\
(0.084)\end{array}$ & $\begin{array}{l}2.52^{* * *} \\
(0.086)\end{array}$ & $\begin{array}{l}2.39^{* * *} \\
(0.091)\end{array}$ & $\begin{array}{l}2.39^{* * *} \\
(0.092)\end{array}$ & $\begin{array}{l}2.08^{* * *} \\
(0.096)\end{array}$ & $\begin{array}{l}2.11^{* * *} \\
(0.098)\end{array}$ & $\begin{array}{l}1.94^{* * *} \\
(0.250)\end{array}$ & $\begin{array}{l}1.90^{* * *} \\
(0.254)\end{array}$ & $\begin{array}{l}0.53^{* * *} \\
(0.157)\end{array}$ & $\begin{array}{l}0.57^{* * *} \\
(0.162)\end{array}$ \\
\hline High-treated $\times$ FRP & $\begin{array}{l}5.36^{* * *} \\
(0.110)\end{array}$ & $\begin{array}{l}5.27^{* * *} \\
(0.112)\end{array}$ & $\begin{array}{l}5.56^{* * *} \\
(0.105)\end{array}$ & $\begin{array}{l}5.52^{* * *} \\
(0.107)\end{array}$ & $\begin{array}{l}5.41^{* * *} \\
(0.117)\end{array}$ & $\begin{array}{l}5.38^{* * *} \\
(0.119)\end{array}$ & $\begin{array}{l}4.68^{* * *} \\
(0.117)\end{array}$ & $\begin{array}{l}4.70^{* * *} \\
(0.120)\end{array}$ & $\begin{array}{l}4.61^{* * *} \\
(0.284)\end{array}$ & $\begin{array}{l}4.67^{* * *} \\
(0.286)\end{array}$ & $\begin{array}{l}1.79^{* * *} \\
(0.160)\end{array}$ & $\begin{array}{l}1.81^{* * *} \\
(0.164)\end{array}$ \\
\hline Covariates & No & Yes & No & Yes & No & Yes & No & Yes & No & Yes & No & Yes \\
\hline Schools & 9,731 & 9,353 & 9,664 & 9,292 & 9,531 & 9,174 & 9,327 & 8,976 & 7,839 & 7,576 & 7,628 & 7,388 \\
\hline Observations & 64,330 & 60,058 & 63,097 & 59,325 & 61,377 & 57,964 & 59,202 & 56,085 & 49,440 & 47,087 & 47,351 & 45,170 \\
\hline
\end{tabular}

Notes: ${ }^{*} p<0.10,{ }^{* *} p<0.05,{ }^{* * *} p<0.01$. Robust standard errors in parentheses, clustered at the at the school-grade level. Where indicated, the estimations control for all the variables listed in Table 1 as covariates. All estimations are weighted by the total number of students per school per year and include year-fixed effects, school-grade fixed effects, and school-grade specific linear trends. 
Table A6: Common trend tests - Early dropout rate ${ }_{t+1}$ heterogenous treatment

\begin{tabular}{|c|c|c|c|c|c|c|}
\hline \multirow{3}{*}{$\begin{array}{l}\text { Pre-treatment trends } \\
\underline{S}\end{array}$} & \multicolumn{2}{|c|}{ Dropout all } & \multicolumn{2}{|c|}{ Dropout males } & \multicolumn{2}{|c|}{ Dropout females } \\
\hline & (1) & $(2)$ & & (4) & & (6) \\
\hline & & & & & & \\
\hline Low-treated $\times 2006$ & $\begin{array}{l}-0.081 \\
(0.078)\end{array}$ & $\begin{array}{l}-0.017 \\
(0.078)\end{array}$ & $\begin{array}{l}-0.041 \\
(0.050)\end{array}$ & $\begin{array}{c}0.018 \\
(0.050)\end{array}$ & $\begin{array}{l}-0.040 \\
(0.041)\end{array}$ & $\begin{array}{l}-0.035 \\
(0.041)\end{array}$ \\
\hline Low-treated $\times 2007$ & $\begin{array}{l}-0.046 \\
(0.076)\end{array}$ & $\begin{array}{l}-0.037 \\
(0.077)\end{array}$ & $\begin{array}{c}0.005 \\
(0.049)\end{array}$ & $\begin{array}{c}0.018 \\
(0.049)\end{array}$ & $\begin{array}{c}-0.051 \\
(0.040)\end{array}$ & $\begin{array}{l}-0.055 \\
(0.040)\end{array}$ \\
\hline Low-treated $\times 2008$ & $\begin{array}{c}0.007 \\
(0.073)\end{array}$ & $\begin{array}{l}-0.002 \\
(0.075)\end{array}$ & $\begin{array}{l}0.028 \\
(0.047)\end{array}$ & $\begin{array}{c}0.028 \\
(0.048)\end{array}$ & $\begin{array}{l}-0.021 \\
(0.038)\end{array}$ & $\begin{array}{l}-0.030 \\
(0.039)\end{array}$ \\
\hline Low-treated $\times 2009$ & $\begin{array}{l}-0.068 \\
(0.073)\end{array}$ & $\begin{array}{l}-0.060 \\
(0.075)\end{array}$ & $\begin{array}{l}-0.032 \\
(0.046)\end{array}$ & $\begin{array}{l}-0.038 \\
(0.047)\end{array}$ & $\begin{array}{l}-0.036 \\
(0.037)\end{array}$ & $\begin{array}{l}-0.022 \\
(0.038)\end{array}$ \\
\hline Low-treated $\times 2010$ & $\begin{array}{c}0.094 \\
(0.069)\end{array}$ & $\begin{array}{l}0.077 \\
(0.070)\end{array}$ & $\begin{array}{c}0.144^{* * *} \\
(0.044)\end{array}$ & $\begin{array}{c}0.132^{* * *} \\
(0.044)\end{array}$ & $\begin{array}{l}-0.050 \\
(0.035)\end{array}$ & $\begin{array}{l}-0.055 \\
(0.036)\end{array}$ \\
\hline Mid-treated $\times 2006$ & $\begin{array}{c}0.069 \\
(0.075)\end{array}$ & $\begin{array}{c}0.095 \\
(0.078)\end{array}$ & $\begin{array}{c}0.044 \\
(0.048)\end{array}$ & $\begin{array}{c}0.060 \\
(0.049)\end{array}$ & $\begin{array}{c}0.025 \\
(0.040)\end{array}$ & $\begin{array}{c}0.035 \\
(0.041)\end{array}$ \\
\hline Mid-treated $\times 2007$ & $\begin{array}{l}0.071 \\
(0.076)\end{array}$ & $\begin{array}{l}0.095 \\
(0.078)\end{array}$ & $\begin{array}{l}0.058 \\
(0.048)\end{array}$ & $\begin{array}{c}0.069 \\
(0.049)\end{array}$ & $\begin{array}{l}0.014 \\
(0.040)\end{array}$ & $\begin{array}{l}0.026 \\
(0.041)\end{array}$ \\
\hline Mid-treated $\times 2008$ & $\begin{array}{c}0.110 \\
(0.076)\end{array}$ & $\begin{array}{c}0.037 \\
(0.076)\end{array}$ & $\begin{array}{c}0.063 \\
(0.048)\end{array}$ & $\begin{array}{c}0.010 \\
(0.047)\end{array}$ & $\begin{array}{l}0.046 \\
(0.040)\end{array}$ & $\begin{array}{l}0.026 \\
(0.041)\end{array}$ \\
\hline Mid-treated $\times 2009$ & $\begin{array}{l}0.009 \\
(0.075)\end{array}$ & $\begin{array}{l}-0.068 \\
(0.078)\end{array}$ & $\begin{array}{c}0.040 \\
(0.047)\end{array}$ & $\begin{array}{l}-0.014 \\
(0.049)\end{array}$ & $\begin{array}{l}-0.031 \\
(0.040)\end{array}$ & $\begin{array}{l}-0.054 \\
(0.041)\end{array}$ \\
\hline Mid-treated $\times 2010$ & $\begin{array}{c}0.490^{* * *} \\
(0.077)\end{array}$ & $\begin{array}{c}0.444^{* * *} \\
(0.079)\end{array}$ & $\begin{array}{c}0.331^{* * * *} \\
(0.048)\end{array}$ & $\begin{array}{c}0.295^{* * *} \\
(0.049)\end{array}$ & $\begin{array}{c}0.159^{* * *} \\
(0.041)\end{array}$ & $\begin{array}{c}0.149^{* * *} \\
(0.042)\end{array}$ \\
\hline High-treated $\times 2006$ & $\begin{array}{l}0.000 \\
(0.071)\end{array}$ & $\begin{array}{l}-0.018 \\
(0.072)\end{array}$ & $\begin{array}{c}0.009 \\
(0.046)\end{array}$ & $\begin{array}{c}0.005 \\
(0.046)\end{array}$ & $\begin{array}{l}-0.009 \\
(0.036)\end{array}$ & $\begin{array}{l}-0.023 \\
(0.036)\end{array}$ \\
\hline High-treated $\times 2007$ & $\begin{array}{l}0.048 \\
(0.073)\end{array}$ & $\begin{array}{l}0.023 \\
(0.073)\end{array}$ & $\begin{array}{c}0.062 \\
(0.047)\end{array}$ & $\begin{array}{l}0.051 \\
(0.047)\end{array}$ & $\begin{array}{l}-0.015 \\
(0.036)\end{array}$ & $\begin{array}{l}-0.028 \\
(0.036)\end{array}$ \\
\hline High-treated × 2008 & $\begin{array}{c}0.032 \\
(0.076)\end{array}$ & $\begin{array}{l}-0.035 \\
(0.077)\end{array}$ & $\begin{array}{l}0.026 \\
(0.048)\end{array}$ & $\begin{array}{l}-0.019 \\
(0.048)\end{array}$ & $\begin{array}{c}0.006 \\
(0.038)\end{array}$ & $\begin{array}{l}-0.016 \\
(0.038)\end{array}$ \\
\hline High-treated × 2009 & $\begin{array}{c}0.054 \\
(0.074)\end{array}$ & $\begin{array}{c}0.045 \\
(0.075)\end{array}$ & $\begin{array}{c}0.045 \\
(0.047)\end{array}$ & $\begin{array}{c}0.048 \\
(0.047)\end{array}$ & $\begin{array}{c}0.009 \\
(0.036)\end{array}$ & $\begin{array}{l}-0.003 \\
(0.037)\end{array}$ \\
\hline High-treated $\times 2010$ & $\begin{array}{c}0.862^{* * * *} \\
(0.079)\end{array}$ & $\begin{array}{c}0.809^{* * *} \\
(0.080)\end{array}$ & $\begin{array}{c}0.621^{* * *} \\
(0.050)\end{array}$ & $\begin{array}{c}0.570^{* * *} \\
(0.051)\end{array}$ & $\begin{array}{c}0.241^{* * *} \\
(0.039)\end{array}$ & $\begin{array}{c}0.239^{* * *} \\
(0.039)\end{array}$ \\
\hline$F R P t$ & & & & & & \\
\hline Low-treated $\times 2011$ & $\begin{array}{c}0.480^{* * *} \\
(0.069)\end{array}$ & $\begin{array}{c}0.434^{* * *} \\
(0.071)\end{array}$ & $\begin{array}{c}0.355^{* * *} \\
(0.044)\end{array}$ & $\begin{array}{c}0.335^{* * *} \\
(0.045)\end{array}$ & $\begin{array}{c}0.125^{* * *} \\
(0.036)\end{array}$ & $\begin{array}{c}0.099^{* * *} \\
(0.037)\end{array}$ \\
\hline Low-treated $\times 2012$ & $\begin{array}{c}0.278^{* * *} \\
(0.065)\end{array}$ & $\begin{array}{c}0.317^{* * * *} \\
(0.067)\end{array}$ & $\begin{array}{c}0.162^{* * * *} \\
(0.040)\end{array}$ & $\begin{array}{c}0.188^{* * * *} \\
(0.041)\end{array}$ & $\begin{array}{c}0.116^{* * *} \\
(0.035)\end{array}$ & $\begin{array}{c}0.129^{* * *} \\
(0.036)\end{array}$ \\
\hline Low-treated $\times 2013$ & $\begin{array}{c}0.312^{* * *} \\
(0.066)\end{array}$ & $\begin{array}{c}0.334^{* * *} \\
(0.068)\end{array}$ & $\begin{array}{c}0.184^{* * *} \\
(0.042)\end{array}$ & $\begin{array}{c}0.201^{* * *} \\
(0.043)\end{array}$ & $\begin{array}{c}0.128^{* * *} \\
(0.036)\end{array}$ & $\begin{array}{c}0.133^{* * *} \\
(0.038)\end{array}$ \\
\hline Mid-treated × 2011 & $\begin{array}{c}0.601^{* * *} \\
(0.081)\end{array}$ & $\begin{array}{c}0.532^{* * *} \\
(0.083)\end{array}$ & $\begin{array}{c}0.406^{* * *} \\
(0.049)\end{array}$ & $\begin{array}{c}0.357^{* * *} \\
(0.050)\end{array}$ & $\begin{array}{c}0.194^{* * *} \\
(0.044)\end{array}$ & $\begin{array}{c}0.174^{* * *} \\
(0.045)\end{array}$ \\
\hline Mid-treated × 2012 & $\begin{array}{c}0.396^{* * *} \\
(0.067)\end{array}$ & $\begin{array}{c}0.425^{* * * *} \\
(0.067)\end{array}$ & $\begin{array}{c}0.230^{* * * *} \\
(0.041)\end{array}$ & $\begin{array}{c}0.245^{* * * *} \\
(0.041)\end{array}$ & $\begin{array}{c}0.166^{* * *} \\
(0.038)\end{array}$ & $\begin{array}{r}0.179^{* * *} \\
(0.038)\end{array}$ \\
\hline Mid-treated × 2013 & $\begin{array}{c}0.371^{* * *} \\
(0.066)\end{array}$ & $\begin{array}{c}0.400^{* * *} \\
(0.065)\end{array}$ & $\begin{array}{c}0.214^{* * *} \\
(0.039)\end{array}$ & $\begin{array}{c}0.236^{* * *} \\
(0.038)\end{array}$ & $\begin{array}{c}0.157^{* * *} \\
(0.036)\end{array}$ & $\begin{array}{c}0.164^{* * *} \\
(0.035)\end{array}$ \\
\hline High-treated $\times 2011$ & $\begin{array}{c}1.157^{* * *} \\
(0.079)\end{array}$ & $\begin{array}{c}1.094^{* * *} \\
(0.080)\end{array}$ & $\begin{array}{c}0.757^{* * *} \\
(0.048)\end{array}$ & $\begin{array}{c}0.702^{* * *} \\
(0.048)\end{array}$ & $\begin{array}{c}0.400^{* * *} \\
(0.040)\end{array}$ & $\begin{array}{c}0.392^{* * *} \\
(0.040)\end{array}$ \\
\hline High-treated $\times 2012$ & $\begin{array}{c}0.451^{* * *} \\
(0.066)\end{array}$ & $\begin{array}{c}0.479^{* * *} \\
(0.066)\end{array}$ & $\begin{array}{c}0.280^{* * *} \\
(0.041)\end{array}$ & $\begin{array}{c}0.294^{* * *} \\
(0.041)\end{array}$ & $\begin{array}{c}0.171^{* * *} \\
(0.034)\end{array}$ & $\begin{array}{c}0.185^{* * *} \\
(0.035)\end{array}$ \\
\hline High-treated $\times 2013$ & $\begin{array}{c}0.435^{* * *} \\
(0.064)\end{array}$ & $\begin{array}{c}0.452^{* * *} \\
(0.064)\end{array}$ & $\begin{array}{c}0.272^{* * *} \\
(0.039)\end{array}$ & $\begin{array}{c}0.280^{* * *} \\
(0.038)\end{array}$ & $\begin{array}{c}0.163^{* * *} \\
(0.033)\end{array}$ & $\begin{array}{c}0.172^{* * *} \\
(0.033)\end{array}$ \\
\hline Covariates & No & Yes & No & Yes & No & Yes \\
\hline Schools & 9,782 & 9,449 & 9,782 & 9,449 & 9,782 & 9,449 \\
\hline School-grades & 53,867 & & 53,867 & 52,037 & 53,867 & 52,037 \\
\hline Observations & 389,775 & 368,433 & 389,775 & 368,433 & 389,775 & 368,433 \\
\hline Adjusted $R^{2}$ & 0.428 & 0.430 & 0.393 & 0.406 & 0.336 & 0.342 \\
\hline
\end{tabular}

Notes: ${ }^{*} p<0.10,{ }^{* *} p<0.05,{ }^{* * *} p<0.01$. Robust standard errors in parentheses, clustered at the at the school-grade level. Where indicated, the estimations control for all the variables listed in Table 1 as covariates. All estimations are weighted by the total number of students per school per year and include year-fixed effects, school-grade fixed effects, and school-grade specific linear trends. 


\section{References}

Alexander, K., E. D. and N. Kabbani (2001). The dropout process in life course perspective. Teachers College Record 70, 87-107.

Bauernschuster, S., T. Hener, and H. Rainer (2016). Children of a (policy) revolution: The introduction of universal child care and its effect on fertility. Journal of the European Economic Association 14(4), 975-1005.

Bertrand, M., E. Duflo, and S. Mullainathan (2004). How much should we trust Differences-in-Differences estimates? The Quarterly Journal of Economics 119(1), 249275 .

Bowers, A. J. (2010). Grades and graduation: A longitudinal risk perspective to identify student dropouts. The Journal of Educational Research 103(3), 191-207.

Bowers, A. J. and R. Sprott (2012). Examining the multiple trajectories associated with dropping out of high school: A growth mixture model analysis. The Journal of Educational Research 105(3), 176-195.

Bowers, A. J., R. Sprott, and S. A. Taff (2012). Do we know who will drop out? a review of the predictors of dropping out of high school: Precision, sensitivity, and specificity. The High School Journal, 77-100.

Busso, M., M. Bassi, and J. S. Muñoz (2013). Is the glass half empty or half full? school enrollment, graduation, and dropout rates in latin america.

Cabrol, M. (2002). Los desafíos de la educación secundaria: ¿ que nos dice el análisis de flujos? Technical report, Inter-American Development Bank.

Dalton, B., E. Glennie, and S. J. Ingels (2009). Late high school dropouts: Characteristics, experiences, and changes across cohorts. descriptive analysis report. nces 2009-307. National Center for Education Statistics.

De Witte, K., S. Cabus, G. Thyssen, W. Groot, and H. M. van den Brink (2013). A critical review of the literature on school dropout. Educational Research Review $\underline{10}$, $13-28$.

Di Gropello, E. (2006). Meeting the challenges of secondary education in Latin America and East Asia: Improving efficiency and resource mobilization. The World Bank.

Eide, E. R. and M. H. Showalter (2001). The effect of grade retention on educational and labor market outcomes. Economics of Education Review 20(6), 563-576.

Ferreira, M., B. Golsteyn, and S. Parra-Cely (2018). The effect of grade retention on secondary school performance: Evidence from a natural experiment. IZA Discussion Paper No. 11604.

Fruehwirth, J. C., S. Navarro, and Y. Takahashi (2016). How the timing of grade retention affects outcomes: Identification and estimation of time-varying treatment effects. Journal of Labor Economics 34(4), 979-1021. 
Havnes, T. and M. Mogstad (2011). Money for nothing? Universal child care and maternal employment. Journal of Public Economics 95(11), 1455-1465.

Ikeda, M. and E. García (2014). Grade repetition. OECD Journal: Economic Studies 2013(1), 269-315.

Jacob, B. A. and L. Lefgren (2009). The effect of grade retention on high school completion. American Economic Journal: Applied Economics 1(3), 33-58.

Janosz, M., M. LeBlanc, B. Boulerice, and R. E. Tremblay (1997). Disentangling the weight of school dropout predictors: A test on two longitudinal samples. Journal of

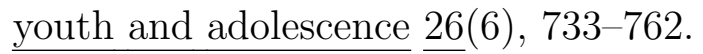

Jimerson, S. R. (1999). On the failure of failure: Examining the association between early grade retention and education and employment outcomes during late adolescence. Journal of School Psychology 37(3), 243-272.

Jimerson, S. R. (2001). Meta-analysis of grade retention research: Implications for practice in the 21st century. School psychology review 30(3), 420-437.

Jimerson, S. R., G. E. Anderson, and A. D. Whipple (2002). Winning the battle and losing the war: Examining the relation between grade retention and dropping out of high school. Psychology in the Schools 39(4), 441-457.

Kattan, R. B. and M. Székely (2015). Analyzing the dynamics of school dropout in upper secondary education in Latin America: a cohort approach. The World Bank.

Lamb, S. and E. Markussen (2011). School dropout and completion: An international perspective. In School dropout and completion, pp. 1-18. Springer.

Lamote, C., S. Speybroeck, W. Van Den Noortgate, and J. Van Damme (2013). Different pathways towards dropout: the role of engagement in early school leaving. Oxford

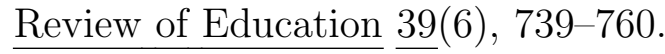

Manacorda, M. (2012). The cost of grade retention. Review of Economics and Statistics $\underline{94}(2), 596-606$.

Martínez, G. and B. Herrera (2002). Finalidades y alcances del decreto 230 del 11 de febrero de 2002. Ministerio de Educación Nacional. Bogotá, 89-90.

McLanahan, S. and G. Sandefur (1994). Growing Up with a Single Parent. What Hurts, What Helps. ERIC.

OECD (2011). Upper Secondary Completion: an OECD Overview. OECD Publishing.

OECD (2012). Education Indicators in Focus. OECD Publishing.

OECD (2016). Education in Colombia Highlights 2016. OECD Publishing.

Pharris-Ciurej, N., C. Hirschman, and J. Willhoft (2012). The 9th grade shock and the high school dropout crisis. Social science research 41(3), 709-730.

Plank, S., D. S. and E. A. (2005). Dropping out of high school and the place of career and technical education: a survival analysis of surviving high school. Technical report, National Research Center for Career and Technical Education: Atlanta, GA. 
Psacharopoulos, G. (2007). The costs of school failure: A feasibility study. EENEE Brussels.

Roderick, M. (1994). Grade retention and school dropout: Investigating the association. American Educational Research Journal 31(4), 729-759.

Rumberger, R. (2011). Dropping Out: Why Students Drop Out of High School and What Can Be Done About It. Cambridge, MA Harvard University Press.

Rumberger, R. W. (1995). Dropping out of middle school: A multilevel analysis of students and schools. American educational Research journal 32(3), 583-625.

Rumberger, R. W. (2004). Dropouts in America: Confronting the Graduation Rate Crisis, Chapter Why students drop out school, pp. 131-155. Harvard Education Press, Cambridge.

Rumberger, R. W. and S. P. Lamb (2003). The early employment and further education experiences of high school dropouts: A comparative study of the united states and australia. Economics of Education Review 22(4), 353-366.

Rumberger, R. W. and K. A. Larson (1998). Student mobility and the increased risk of high school dropout. American journal of Education 107(1), 1-35.

Stearns, E. and E. J. Glennie (2006). When and why dropouts leave high school. Youth \& Society 38(1), 29-57.

Stearns, E., S. Moller, J. Blau, and S. Potochnick (2007). Staying back and dropping out: The relationship between grade retention and school dropout. Sociology of Education 80(3), 210-240.

Swanson, C. B. (2004). Sketching a portrait of public high school graduation: Who graduates? who doesn't. Dropouts in America: Confronting the graduation rate crisis, $13-40$.

Temple, J., A. Reynolds, and S.-R. Ou (2004). Grade retention and school dropout: Another look at the evidence: Grade retention, tracking and grouping. In Can unlike students learn together? Grade retention, tracking and grouping: Grade retention, tracking and grouping. Information Age. 